\title{
Orbiter BLT flight experiment wind tunnel simulations: nearfield flow imaging and surface thermography
}

\author{
P. M. Danehy ${ }^{*}$, C. B. Ivey ${ }^{\dagger}$, B. F. Bathel ${ }^{\ddagger}$, J. A. Inman ${ }^{\S}$, S. B. Jones ${ }^{* *}$, A. N. \\ Watkins, K. Z. Goodman ${ }^{\dagger \dagger}$, A. C. McCrea ${ }^{\dagger \dagger}$. B. D. Leighty and W. K. Lipford \\ NASA Langley Research Center, Hampton VA, 23681-2199 \\ N. Jiang ${ }^{\star *}$, M. Webster ${ }^{\S}$, W. Lempert ${ }^{* * *}$ \\ The Ohio State University, Columbus $\mathrm{OH}$ \\ J. Miller, ${ }^{\dagger \dagger}$ T. Meyer ${ }^{+*}$ \\ The Iowa State University, Ames IA
}

\begin{abstract}
This paper reports a series of wind tunnel tests simulating the near-field behavior of the Space Shuttle Orbiter Boundary Layer Transition Detailed Test Objective (BLT DTO) flight experiment. Hypersonic flow over a flat plate with an attached BLT DTO-shaped trip was tested in a Mach 10 wind tunnel. The sharp-leading-edge flat plate was oriented at an angle of 20 degrees with respect to the freestream flow, resulting in post-shock edge Mach number of approximately 4. The flowfield was visualized using nitric oxide (NO) planar laser-induced fluorescence (PLIF). Flow visualizations were performed at $10 \mathrm{~Hz}$ using a wide-field of view and high-resolution NO PLIF system. A lower spatial resolution and smaller field of view NO PLIF system visualized the flow at $500 \mathrm{kHz}$, which was fast enough to resolve unsteady flow features. At the lowest Reynolds number studied, the flow was observed to be laminar and mostly steady. At the highest Reynolds number, flow visualizations showed streak instabilities generated immediately downstream of the trip. These instabilities transitioned to unsteady periodic and spatially irregular structures downstream. Quantitative surface heating imagery was obtained using the Temperature Sensitive Paint (TSP) technique. Comparisons between the PLIF flow visualizations and TSP heating measurements show a strong correlation between flow patterns and surface heating trends.
\end{abstract}

\section{Introduction}

$\mathrm{I}^{\mathrm{n}}$ 2009, during missions STS-119 and STS-128, NASA used the Space Shuttle Orbiter's heat shield to perform a hypersonic boundary layer transition (BLT) experiment. ${ }^{1,2}$ Two different height protuberances $(6.35 \mathrm{~mm}[0.25 \mathrm{in}]$ for STS-119 and $8.89 \mathrm{~mm}$ [0.35 in] during STS-128) were attached to the windward side of the starboard wing of the Orbiter. The trips were small enough to not initiate transition to turbulence until well beyond peak heating (to ensure safety of the vehicle and crew) but large enough to trip the flow to transition in the hypersonic portion of the vehicle's descent - earlier than where natural transition would occur. Downstream of the protuberance, several thermocouples measured the surface temperature to detect the increase in heating associated with the transition to turbulence. The goal

\footnotetext{
${ }^{*}$ Research Scientist, Advanced Sensing and Optical Measurement Branch, MS 493, AIAA Associate Fellow.

${ }^{\dagger}$ NASA LARSS Student, Advanced Sensing and Optical Measurements Branch, MS 493, and undergraduate student at Johns Hopkins University,

* PhD Student, University of Virginia, Charlottesville VA and Graduate Student at the National Institute of Aerospace, Hampton VA, AIAA Student Member.

${ }_{* *}^{\S}$ Research Scientist, Advanced Sensing and Optical Measurement Branch, MS 493, AIAA Member.

** Technician, Advanced Sensing and Optical Measurement Branch, MS 493.

† ATK Space Systems, Hampton VA.

\# Post-Doctoral Researcher, AIAA Member.

$\S \S$ Graduate Research Assistant, AIAA Student Member.

${ }^{* * *}$ Professor, AIAA Associate Fellow.

t† Graduate Research Assistant, AIAA Student Member.

* Assistant Professor, AIAA Associate Fellow.
} 
of the flight experiment was to provide a unique, controlled, flight-based dataset for validating computational predictive models for transition. Despite study for many decades ${ }^{3}$ transition to turbulence remains one of the most poorly understood aspects of hypersonic flight.

A companion experiment, the Hypersonic Thermodynamic Infrared Measurement (HYTHIRM) project, ${ }^{4}$ acquired global heating patterns of the Orbiter heatshield during descent for both missions. HYTHIRM used an airplane-based long-range infrared imaging system to measure heating patterns over the entire Orbiter heatshield. The HYTHIRM experiment provided quantitative, global (covering the entire windward heatshield) heating maps, though over a limited segment of the vehicle entry trajectory. The thermocouple data on the Shuttle provided quantitative information throughout the vehicle descent, although only at about a dozen discrete locations on the vehicle. While both data sets are invaluable, neither data set is comprehensive. For example, neither data set provides detailed off-body flowfield information in the vicinity of the trip itself, nor does either data set provide high-resolution, two-dimensional heating maps immediately in front of, or downstream of, the trip. To complement these existing flight datasets, ground testing of a scaled vehicle, ${ }^{5}$ as well as flat plate configurations (the present work), is ongoing. Additional flight tests are also planned. Numerous computational efforts (for example Refs. 6 and 7) are also being undertaken to compare with these flight and ground test data. Because neither wind tunnel nor flight test can produce all the comprehensive data required to fully quantify and understand such transitional flows, the disparate data sets will be tied together by such computational efforts.

In this paper, we describe wind tunnel experiments in which the nearfield flow and surface heating patterns were obtained on a flat plate configuration designed to simulate the BLT-DTO flight experiment. These tests occurred over four short test entries as part of a larger series of instrumentation-development tests. The experiments took place in the 31-Inch Mach 10 Air Tunnel at the NASA Langley Research Center during 2009, concurrent with the flight experiments.

To summarize the experimental setup, the model, shown in Fig. 1, was a sharp-leading-edge, wedge/flat-plate configuration with either the Orbiter BLT DTO flight experiment protuberance shape or a 1-mm tall rectangular fence attached in the middle of the plate. The trip was oriented at a $45^{\circ}$ angle with respect to the oncoming flow. Flow conditions and model geometries were chosen so that the height of the trip was approximately the same as the laminar boundary layer thickness just upstream of the trip (though the boundary layer thickness varied with tunnel operating conditions). The tunnel produces flow nominally at Mach 10 but the flat plate was inclined at a $20^{\circ}$ angle to the flow to obtain a boundary layer edge Mach number of about 4. Three different Reynolds numbers were tested with other test parameters remaining constant.

The flowfield measurements were performed using the nitric oxide planar laser-induced fluorescence (NO PLIF) imaging method. NO was seeded into the flow and interrogated by a UV laser sheet and captured by a camera to provide images of the flow. Two different NO PLIF systems were used: a 10-Hz system that obtained high-resolution and wide-field-of-view PLIF images and a lower-resolution MHz NO PLIF system that obtained images at a rate of 500 $\mathrm{kHz}$, which is fast enough to both freeze the flow and to observe the flow structures evolve and convect downstream. Temperature sensitive paint (TSP) was used to measure surface temperatures upstream and downstream of the protuberance. The rate of change of the surface temperature was analyzed to determine the heat transfer to the surface.
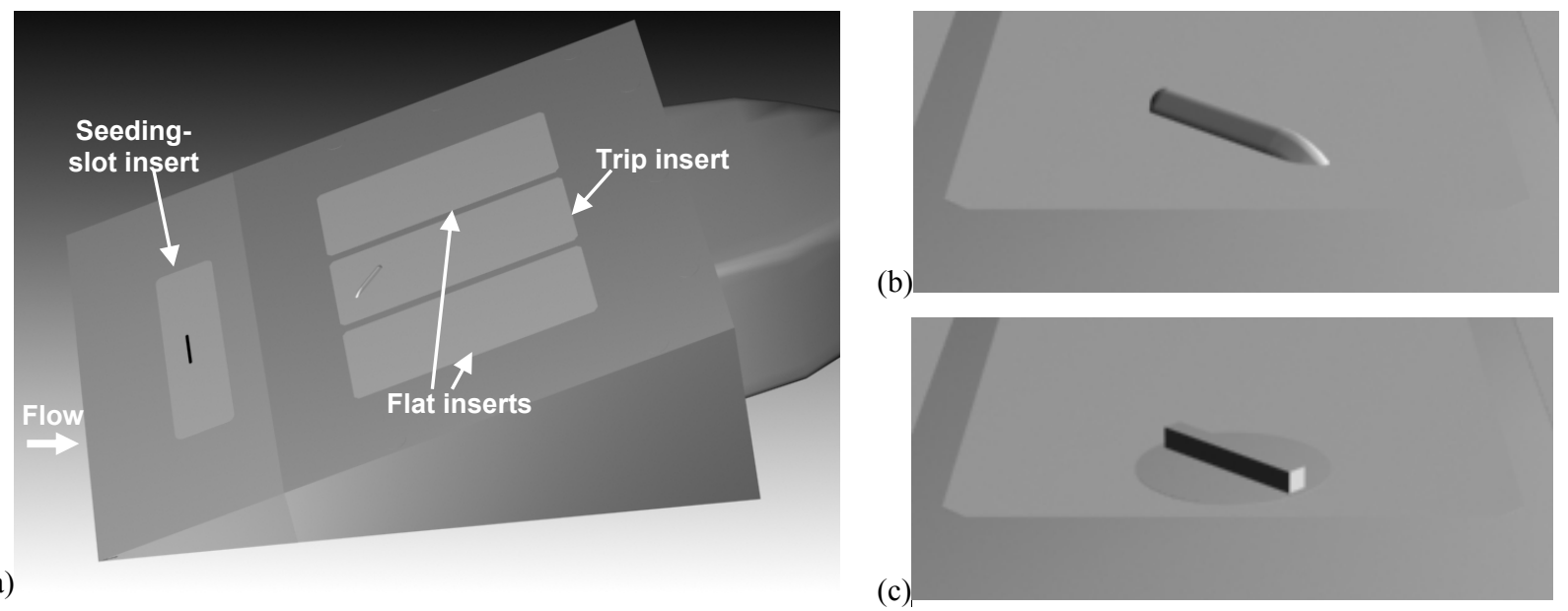

Figure 1. Perspective view (a) of the assembled $20^{\circ}$ full-angle wedge test article used in the experiment. View from upstream of (b) the Orbiter entry BLT DTO flight experiment protuberance, and (c) the 1-mm tall rectangular fence, both oriented at $45^{\circ}$ with respect to the oncoming flow. The flow in (a) is from left to right and in (b) and (c) is from bottom to top. The model includes, from left to right, the sharp leading-edge, the seeding-slot insert, the flat plate (top surface of wedge) containing the trip insert and two flat inserts, and the sting. 


\section{Experiment and Analysis Description}

The experiments were performed in the 31-Inch Mach 10 Air Tunnel at NASA Langley Research Center. The test apparatus consisted of five main components: the test article, the wind tunnel facility, the $10 \mathrm{~Hz}$ PLIF system, the MHz PLIF system and the TSP system. The analysis includes image processing and subsequent rendering in a threedimensional software environment. These procedures are summarized briefly in this section.

\section{A. Test Article}

The test article was a $20^{\circ}$ full-angle wedge with a sharp leading edge. Figure 1 shows computer renderings of the trips and the model. The top surface of the wedge is a planar surface, herein referred to as a flat plate. The flat plate was $127.0 \mathrm{~mm}$ (5 in.) wide and $162.5 \mathrm{~mm}$ (6.4 in.) long. This flat plate was oriented at an angle of $20^{\circ}$ with respect to the oncoming flow during all experiments. Two different protuberance shapes were attached to this surface to trip the flow from laminar to turbulent. The protuberance used for most of the runs was the same shape as the $8.89 \mathrm{~mm}(0.35$ inch) tall BLT DTO flight experiment protuberance, but scaled to be $1.00 \pm 0.02 \mathrm{~mm}(0.039 \mathrm{in}$.) tall. The outermost width of this scaled-down trip was $11.3 \pm 0.1 \mathrm{~mm}(0.45 \mathrm{in}$.) while the full-width at half maximum (perhaps a better measure for flow-blocking considerations) was $10.4 \pm 0.1 \mathrm{~mm}(0.408 \mathrm{in}$.). The forward-most edge of this trip was located $74.8 \pm 0.2 \mathrm{~mm}$ (2.94 in.) downstream of the leading edge of the model. This BLT DTO shaped trip was oriented at a $45^{\circ}$ angle with respect to the oncoming boundary layer flow, to simulate the flow direction over the protuberance during the flight experiment. ${ }^{1}$ The BLT DTO shaped trip was directly attached to the $63.5-\mathrm{mm}$ (2.5-in) long by 50.8 $\mathrm{mm}$ (1-in) wide trip insert. These were manufactured as a single piece using a stereo lithography apparatus (SLA) at the Fabrication Shop at NASA Langley Research Center. The SLA material used was a high-temperature nanocomposite material (NanoForm ${ }^{\mathrm{TM}} 15120$ from DSM Somos). This SLA material was primed and painted with temperature sensitive paint as described below. For one wind tunnel run described herein (Test 462, Run 4), a 1-mm tall rectangular fence trip was used instead of the BLT DTO shaped trip. This trip was also oriented at a $45^{\circ}$ angle with respect to the incoming boundary layer flow. The height of this trip was $1.00 \pm 0.03 \mathrm{~mm}(0.039 \mathrm{in}$.), the width was $8.35 \pm 0.03 \mathrm{~mm}$ ( $0.329 \mathrm{in})$ and the thickness was $1.05 \pm 0.03 \mathrm{~mm}(0.041 \mathrm{in}$.), after being painted black. The edges and corners of the trip were sharp. This trip is one of several interchangeable trips that flush mount into a stainless steel $63.5-\mathrm{mm}$ (2.5-in) long by 50.8-mm (1-in) wide trip insert that then mounts into the model as shown in Fig. 1. The center of this fence trip was $75.4 \pm 0.2 \mathrm{~mm}$ ( $2.97 \mathrm{in})$ downstream of the sharp leading edge of the model.

NO was seeded into the flow through an $11.0 \pm 0.1 \mathrm{~mm}(0.43 \mathrm{in})$ by $0.81 \pm 0.1 \mathrm{~mm}(0.032 \mathrm{in})$ spanwise-oriented slot, located on the model centerline, as shown in Fig. 1. The upstream edge of the slot was located $29.4 \pm 0.1 \mathrm{~mm}$ (1.16 in) downstream of the model's leading edge. Pure NO was supplied through a mass flow controller to a plenum below this slot and the NO then passed through the slot into the flow. A flowrate of 300 standard cubic centimeters per minute $(\mathrm{sccm})$ was used for all but the lowest stagnation pressure runs, for which $150 \mathrm{sccm}$ was used. The influence of NO seeding on the boundary layer flow was studied in Reference 13. Based on that study, we assume in the present paper that the NO seeding does not perturb the flow. Rather it mixes uniformly with the boundary layer fluid. The fraction of NO in a boundary layer is approximately 1 to $3 \%$ with the balance being air, depending on the conditions tested. ${ }^{13}$ Based on a simple half-life analysis using: a) the computed ${ }^{8}$ post-shock conditions including the $250 \mathrm{~K}$ temperature, b) an assumed $10 \% \mathrm{NO}, 90 \%$ air composition and c) a computed reaction rate from the literature ${ }^{9}$ which is valid between $226 \mathrm{~K}$ and $758 \mathrm{~K}$, the reaction of $\mathrm{NO}$ and $\mathrm{O}_{2}$ to form $\mathrm{NO}_{2}$ in this flowfield was found to be negligibly slow. That is, the decomposition half-life of the NO is nearly 4 orders of magnitude longer than the flow timescales, even at the most reactive conditions.

The model used in these experiments contained some imperfections. The seeding slot was an interchangeable insert shown in Fig. 1. The insert itself was $63.5 \pm 0.1 \mathrm{~mm}$ by $15.9 \pm 0.1 \mathrm{~mm}$ ( 2.5 in by $0.625 \mathrm{in})$, oriented with the long dimension in the spanwise direction as shown in Fig 1. The front edge of the seeding slot was $6.1 \mathrm{~mm}(0.24 \mathrm{in})$ downstream of the front of the insert. The gaps were sealed with a high-temperature RTV silicone, but some notable steps and gaps persisted. The seeding insert was modified to have alignment spacers prior to Test 462 to allow the insert to mount flush with the surface. Unfortunately, for Test 462, when the model was assembled and sealed with the silicone adhesive the day of the test, this insert was raised slightly relative to the plane of the flat plate. Consequently the insert presented a $0.20 \pm 0.02 \mathrm{~mm}(0.008 \mathrm{in})$ forward-facing step to the oncoming flow followed by comparable sized rearward-facing step. Also, the port side of the seeding insert was raised slightly higher than the starboard side [details can be obtained from the authors]. Between Tests 462 and 467, the insert was machined flush with the surface. However, the model was disassembled during the test (prior to acquiring all the MHz PLIF data shown in this paper), and upon re-assembly this insert again presented a forward facing step of $0.10 \pm 0.02 \mathrm{~mm}(0.004 \mathrm{in})$ followed by a slightly larger rearward facing step. Again the port side was raised more than the starboard side. Nonetheless, in the absence of a trip placed on the model, the flow remained laminar for the length of the flat plate despite these flaws. In the present series of experiments, the metallic parts were primed and painted matte black with high-temperature primer and paint. This significantly reduced paint chipping and flaking off of the plate, which had been noted in previous 
tests. ${ }^{13}$ The model did not require repainting during the test, though some small chips and flakes did occur. The resulting roughness was less than one layer of paint. These surface imperfections were nearly an order of magnitude smaller than the $1 \mathrm{~mm}$ tall trip used to perturb the flow. Despite efforts to measure it, the sharpness of the leading edge could not be quantified due to lack of appropriate instrumentation in our laboratory. Care was taken to prevent the sharp leading edge from becoming damaged, though slight imperfections may have existed. To first order, the model imperfections described should be negligible, but could have an effect on higher fidelity computations of the flow.

\section{B. Wind Tunnel, Tunnel Operating Conditions and Data Acquisition}

The 31-Inch Mach 10 Air Tunnel is an electrically-heated blowdown facility located at NASA Langley Research Center in Hampton, Virginia, USA. Reference 10 details this facility, a brief summary of which is provided here. The facility has a nominal Mach number of 10 and a $0.787 \mathrm{~m}$ (31 in.) square test section that operates with electrically heated, compressed air. Large windows, transparent in the ultraviolet down to approximately $190 \mathrm{~nm}$, form three walls (including top and bottom) of the test section with the fourth wall formed by the model insertion system. In both experiments, the model was side-mounted to this fourth wall. Run durations for the current tests were about one minute for PLIF runs and less than 10 seconds for TSP runs. The nominal stagnation temperature was $1,000 \mathrm{~K}\left(1,340^{\circ} \mathrm{F}\right)$ for all tests. Three different facility stagnation pressures, $\mathrm{P}_{0}$, were used: $2.40 \mathrm{MPa}(350 \mathrm{psia}), 4.96 \mathrm{MPa}$ (720 psia) and 9.31 MPa (1350 psia), referred to hereafter as the low, middle and high Reynolds number cases, respectively. The three operating pressures simulate freestream unit Reynolds numbers of $1.7,3.3$ and $6.1 \mathrm{million} / \mathrm{m}(0.5,1.0$ and 1.9 million/ft), respectively. Table 1 summarizes the test conditions and configurations for the data presented in this paper. Further details of the flow properties at these conditions can be found in Hollis et al. ${ }^{11}$ or can be requested from the authors.

\begin{tabular}{|c|c|c|c|c|c|c|c|c|c|c|}
\hline Test & Run & Primary Measurement & $\begin{array}{l}\text { Framing } \\
\text { Rate }\end{array}$ & Trip Type & $\begin{array}{l}\text { Trip } \\
\text { Height }\end{array}$ & $\begin{array}{l}\text { Trip } \\
\text { Width }\end{array}$ & $\begin{array}{c}\text { Stagnation } \\
\text { Pressure }\end{array}$ & $\begin{array}{c}\text { Stagnation } \\
\text { Temperature }\end{array}$ & $\begin{array}{c}\text { Unit } \\
\text { Reynolds } \\
\text { Number }\end{array}$ & $\begin{array}{l}\text { NO flow } \\
\text { rate }\end{array}$ \\
\hline & & & & & $(\mathrm{mm})$ & $(\mathrm{mm})$ & $(\mathrm{MPa})$ & $(\mathrm{K})$ & $(1 / \mathrm{m})$ & $(\mathrm{sccm})$ \\
\hline 462 & 2 & PLIF Flow Vis & $10 \mathrm{~Hz}$ & BLT DTO & 1.00 & 10.36 & 2.40 & 988 & 1.71 & 150 \\
\hline 462 & 3 & PLIF Flow Vis & $10 \mathrm{~Hz}$ & BLT DTO & 1.00 & 10.36 & 4.97 & 1002 & 3.35 & 300 \\
\hline 462 & 4 & PLIF Flow Vis & $10 \mathrm{~Hz}$ & rectangular fence @ 45 deg & 1.00 & 8.35 & 4.97 & 997 & 3.38 & 300 \\
\hline 462 & 5 & PLIF Flow Vis & $10 \mathrm{~Hz}$ & BLT DTO & 1.00 & 10.36 & 9.33 & 1002 & 6.12 & 300 \\
\hline 462 & 34 & TSP Heating & -- & none & -- & -- & 4.97 & 1001 & 3.35 & 300 \\
\hline 462 & 35 & TSP Heating & -- & BLT DTO & 1.00 & 10.36 & 4.97 & 1002 & 3.35 & 300 \\
\hline 462 & 36 & TSP Heating & -- & BLT DTO & 1.00 & 10.36 & 2.39 & 990 & 1.71 & 300 \\
\hline 467 & 15 & PLIF Flow Vis & $500 \mathrm{kHz}$ & BLT DTO & 1.00 & 10.36 & 9.28 & 994 & 6.17 & 300 \\
\hline 467 & 18 & PLIF Flow Vis & $500 \mathrm{kHz}$ & BLT DTO & 1.00 & 10.36 & 9.31 & 990 & 6.17 & 300 \\
\hline
\end{tabular}

Table 1. Experimental test matrix. The plate angle was $20^{\circ}$ for each of these runs.

The model was oriented so that the leading edge was nearly vertical and facing the oncoming flow. The model's sting was yawed $+10^{\circ}$, resulting in a $20^{\circ}$ angle between the freestream flow and the flat plate. This angle, hereafter called the plate angle was set to $20^{\circ}$ for all the runs reported in this paper. An oblique shockwave originating from leading edge of the model reduces the Mach number and velocity of the flow while increasing the gas temperature and pressure. The post-shock Mach number was about 4, varying slightly with the operating conditions. The model was also rolled $1.5^{\circ}$ clockwise (as viewed from downstream) so the laser reflection from the bottom window of the tunnel would not illuminate the flow field; rather, the reflection hit the bottom of the model. This slight roll angle should have a negligible effect on the fluid mechanics of the experiment.

\begin{tabular}{|l|l|l|l|l|l|}
\hline \multirow{2}{*}{\multicolumn{1}{|c|}{ Property }} & \multicolumn{2}{c|}{ Flight } & \multicolumn{3}{c|}{ Wind Tunnel Test } \\
\cline { 2 - 6 } & $t=999 \mathrm{~s}$ & $t=1200 \mathrm{~s}$ & Low Re & \multicolumn{1}{c|}{ Mid Re } & High Re \\
\hline Freestream Mach Number, $M_{\infty}$ & 15 & 8.5 & 9.68 & 9.80 & 9.93 \\
\hline Angle of attack & $40 \mathrm{deg}$ & $38 \mathrm{deg}$ & $20 \mathrm{deg}$ & $20 \mathrm{deg}$ & $20 \mathrm{deg}$ \\
\hline Edge Mach Number, $M_{e}$ & 2.9 & 2.2 & 3.7 & 3.8 & 3.9 \\
\hline Boundary Layer Thickness, $\delta_{99.5 \%}$ & $26 \mathrm{~mm}$ & $21 \mathrm{~mm}$ & $1.37 \mathrm{~mm}$ & $0.95 \mathrm{~mm}$ & $0.70 \mathrm{~mm}$ \\
\hline Momentum Thickness, $\theta$ & $3.8 \mathrm{~mm}$ & $3.1 \mathrm{~mm}$ & $0.13 \mathrm{~mm}$ & $0.093 \mathrm{~mm}$ & $0.068 \mathrm{~mm}$ \\
\hline Trip height, $k$ & $6.4 \mathrm{~mm}$ & $6.4 \mathrm{~mm}$ & $1 \mathrm{~mm}$ & $1 \mathrm{~mm}$ & $1 \mathrm{~mm}$ \\
\hline$k / \delta$ & 0.25 & 0.30 & 0.73 & 1.05 & 1.44 \\
\hline Reynolds Number, $\operatorname{Re}_{k}$ & 576 & 1050 & 1470 & 3020 & 5650 \\
\hline Reynolds Number, $\operatorname{Re}_{\theta}$ & 488 & 696 & 193 & 277 & 379 \\
\hline $\operatorname{Re}_{\theta} / M_{e}$ & 181 & 318 & 50 & 72 & 99 \\
\hline
\end{tabular}

Table 2. Definition of terms and comparison between the flight experiment and ground test conditions for the current paper. Ground test conditions are approximate and are reported near the trip location (75.4 $\mathrm{mm}$ downstream of the leading edge of the flat plate). Flight conditions are post-flight best estimate trajectory from STS-119. ${ }^{12}$ 
Computational fluid dynamic simulations have been performed for this flat plate, allowing estimation of various flow parameters. ${ }^{8}$ Computations were only performed for the middle Reynolds number condition at this $20^{\circ}$ plate angle. Simple scaling rules have been used to extrapolate these results to the low- and high-Reynolds number cases. For this extrapolation, the Reynolds number based on the trip height, $R e_{\mathrm{k}}$ was assumed to scale with stagnation pressure. The flow enthalpy-based boundary layer thickness, $\delta_{99.5 \%}$, and the momentum thickness, $\theta$, were assumed to be proportional to $R e^{-1 / 2}$, the inverse square-root of the unit Reynolds number. $R e_{\theta}$ was assumed to be proportional to the stagnation pressure and the newly estimated value of $\theta$. Computations of the Shuttle Orbiter flight trajectory and the resulting boundary layer conditions, including those at the edge of the boundary layer, were also performed in Refs. 2 and 12. Table 2 summarizes both of these computations, with just two points of interest (Mach 8.5 and 15) in the flight trajectory shown.

In the wind tunnel tests, the unit Reynolds number changes by a factor of two between each of the conditions. The resulting boundary layer thickness changes by a factor of the square root of two while the other conditions remain roughly constant. Compared to flight at Mach 15, the wind tunnel edge Mach number is about $30 \%$ larger, the Reynolds numbers based on the trip height are 5-10 times larger and the $k / \delta$ is 3-5 times larger. The wind tunnel tests approach the predicted flight momentum thickness Reynolds number, $R e_{\theta}$. Constraints on the wind tunnel model, wind tunnel size and operating conditions prevented a closer match to flight conditions.

One basic limitation in the design of the experiment was that the existing flat plate used was too short. If a lower Reynolds number (to match $R e_{k}$ ) or a shorter trip (to match $k / \delta$ ) or both had been used, the flow would have been steady and laminar over the entire flat plate, even at the highest Reynolds number tested. Perhaps in future experiments, a higher angle of attack, a smaller trip and a longer flat plate could be used to more closely match the flight conditions. The finite size of the wind tunnel test section may ultimately limit the conditions that could be obtained.

\section{C. $10 \mathrm{~Hz}$ Planar Laser-Induced Fluorescence (PLIF) Imaging System}

The PLIF system consisted primarily of the laser system, beam-forming optics and a dual-camera detection system. The laser system had a Newport/Spectra Physics Pro-230 Nd:YAG pump laser, a Newport/Sirah Cobra Stretch tunable pulsed dye laser, and a Newport/Sirah Frequency Conversion Unit (FCU), all operating at $10 \mathrm{~Hz}$ and with a about $10 \mathrm{~ns}$ pulse duration. This laser system uses a new dye laser and FCU compared to our prior PLIF work. ${ }^{13,14,15,16}$ The dye laser operated at $622 \mathrm{~nm}$; this output was mixed with $355 \mathrm{~nm}$ light from the Nd:YAG laser to obtain UV output near $226 \mathrm{~nm}$. The laser output was tuned to a wavelength of $226.256 \mathrm{~nm}$, chosen to excite the strongly fluorescing spectral NO A-X $(0,0)$ lines near the $\mathrm{Q}_{1}$ branch band head. The laser beam was directed to the tunnel using a series of prisms as shown in Fig. 2(a). Lenses then formed the laser beam into a sheet. The sheet was about $0.2 \mathrm{~mm}$ thick and was diverging slightly to a width of about $150 \mathrm{~mm}$ (6 in) to illuminate the flow above the surface of the model.

Images were acquired using a pair of Princeton Instruments PI-MAX II intensified CCD cameras with 512x512 pixel resolution. The cameras were mounted side-by-side with a slight angular separation $\left(<15^{\circ}\right)$ so that they both viewed the center of the wedge model. One camera used a Nikon 105-mm focal length, F/4.5 UV Nikkor lens. The other used a Cerco $45-\mathrm{mm}$ focal length, F/1.8 UV lens, resulting in approximately 3 times larger field of view. All of the ViDI-processed $10 \mathrm{~Hz}$ PLIF images in this paper were obtained with the larger field of view camera/lens system (see Section G. below for an explanation of ViDI processing). Custom made transmission filters from Layertec, $\mathrm{GmbH}$ were placed in front of the lenses to efficiently block the laser's wavelength while transmitting most of the red-shifted fluorescence (transmit $<1 \% @ 226 \mathrm{~nm}$ and $>80 \% @ 235-280 \mathrm{~nm}$ ). The two cameras were synchronized to acquire simultaneous images. Flow visualization images were acquired with a $1 \mu$ s camera gate at $10 \mathrm{~Hz}$, in sync with the laser. So-called dotcards (a flat card marked with evenly spaced dots) were used to determine image magnification in postprocessing and for correcting perspective and lens distortion as in previous work. ${ }^{15}$ The spatial resolutions were 9.8 pixels/mm (249 pix/in.) and 3.2 pixels/mm (81 pix/in.) for the two cameras, respectively.

By translating the laser sheet, measurements were possible at different locations in the flow, thereby visualizing flow structures that developed and evolved both along and away from a surface. The laser sheet was oriented parallel to the surface of the model to provide a plan view of the flow. The camera was oriented approximately normal to the laser sheet, though some perspective distortion was present and had to be removed via image processing. Further details of the mobile NO PLIF system and its use in NASA Langley Research Center's 31-Inch Mach 10 Air Tunnel can be found in Refs. 17 and 18.

A new method for monitoring the spatial variation in the intensity of laser sheet (i.e. sheet profiling) was developed and implemented in Tests 462, though it was not used in Test 467. After passing by the model, the laser sheet was allowed to pass through the bottom window of the test section and onto a flat surface oriented at $45^{\circ}$ with respect to the horizontal. This is shown schematically in Figs 2(a) and (b). The flat surface was coated with a fluorescent paint that absorbed in the ultraviolet and emitted in the visible. A camera oriented approximately perpendicular to the laser sheet imaged the resulting florescence, which appeared as a diagonal line on the CCD camera. During initial setup, a

procedure was used to determine the relative alignment of the PLIF and sheet profiling cameras: a mask was placed in 
the laser sheet above the test section to create a series of shadows both in the test section and on the flat surface under this section, to provide spatial registration marks. Images were then acquired with all cameras. These registration marks allowed the images acquired by the different cameras to be properly scaled and aligned in post-processing. Prior to the first tunnel run, this mask was removed. The sheet profiling camera was synchronized with the PLIF cameras, and acquired an image for every laser pulse during a run. For the $10 \mathrm{~Hz}$ PLIF system, a Photometrics CoolSnapES unintensified CCD camera equipped with a zoom lens was used to acquire the sheet profile images. In post-test image processing, the sheet profiling images obtained could be used to correct the PLIF images on a shot-by-shot basis for both laser intensity and spatial variation in the laser profile.

Unfortunately, two problems were observed with this approach. First, the paint's fluorescent emission was found to be nonlinear with incident laser intensity, for example exhibiting photo-bleaching when the high laser energies were used. This resulted in imperfect laser sheet corrections. Secondly, when the laser sheet was scanned close to the surface, the sheet partially or completely hit the model and was scattered or deflected away from the flat painted surface, resulting in the anomalously low sheet profile intensities, resulting in unrealistic sheet profile corrections. Thus for some measurements near the surface of the model, the sheet profile data were not used. In the future, this system could potentially be used to monitor the spatial location of the laser sheet passing under this test section, although this information has not been used in the current work.
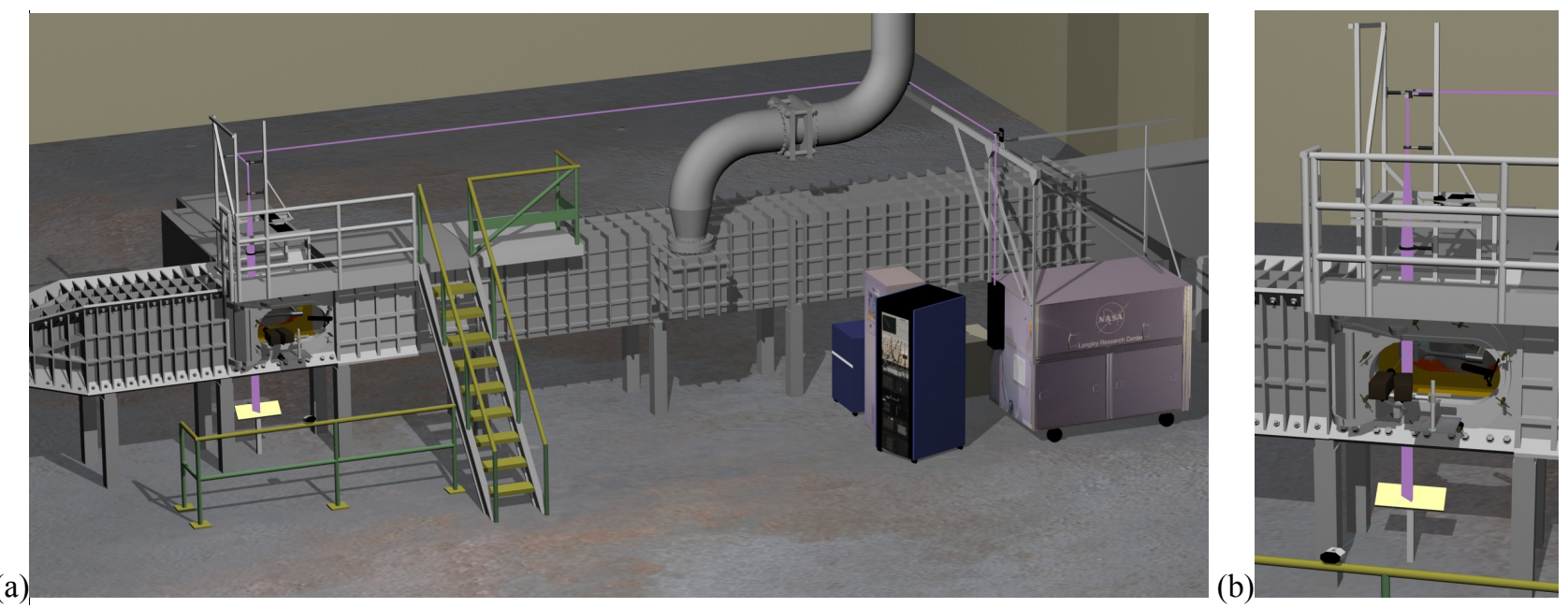

Figure 2. Schematic of the $10 \mathrm{~Hz}$ NO PLIF system installed adjacent to the 31-Inch Mach 10 Air wind tunnel for Test 462 . The NASA $10 \mathrm{~Hz}$ PLIF system is shown on the right side of (a). A close-up of the pair of cameras mounted near the tunnel window is shown in (b). The camera mounted on the yellow railing is the sheet profiling camera that imaged the laser sheet which passes over the model, through the bottom window of the test section and onto the yellow painted plate.

\section{MHz Planar Laser-Induced Fluorescence (PLIF) Imaging System}

A custom built MHz-rate PLIF imaging system was used for part of the test. This laser is described in detail in Refs. 19 and 20. The laser system was installed next to the facility between the stairs and the blue instrument rack shown in Fig. 2. This laser produced bursts of pulses at 1.06 microns with about $100 \mathrm{~mJ} /$ pulse which is then converted to second $(532 \mathrm{~nm})$ and third $(355 \mathrm{~nm}$ ) harmonic wavelengths. The third harmonic (about $30 \mathrm{~mJ} / \mathrm{pulse}$ ) is then used as the pump for a custom built injection-seeded optical parametric oscillator (OPO) system. OPO output is sum-frequency mixed with residual $355 \mathrm{~nm}$ pump, creating $500 \mathrm{kHz}, 20$-pulse bursts of tunable output in the vicinity of $226 \mathrm{~nm}$ with about $0.15 \mathrm{~mJ} /$ pulse, which are used for NO PLIF imaging. The repetition rate of the burst sequence is $1 \mathrm{~Hz}$. The OPO "idler" beam is seeded by an External Cavity Diode Laser (ECDL), which results in line-narrowed output for both the idler and signal waves. The seeding laser was tuned to $827.456 \mathrm{~nm}$ (vacuum wavelength), which after mixing with the third harmonic beam produced UV output at $225.838 \mathrm{~nm}$, exciting the $\mathrm{R}_{1}(12)$ transition of the NO A-X $(0,0)$ band. As with the $10 \mathrm{~Hz}$ system, the $\mathrm{MHz}$ laser beam was formed into a sheet using a combination of cylindrical and spherical lenses. This sheet could be scanned through the flow during a tunnel run to investigate different planes above the model surface.

PLIF image sequences were captured using a Princeton Scientific Instruments PSI-IV framing ICCD camera, with a $100 \mathrm{~mm}$ F/2 UV lens from B. Halle GmbH. The basic PSI-IV image sensor consists of an $80 \times 160$ array of $115 \times 115$ micron pixels, each of which has its own integrated 28 element memory buffer, allowing 28 images to be obtained. Charge is shifted from the photo active area, which constitutes approximately $50 \%$ of the total pixel area, to memory at a maximum frame rate of $1 \mathrm{MHz}$. The camera used in this experiment consists of a pair of sensors, with total available resolution of $160 \times 160$ pixels. A lens-coupled UV-sensitive micro-channel plate intensifier, with a fast decaying 
phosphor, is added in front of the camera to amplify the image intensity. The resulting magnification for Test 467 was 2.54 pixels $/ \mathrm{mm}$ (64.5 pixels/in) with a FOV (field of view) equal to $63 \mathrm{~mm}$ x $63 \mathrm{~mm}$ (2.5 in x $2.5 \mathrm{in}$ ). Gain of about $80 \%$ of the maximum was used for this experiment. The download time between image sequences was greater than 4 seconds, resulting in a $0.2 \mathrm{~Hz}$ repetition rate for the $\mathrm{MHz}$ laser/camera system to acquire bursts of pulses. Reference 20 shows a schematic, similar to Fig. 2 for the MHz laser and camera systems, as installed near the wind tunnel in Tests 463 and 467.

\section{E. PLIF Flow Visualization Image Processing}

The raw grayscale PLIF images were first corrected to remove lens and perspective distortion (see Ref. 15). Next, a background image was subtracted from both the single-shot PLIF images and the sheet profile images to remove background counts. The 10-Hz NO PLIF images presented herein were then processed to correct for the variation in the laser sheet's intensity across the field of view of the camera: the measured sheet profile images were first rotated to make the diagonal line image horizontal and then each column was summed to collapse the image into a single row. Second, image registration corrections and a smoothing function were applied. Third, each row in the PLIF image was divided by this sheet profile. Finally, a false color table was then applied to this sheet corrected image. The color table goes from transparent at very low signal intensities to purple to red to yellow to white as the PLIF intensity increases.

\section{F. Temperature Sensitive Paint (TSP) Heat Transfer Measurement System}

The temperature sensitive paint system employed in this study was based on a formulation developed at NASA LaRC and described previously. ${ }^{21}$ Essentially, the TSP layer is made by dissolving the luminophore ruthenium trisbypyridine (Rubpy) in a commercially available clear urethane sealant that is them applied to the model using conventional spraying techniques. Before application to the model, the SLA Nanoform surface was cleaned and degreased using acetone. After drying, a white acrylic primer was applied to the surface to act as a basecoat to enhance adhesion of the urethane sealant as well as enhance scattering of the luminescence intensity back to the camera. Calibration of the TSP was performed separate from the wind tunnel in a laboratory calibration chamber. The TSP formulation displayed adequate sensitivity up to about $420 \mathrm{~K}$, though the luminescence was significantly quenched (less than $1 \%$ of the original signal).

TSP data in the wind tunnel facility was acquired by illuminating the surface with several light emitting diode (LED) - based arrays. The LEDs that make up the arrays have a center wavelength of $400 \mathrm{~nm}$ with a very narrow emission (approximately $20 \mathrm{~nm}$ full width at half maximum). Images were collected using a 14-bit thermoelectrically cooled digital camera. The camera has an array size of $2048 \times 2048$ pixels, though binning was employed to increase the collection efficiency (image sizes are 1024 x 1024 pixels). Optical filters were placed in front of the camera lens to discriminate between the luminescence of the TSP and excitation and background light. A reference image for each run was acquired by injecting the model into the test section before tunnel operation. The model was then retracted into the model box, and the tunnel started. Once tunnel conditions stabilized, the model was re-injected and data collection began. TSP images were acquired every $500 \mathrm{~ms}$ throughout the run, lasting approximately 5-7 seconds while the model was in the tunnel on centerline. The ratio between the run image and the calibration image was calculated. These ratioed TSP images were then converted to temperature which was used to calculate the convective heat transfer coefficient, as detailed previously. ${ }^{1}$ Because an exact value for the substrate thermal product was unknown for the SLA Nanoform material, the heating results are presented as a ratio of $\mathrm{C}_{\mathrm{h}} / \mathrm{C}_{\mathrm{hFR}}$ multiplied by $\beta_{\mathrm{REF}} / \beta$ to acknowledge a factor of error. The TSP heating maps have been normalized to the Fay-Riddell stagnation point heating value (the heating rate that would have occurred at the stagnation point of a hemisphere at these same conditions, according to theory of Fay and Riddell ${ }^{22}$ ).

\section{G. Virtual Diagnostics Interface (ViDI)}

The Virtual Diagnostics Interface (ViDI) ${ }^{23}$ is a software tool, developed at NASA Langley Research Center, which provides unified data handling and interactive three-dimensional display of experimental data and computational predictions. It is a combination of custom-developed software applications and Autodesk ${ }^{\circledR} 3 \mathrm{ds} \mathrm{Max}^{\circledR}$, a commercially available, CAD-like software package for three-dimensional rendering and animation. ${ }^{24}$ ViDI technology can be applied to three main areas: 1) pre-test planning and optimization; 2) visualization and analysis of experimental data and/or computational predictions; and 3) establishment of a central hub to visualize, store and retrieve experimental results. For this experiment, ViDI was used for post-test visualization of the PLIF and TSP images, which had been processed as described in the previous sections. Images were overlaid on the model using dotcard images to ensure proper scaling and orientation. Renderings of the model and the image plane were generated using a virtual camera: the same virtual camera position has been used for every image shown in this paper (except Figs. 1 and 2). 


\section{Results}

\section{A. $10 \mathrm{~Hz}$ PLIF Flow visualization}

\section{Interpretation of NO PLIF visualizations}

Figure 3 shows a ViDI rendering of a typical $10 \mathrm{~Hz}$ NO PLIF flow visualization image obtained in Run 5 of Test 462. Flow is from left to right over the model. The laser sheet was oriented parallel to the surface of the model and passed from top to bottom both in the tunnel (as shown in Fig. 2) and in this image. Consequently, a shadow forms under the trip as indicated in Fig. 3. The nitric oxide seeded from the slot is only visualized when it is both illuminated by the laser and is within the camera's field of view (FOV) which is also indicated in figure.

Between the slot and the trip, the flow is smooth and laminar, as evidenced by a lack of streaks or irregular flow structures. The slight variation in PLIF intensity observed in this laminar flow region is caused by a variety of factors including different surface smoothness of the model which varies the intensity of fluorescence reflected from the model surface. Also, as mentioned above, the laser sheet intensity profile correction is imperfect. For example, some of the laser light may be clipped by the model for this image in which the laser sheet is nominally positioned at the surface (sheet position $=0 \mathrm{~mm}$, as indicated by the legend on the left of the figure).

The trip deflects part of the boundary layer flow spanwise (starboard direction) towards the top of the image. Downstream of the trip several streaks form. These streaks are evidence of instabilities in the flow being generated by the trip. The streaks are probably streamwise vortices having strong temperature gradients that also transport unseeded fluid towards the wall, adjacent to seeded fluid. As discussed below, these effects combine to provide the high-contrast streaks in the image. Even further downstream, these streaks become unstable, oscillating with periodic structures and then breaking down into much more irregular structures. In the diagram, this region of the flow is labeled "transition to turbulence".

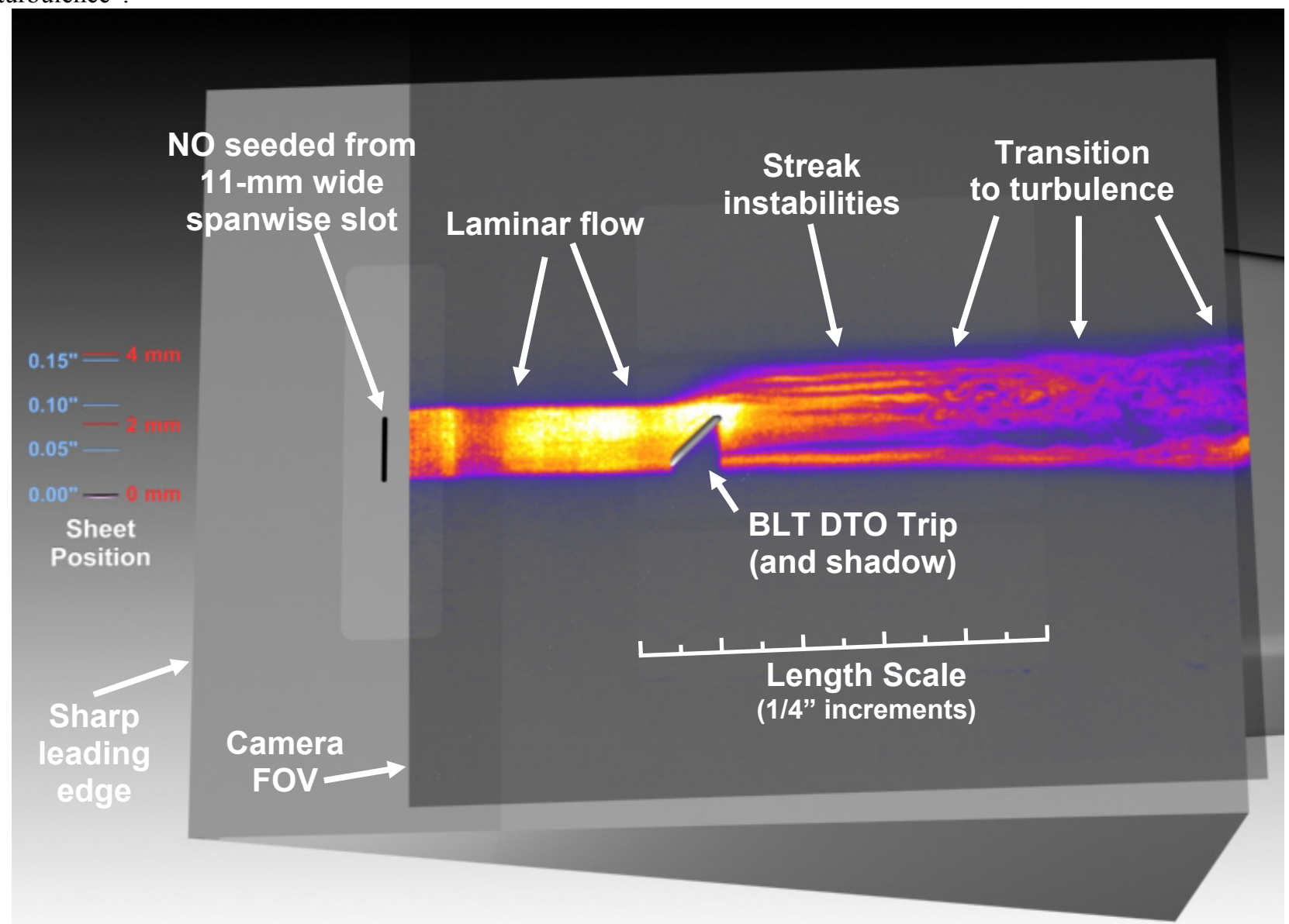

Figure 3. ViDI rendering of a typical $10 \mathrm{~Hz}$ NO PLIF image from Run 5, Test 462 . The length scale shows $1 / 4$ inch (6.35 mm) increments. 
(a)

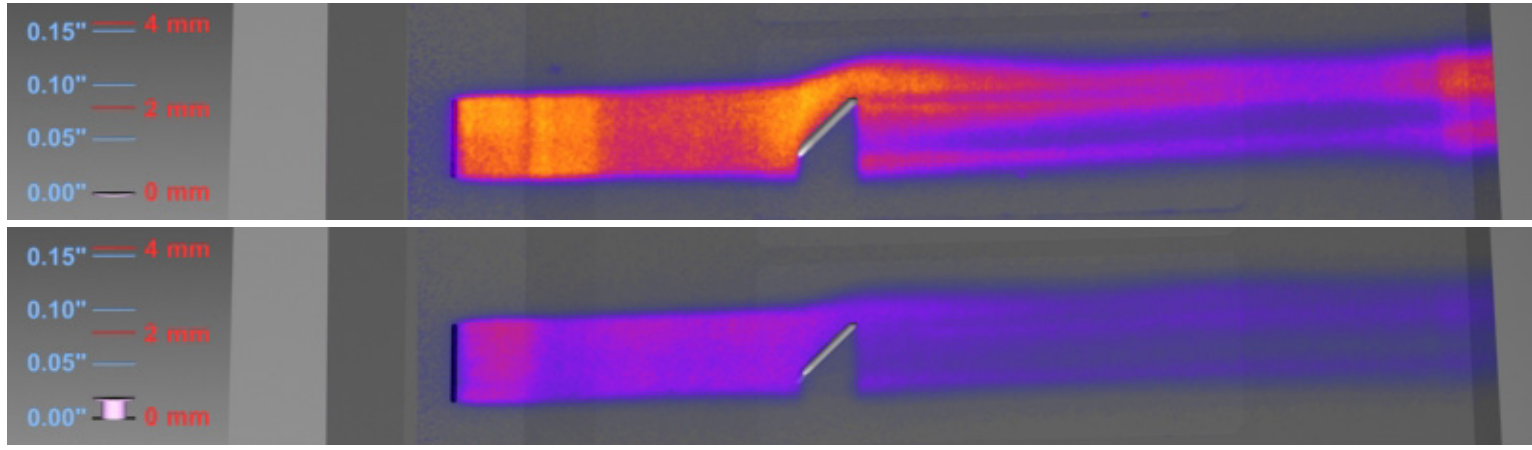

(b)

(c)

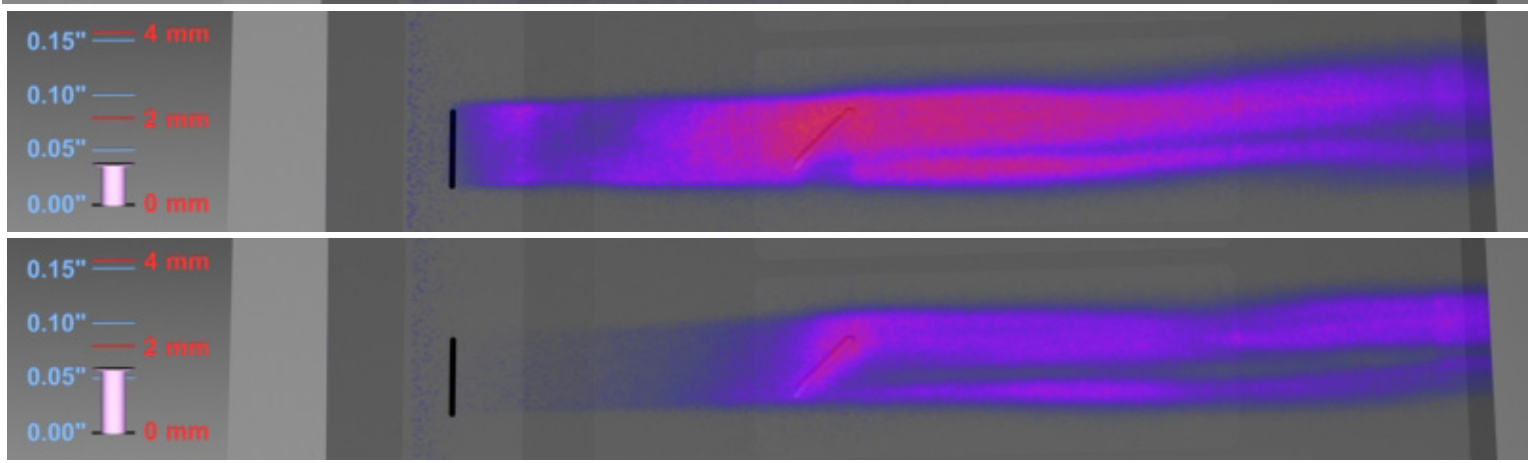

Figure 4. Test 462, Run 2, 1-mm tall BLT DTO trip, plate angle $=20^{\circ}, 11-\mathrm{mm}$ wide slot seeding, $\dot{m}=300 \mathrm{sccm}, \mathrm{P}_{0}=2.4 \mathrm{MPa}$, the position of the laser sheet above surface of the plate was varied from 0 to $1.5 \mathrm{~mm}$ in $0.5 \mathrm{~mm}$ increments from (a) to (d). Images were acquired at a repetition rate of $10 \mathrm{~Hz}$.

(a)

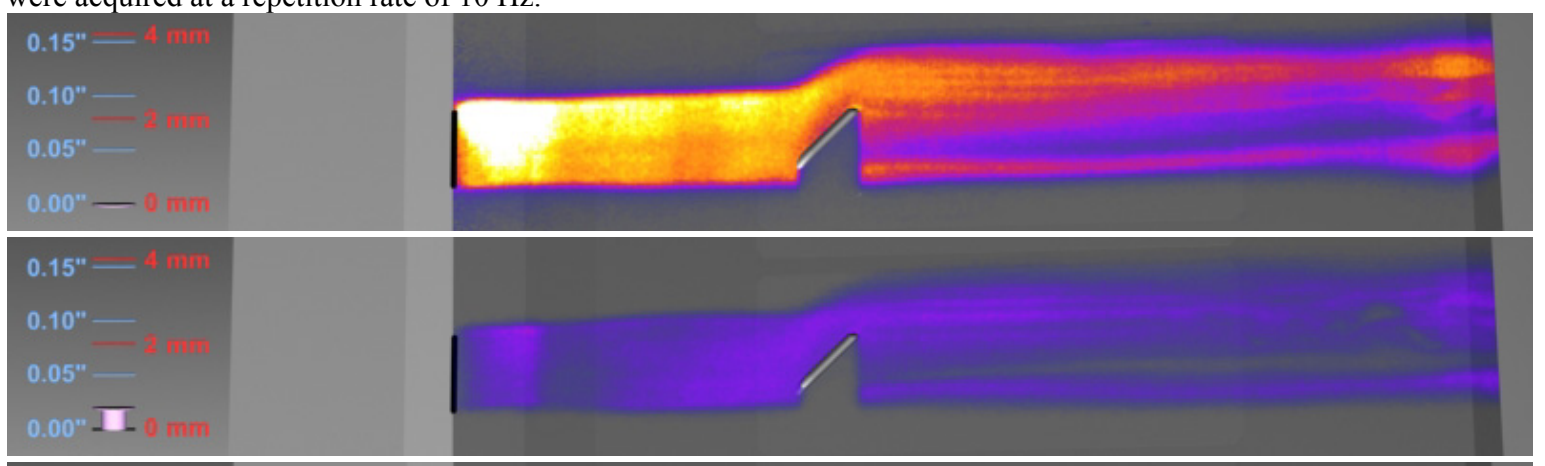

(b)

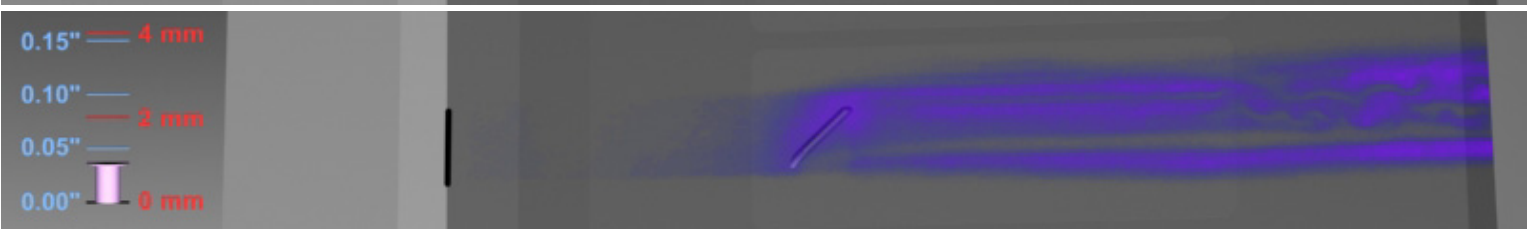

(c)

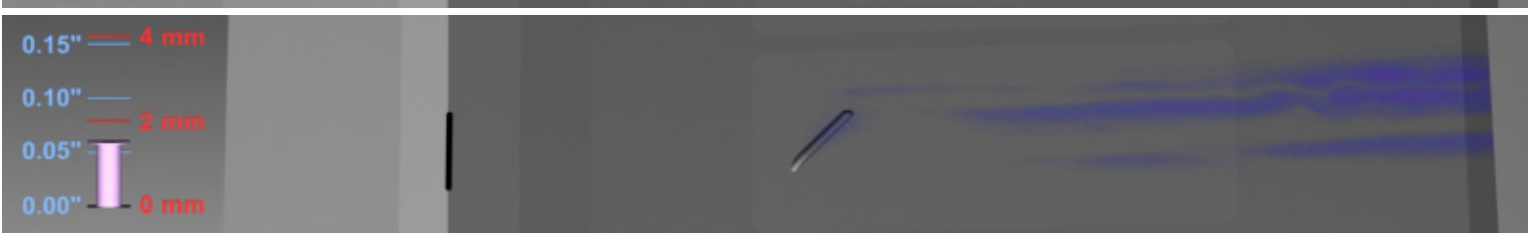

Figure 5. Test 462, Run 3, 1-mm tall BLT DTO trip, plate angle $=20^{\circ}, 11-\mathrm{mm}$ wide slot seeding, $\dot{m}=300 \mathrm{sccm}, \mathrm{P}_{0}=4.97 \mathrm{MPa}$, the position of the laser sheet above surface of the plate was varied from 0 to $1.5 \mathrm{~mm}$ in $0.5 \mathrm{~mm}$ increments from (a) to (d). Images were acquired at a repetition rate of $10 \mathrm{~Hz}$.

\section{Variation of Reynolds number and sheet position}

As indicated in Table 1, tunnel runs were performed at three different tunnel stagnation pressures to investigate the effect of Reynolds number on the flow over the BLT DTO trip. During each run, the laser sheet was positioned at various heights above the model surface. Initially the sheet was placed at a nominal sheet position of zero, where the 
laser was just skimming the surface of the model. For Run 2, shown in Fig. 4, ten seconds of data (100 PLIF images) was obtained at a sheet position of zero. Images were then continuously acquired while the sheet position was scanned over 10 seconds to $4 \mathrm{~mm}(0.157$ in.) above the surface of the model, where an additional 100 images were then acquired. The laser was then rapidly scanned in 1-mm (0.039 in.) increments to the surface, with 100 images acquired at each position. The following three figures each show PLIF images obtained at four heights above the surface, with the height of the laser sheet above the surface indicated by the legend to the left. The reported sheet positions have an accuracy of about $0.2 \mathrm{~mm}$ for all but the highest Reynolds number tested, where vibrations, which misalign the laser sheet, increased this uncertainty. For Test 467 , this uncertainty was observed to be as large as $0.5 \mathrm{~mm}$. However, the sheet position for certain images and image sequences can be more accurately identified. For example, images showing fluorescence aft of the trip simultaneous with partial shadows in the fluorescence on the port side of the trip must be skimming the top of the trip. Many additional images at varying heights are shown in the appendix.

Figure 4 shows PLIF images for the lowest Reynolds number run. The flow is observed to be relatively smooth, laminar, and mostly steady. Some laminar streamwise streaks appear downstream of the edges of the trip, likely evidence of vortices being generated by the corners of the trip. A small degree of laminar unsteadiness was observed in the images. Such unsteadiness can be observed by comparing several images acquired at the same height (see the appendix). Unsteadiness can also be observed from individual images, for example in Figs. 4(c) and (d) where long wavelength oscillations are observed downstream of the trip.

As the laser sheet is scanned away from the surface it eventually passes above the trip, which no longer generates a shadow. When the laser sheet is $1.5 \mathrm{~mm}$ (0.059 in.) above the surface, the upstream portion of laser no longer interrogates the seeded NO gas, preventing generation of a fluorescence signal. Near the axial position of the trip, the boundary layer thickness is estimated to be only $1.3 \mathrm{~mm}(0.055 \mathrm{in}$.) thick (in the absence of the trip). This is consistent with the images shown, assuming that NO is contained within the laminar boundary layer. Notably in this run the boundary layer fluid is observed in Fig. 4(d) to pass up over the trip and into the laser sheet.

PLIF images from the medium Reynolds number Run are shown in Fig. 5. These images show many of the same features observed in Fig. 4. The most notable difference is the development of curved flow structures towards the right side of the images. Based on observations of many such images, the images closer to the wall show laminar flow extending further downstream; the irregular structures occur further upstream for measurements further away from the wall. This is consistent with the conventional understanding that transition in hypersonic boundary layers begins near the edge of the boundary layer and propagates towards the wall as flow moves downstream.

(a)

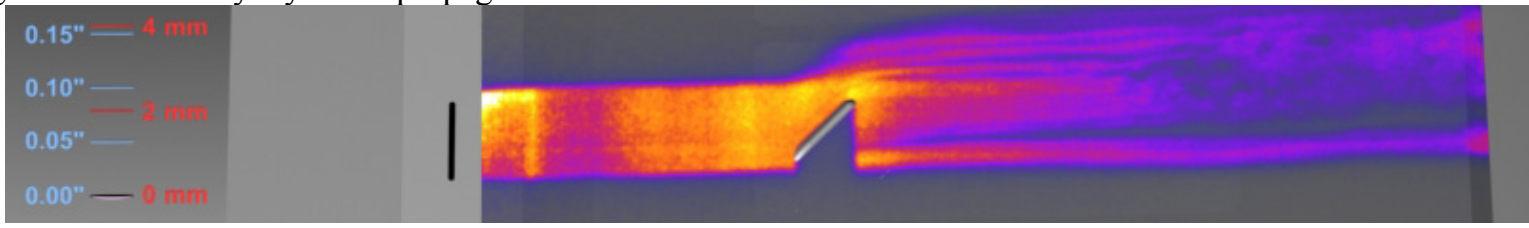

(b)

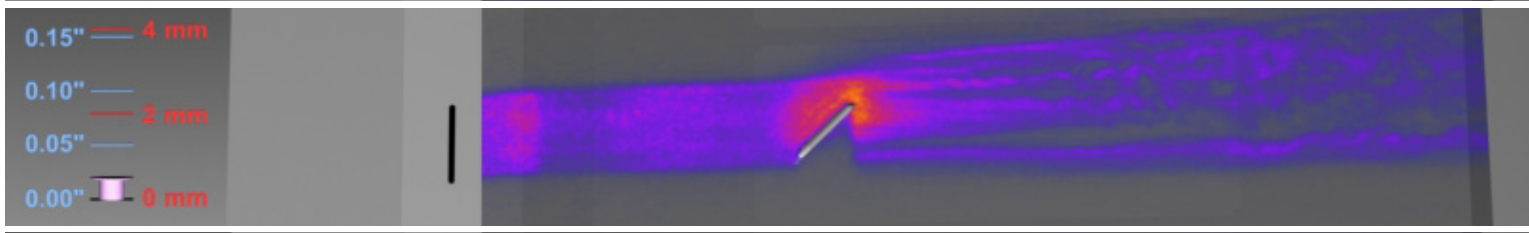

(c)

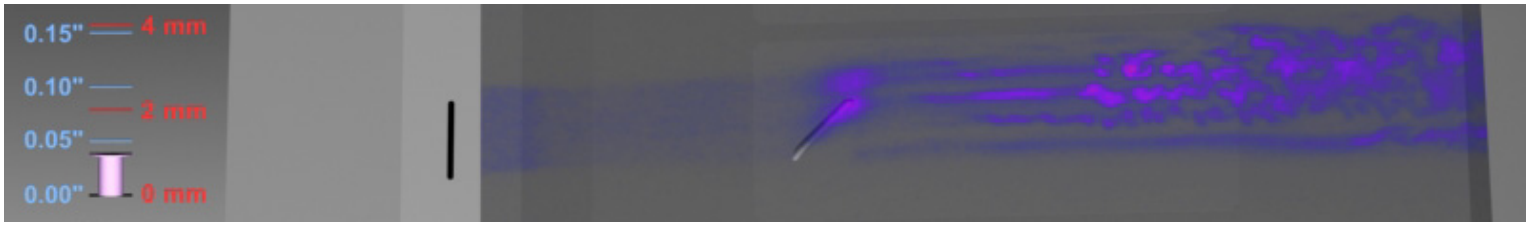

(d)

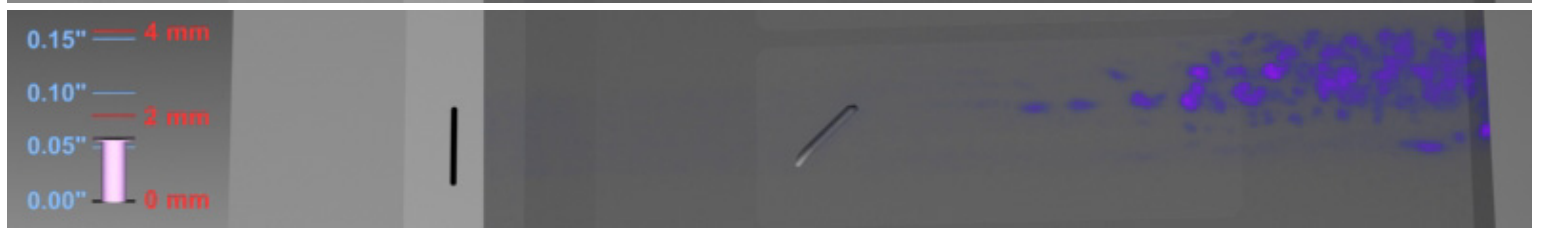

Figure 6. Test 462, Run 5, 1-mm tall BLT DTO trip, plate angle $=20^{\circ}, 11$-mm wide slot seeding, $\dot{m}=300 \mathrm{sccm}, \mathrm{P}_{0}=9.33 \mathrm{MPa}$, the position of the laser sheet above surface of the plate was varied from 0 to $1.5 \mathrm{~mm}$ in $0.5 \mathrm{~mm}$ increments from (a) to (d). Images were acquired at a repetition rate of $10 \mathrm{~Hz}$.

Figure 6 shows PLIF images from the highest Reynolds number tested. Again laminar flow is observed upstream of the trip, streaks are observed downstream of the trip. These streaks develop into periodic structures which break down 
into irregular, randomly oriented structures downstream. Evidence of corkscrew-shaped vortices is seen in Fig. 6(b). Consistent with the trend observed in Fig. 5, the oscillating structures occur further upstream in images acquired farther above the surface of the plate. The length scale of the smallest flow structures in Fig. 6 are significantly smaller than the smallest structures in Fig. 5, consistent with higher Reynolds number test conditions used for Fig. 6.

\section{DTO Trip vs Fence Trip}

To study the effect of the trip geometry, a fence-shaped trip, containing sharp edges and corners was also tested at the intermediate Reynolds number. Similar to the BLT DTO trip, the fence trip was nominally $1 \mathrm{~mm}(0.039 \mathrm{in}$.) tall and was oriented at a $45^{\circ}$ angle with respect to the oncoming flow. However, the trip was $8.35 \mathrm{~mm}$ (0.329 in.) wide which is about $20 \%$ smaller than the full width at half maximum width of the BLT DTO trip. The images, shown in Fig. 7, look generally similar to the images in Figs. 5 and 6: the smooth laminar flow incident on the trip is deflected starboard around the trip leading to streaks that transition to irregular structures downstream. Some of the streaks in Figs. 7(a) and (b) show that they originate in front of the trip, probably as a vortex rolling up in front of the trip. Upon closer inspection, similar, though less pronounced, flow patterns are observed even in the BLT DTO trip cases (see for example, Fig. 6(a) and (b)). The location of the transition from straight streaks to unsteady oscillating streaks in Fig. 7 most closely resembles those in Fig. 6. However Fig. 6 was obtained with a Reynolds number twice that of Fig. 7. Directly comparing Figs. 5 and 7, which were acquired at the same Reynolds number, show that the streamlined shape of the BLT DTO trip delays the onset of instabilities in the flow field by a distance of a factor of two compared to the sharp-cornered fence trip.

(a)

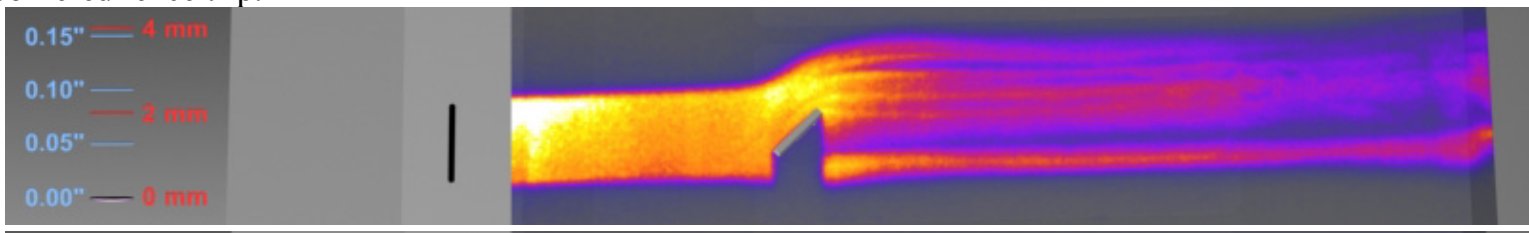

(b)

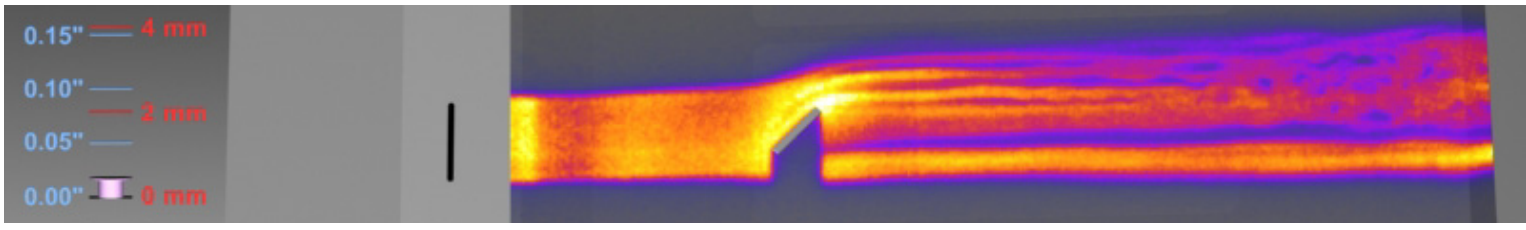

(c)

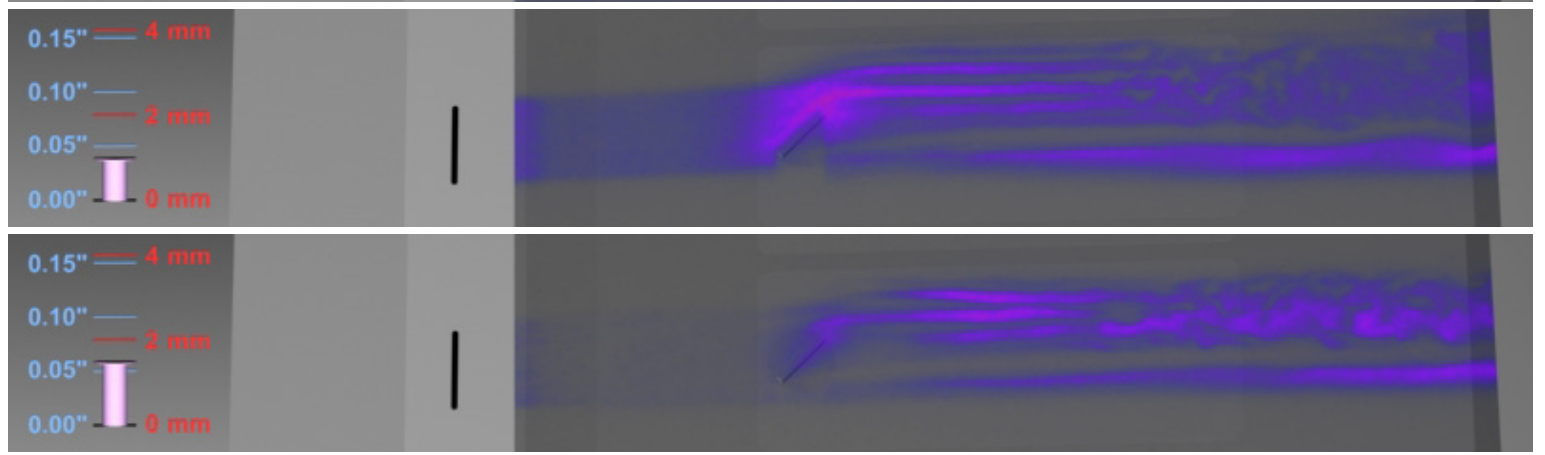

(d)

Figure 7. Test 462 , Run $4,1-\mathrm{mm}$ tall by $8 \mathrm{~mm}$ wide fence trip at $45^{\circ}$, plate angle $=20^{\circ}$, 11 -mm wide slot seeding, $\dot{m}=300$ sccm, $\mathrm{P}_{0}=4.97 \mathrm{MPa}$, the position of the laser sheet above surface of the plate was varied from 0 to $1.5 \mathrm{~mm}$ in $0.5 \mathrm{~mm}$ increments from (a) to (d). Images were acquired at a repetition rate of $10 \mathrm{~Hz}$.

\section{Numbers of streaks}

Another noticeable difference in the images in Figs. 4 through 7 is the number of streaks observed downstream of the trip. Comparing the (a) image of each figure, which show the closest measurement to the surface, the lowest Reynolds number case shows three streaks, the intermediate Reynolds number case shows five streaks, and the highest Reynolds number case shows seven streaks for the BLT DTO trip. It is possible that additional streaks occur further from the trip in an area of the flow not seeded within nitric oxide, however there is clearly a noticeable increase in the number, and decrease in spacing of the streaks as a Reynolds number is increased. The fence trip typically shows six streaks, which is one streak more than BLT DTO trip at the same operating conditions.

\section{B. $500 \mathrm{kHz}$ PLIF flow visualization}

NO PLIF images acquired at a $500 \mathrm{kHz}$ rate allow the time evolution of the flow structures to be studied. The PLIF system used to acquire these images had a smaller field of view than the $10 \mathrm{~Hz}$ system used to obtain the data shown in 
the figures above. It was not possible to move the field of view downstream on the model because of experimental schedule time constraints. The lower and intermediate Reynolds number cases studied above would not have generated unsteady flows in the field of view of the camera, though they did become unsteady further downstream. Thus experimental results are only reported here for the highest Reynolds number condition tested (corresponding to the same conditions as Fig. 6).

Figure 8 shows ViDI renderings of several frames from the $500 \mathrm{kHz}$ PLIF system, with the laser sheet $0.5 \mathrm{~mm}$ above the surface. The time between the images corresponds to $2 \mu \mathrm{s}$, with the whole sequence of images collected in approximately $20 \mu \mathrm{s}$. These images are best viewed as animated movie sequences, although useful information can also be obtained from still-image sequences like those shown in Fig. 8. Individual features can be tracked, image by image, to see, for example, a streak begin to oscillate with increased side-to-side amplitude and then form an irregular structure downstream. Figure 9 shows an image sequence obtained near the top of the trip about $1 \mathrm{~mm}$ above the surface. Seven different streaks are observed, in various stages of instability. The one becoming unstable furthest upstream shows a periodic corkscrew shape. In subsequent frames, this corkscrew shaped vortex convects downstream and breaks up, becoming more irregularly shaped. It is replaced upstream by a more stable, laminar streak. Figure 10 shows an image sequence obtained above the height of the trip. The gas observed in this image has been deflected up into the laser sheet by the streaks and vortices generated by the trip. Several structures with a $45^{\circ}$ orientation (again, possible cross sections of corkscrew shaped vortices) are observed to convect downstream. One such structure is identified by a green box in Fig. 10(g). These time-correlated image sequences allow observation of streak instabilities and their breakup into irregular shaped structures, corroborating observations from single-frame images in Figs 3-7 above. One of the advantages of these image sequences is that the origin of the differently shaped flow structures towards the right side of the images can be traced back to the specific instability from which they developed.

(a)

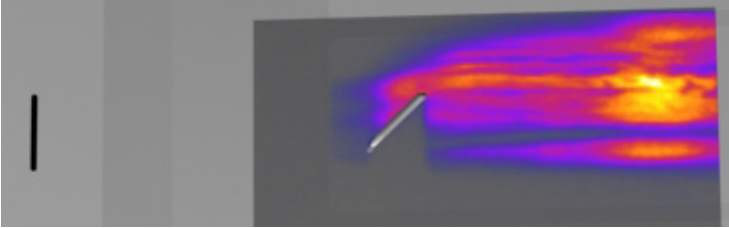

(c)

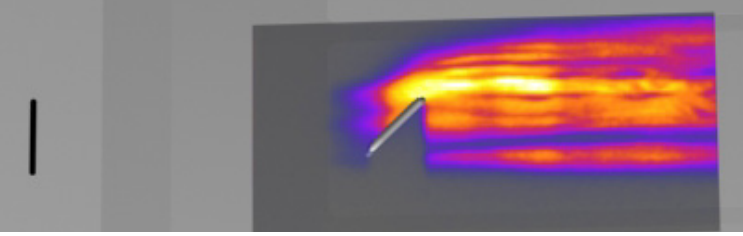

(e)

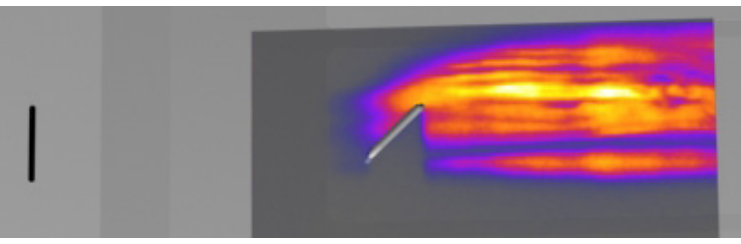

(g)

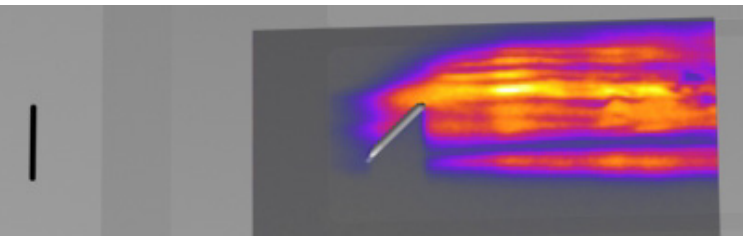

(b)

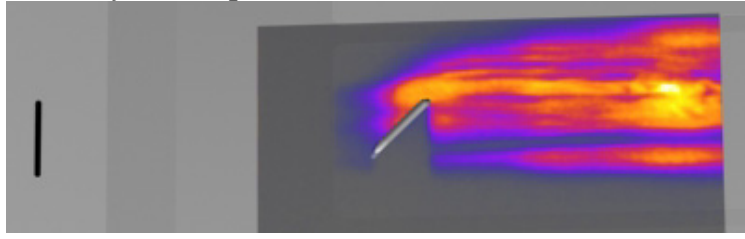

(d)

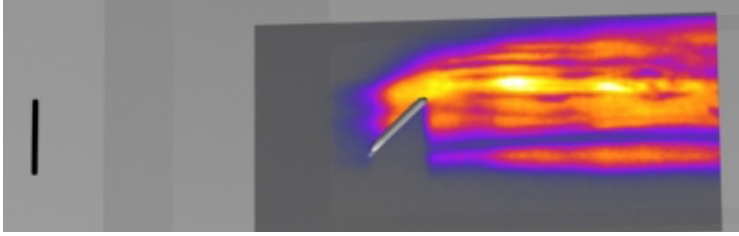

(f)

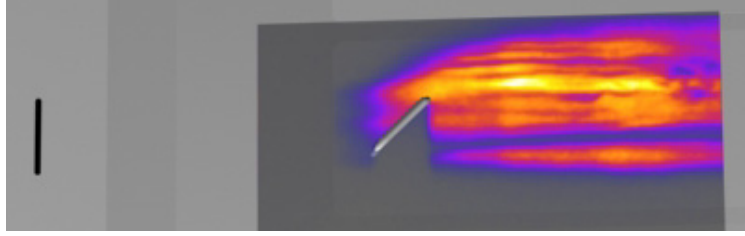

(h)

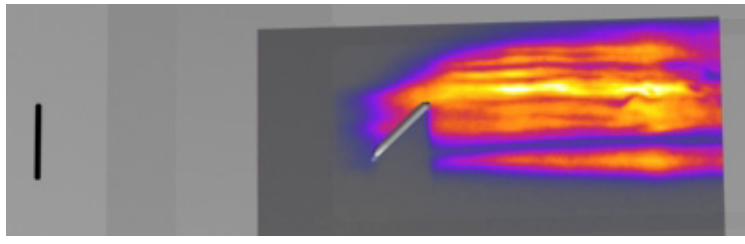

Figure 8. Test 467 , Run 18,1 -mm tall BLT DTO trip at $45^{\circ}$, plate angle $=20^{\circ}, 11$-mm wide slot seeding, $\dot{m}=300 \mathrm{sccm}, \mathrm{P}_{0}=$ 9.3 MPa, the position of the laser sheet above surface of the plate was $0.5 \mathrm{~mm}$. Images were acquired at a repetition rate of 500 $\mathrm{kHz}$. The length of the field of view of the camera (dark grey area) is about 2.5 inches $(50 \mathrm{~mm})$. 
(a)

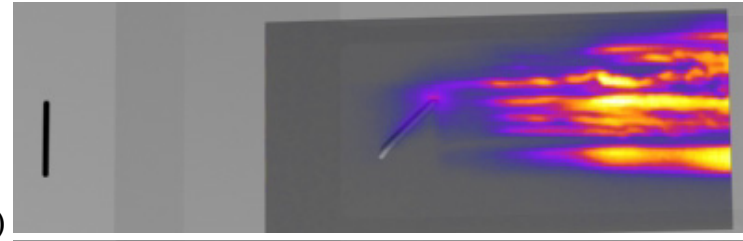

(c)

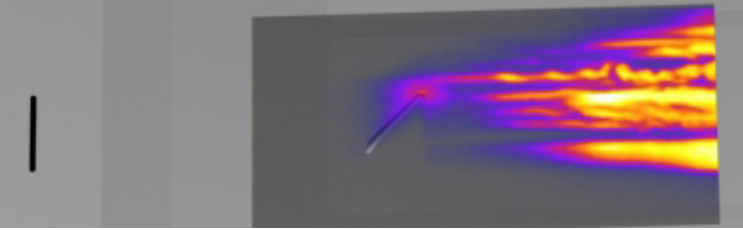

(e)

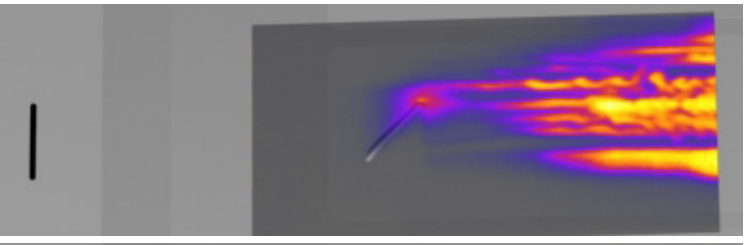

(g)

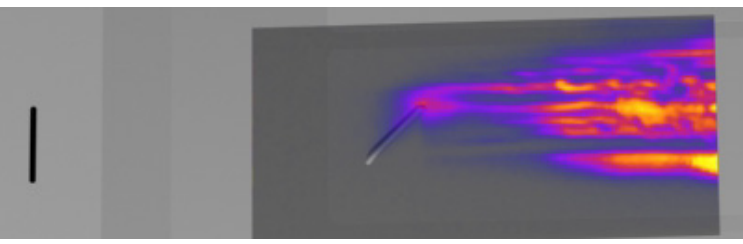

(b)

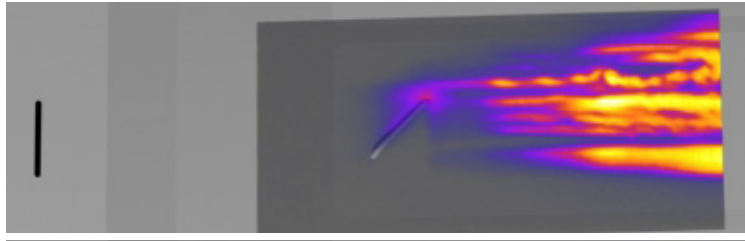

(d)

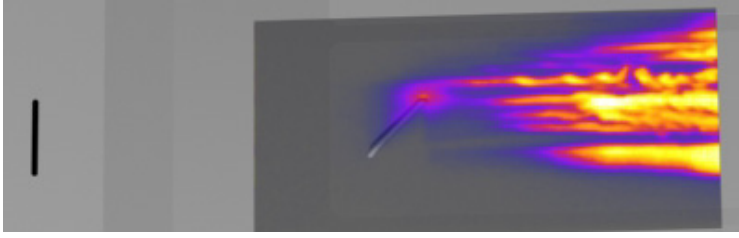

(f)

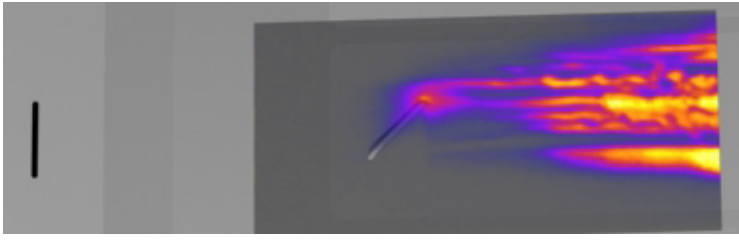

(h)

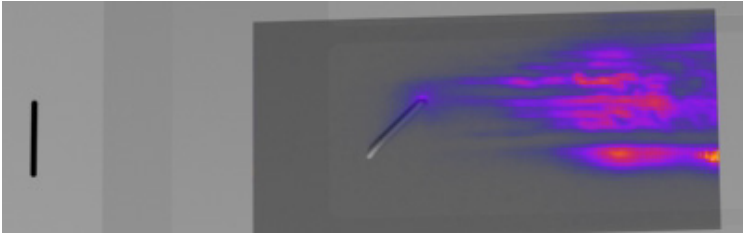

Figure 9. Test 467 , Run 18,1 -mm tall BLT DTO trip at $45^{\circ}$, plate angle $=20^{\circ}, 11$-mm wide slot seeding, $\dot{m}=300 \mathrm{sccm}, \mathrm{P}_{0}=$ $9.3 \mathrm{MPa}$, the position of the laser sheet above surface of the plate was $1.0 \mathrm{~mm}$. Images were acquired at a repetition rate of 500 $\mathrm{kHz}$.

(a)

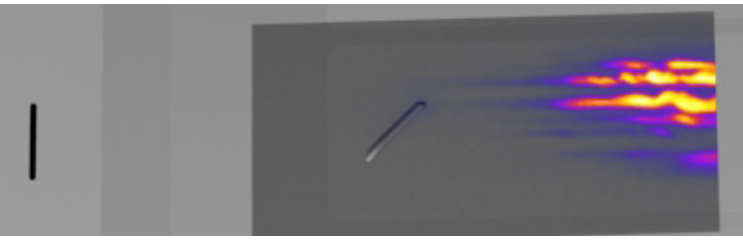

(c)
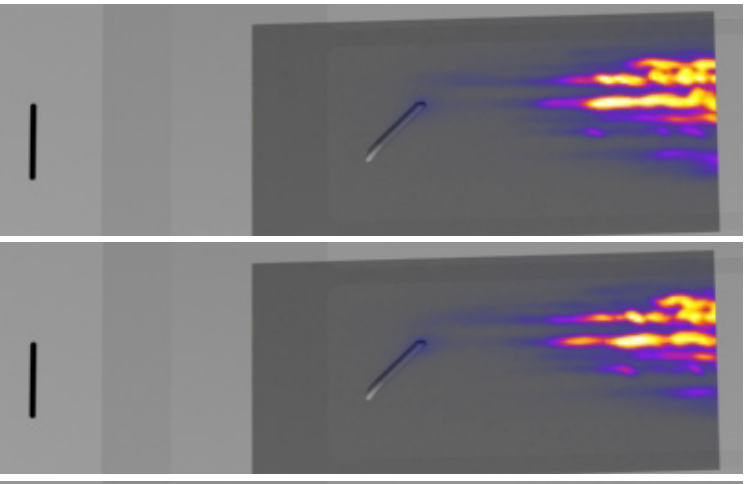

(e)

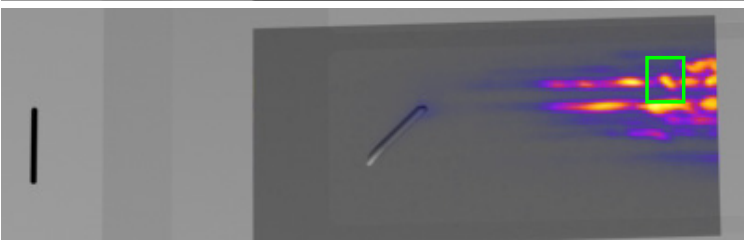

(b)

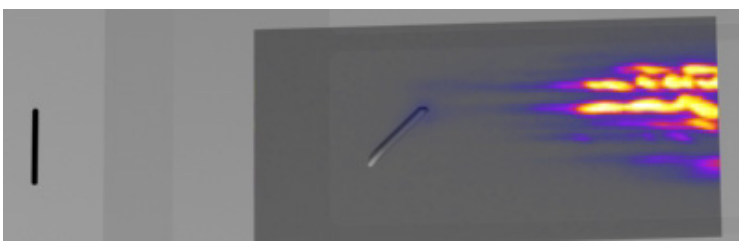

(d)

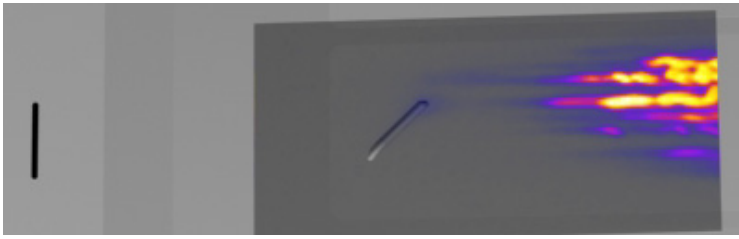

(f)

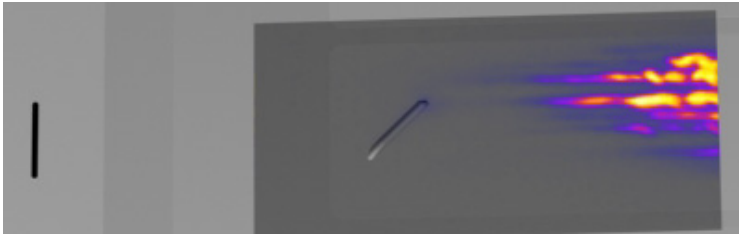

(h)

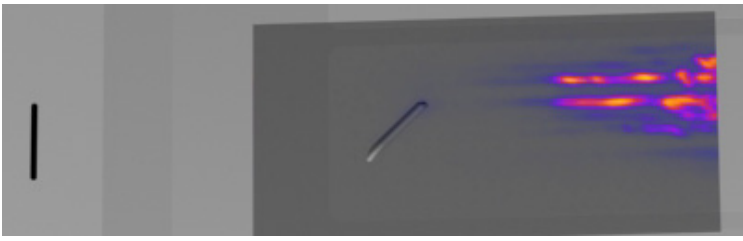

Figure 10. Test 467 , Run $18,1-\mathrm{mm}$ tall BLT DTO trip at $45^{\circ}$, plate angle $=20^{\circ}, 11-\mathrm{mm}$ wide slot seeding, $\dot{m}=300 \mathrm{sccm}, \mathrm{P}_{0}=$ $9.3 \mathrm{MPa}$, the position of the laser sheet above surface of the plate was $1.2 \mathrm{~mm}$. Images were acquired at a repetition rate of 500 $\mathrm{kHz}$. The boxed structure in $(\mathrm{g})$ is described in the text. 


\section{Temperature sensitive paint measurements}

Temperature sensitive paint (TSP) measurements were also performed to determine the surface temperature and the surface heating induced by the flow. The results of these measurements are shown in Fig. 11. For all the TSP measurements, flat TSP-coated inserts were placed adjacent to the TSP-insert that contained the trip. As a baseline case, a third TSP-coated flat surface replaced the BLT DTO trip for one run at the medium Reynolds number. The result of this baseline case test is shown in Fig. 11(a). The heating pattern over the central insert is relatively uniform and about $25 \%$ of the heating that a hemisphere would experience at its stagnation point for the same tunnel conditions. However, streamwise streaks are observed in both of the adjacent inserts. These streaks appear to originate at the edges of the seeding insert. Recall that the insert was raised slightly above the surface of the flat plate. Thus vortices probably originate from the corners and pass downstream over the inserts. Nonetheless the central TSP-coated insert, which is of primary concern, appears not to have significant flow disturbance caused by the seeding insert. This baseline case provides a reference from which the increase in heating can be measured with the BLT DTO trip in place.

For the lowest Reynolds number case containing the BLT DTO trip, both increases and decreases in the surface heating are observed at different places in the flow. A slight decrease in heating occurs forward of and to the starboard side of the trip. This locally cool region extends to the end of the trip insert. Another cool region is on the leeward side of the trip, which also continues faintly to the end of the trip insert. The regions of increased heating are on the windward side of the trip, as expected, and then in two parallel streamwise streaks originating from the corners of the trips. The starboard streak shows significantly lower heating than the port-side streak, possibly indicating a stronger vortex on the port side. The port-side streak increases in width and decreases slightly in intensity with downstream distance. The starboard streak diminishes significantly with the distance. When the Reynolds number is increased by a factor of two, in Fig. 11(c), most of the same features are observed, but with greater size and intensity. An important difference observed between the two Reynolds number cases is that evidence of at least one additional streamwise vortex is shown in the higher Reynolds number case, as evidenced by an additional thin horizontal light-blue streak in Fig. 11(c). Another difference is that the main starboard streak stays nearly constant in heating magnitude as it propagates to the end of the insert. The maximum overall heating observed in the experiment is shown in the port side streak downstream of the trip. The heating level there is about $63 \%$ of the heating that would be experienced by the stagnation point of a hemisphere at the same conditions (described in Section II.F), or a bump factor of 2.5 over the notrip case. If the highest Reynolds number condition had been tested with this trip configuration, two problems would have occurred. First, the surface temperatures would have exceeded the dynamic range of the TSP measurement system. Secondly, the paint would have become damaged under such high heating loads. Thus, TSP measurements at the highest Reynolds number conditions were not attempted.

The TSP also measured the surface temperature on the trip insert three seconds after model injection. For Run 34, the temperature was uniformly about $350 \mathrm{~K}$. For Run 35 , the surface temperature varied from $350 \mathrm{~K}$ in the cooler regions to $420 \mathrm{~K}$ in the highest temperature regions. For Run 36, the temperature varied from 340 to $380 \mathrm{~K}$ over the insert. The steel model, however, acts as a heat sink and would have remained much cooler (room temperature) in the first few seconds of operation. 


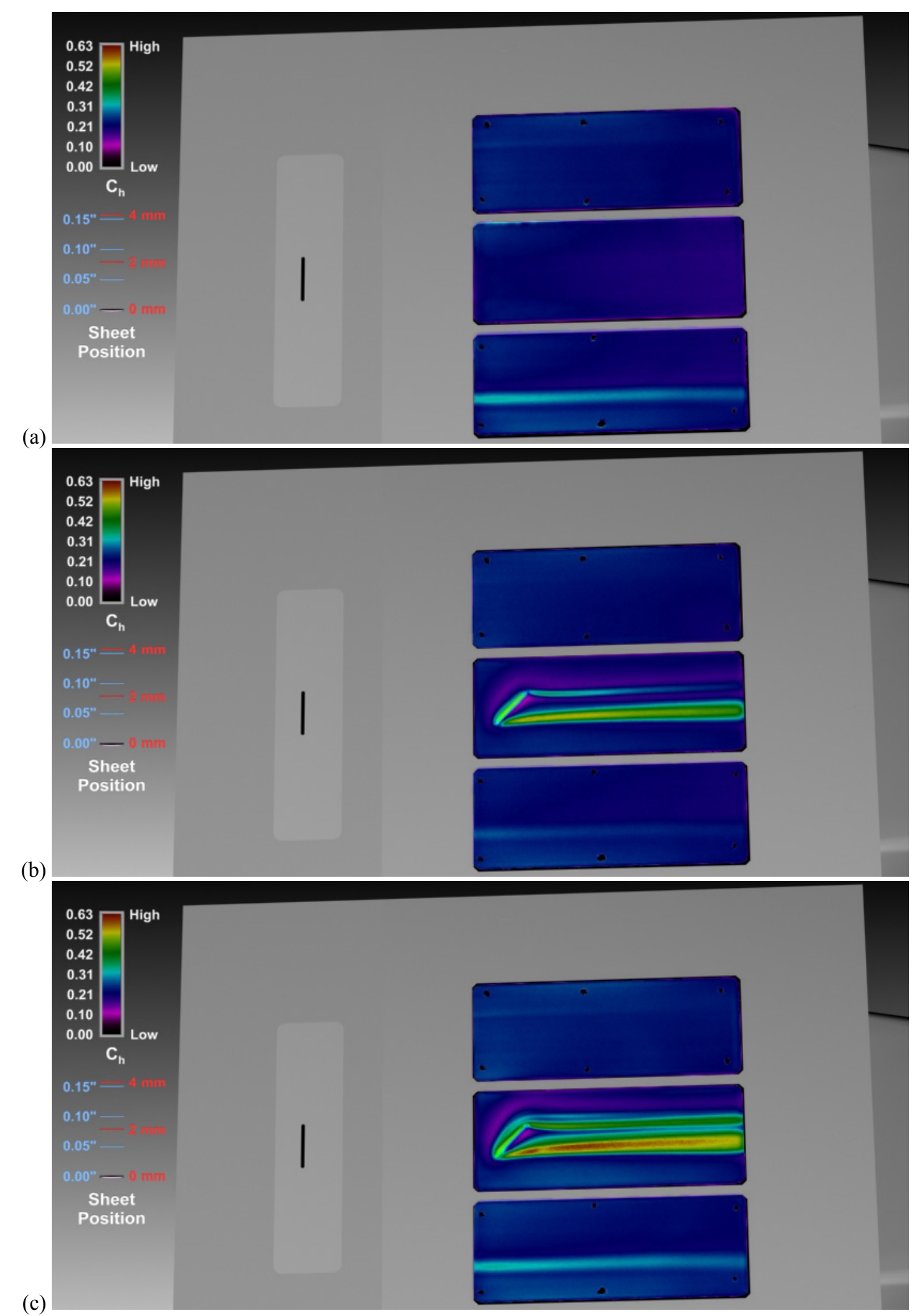

Figure 11. ViDI renderings of TSP measurements from Test 462, (a) Run 34 with $\mathrm{P}_{0}=4.97 \mathrm{MPa}, \dot{m}=300$ sccm, no trip; (b) Run 36, $2.90 \mathrm{MPa}, \dot{m}=150 \mathrm{sccm}, 1-\mathrm{mm}$ tall BLT DTO trip; (c) Run 35, $4.97 \mathrm{MPa}, \dot{m}=300 \mathrm{sccm}, 1-\mathrm{mm}$ tall BLT DTO trip. All cased used plate angle $=20^{\circ}$ and $11-\mathrm{mm}$ wide slot seeding. 
(a)

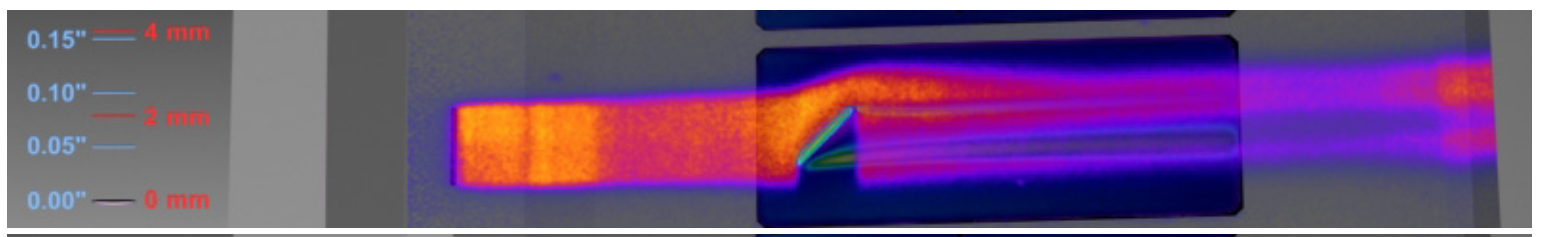

(b)

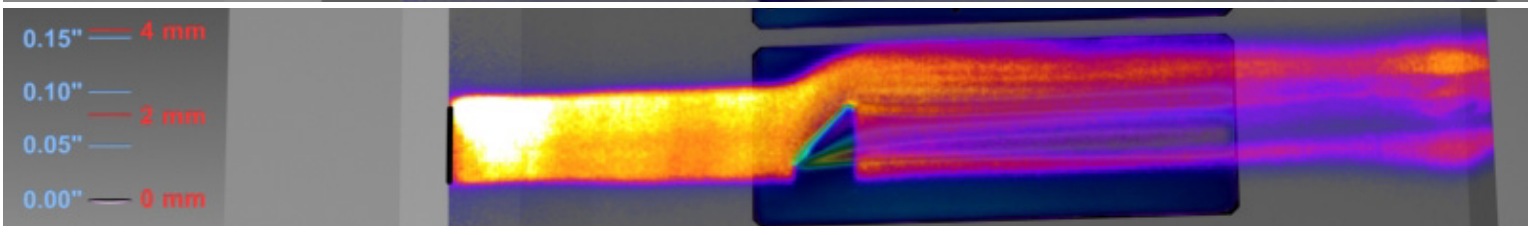

Figure 12. ViDI renderings superimposing NO PLIF and TSP results for (a) PLIF Run 2 and TSP Run $36, \dot{m}=150 \mathrm{sccm}, \mathrm{P}_{0}=$ 2.40 MPa, (b) PLIF Run 3 and TSP Run 35, $\dot{m}=300 \mathrm{sccm}, \mathrm{P}_{0}=4.97 \mathrm{MPa}$. Both cases used the BLT DTO trip with plate angle $=$ $20^{\circ}$ and $11-\mathrm{mm}$ wide slot seeding and PLIF sheet position $=0.1 \mathrm{~mm}$.

NO PLIF and TSP results can be compared using ViDI to investigate any correlations between the observed flow patterns. Figure 12 shows such a comparison. The PLIF images used were acquired adjacent to the surface. For both cases shown in Fig. 12, the regions of peak heating in the TSP correspond to regions of lower PLIF signal. At least two such correlating streaks are observed in each image, both originating from the corners of the trip. The factor of 2 to 4 decrease in PLIF signal in the streaks could occur for two different reasons: the NO concentration could have decreased because fluid from outside the boundary layer (fluid that does not contain NO) has been convected towards the surface, for example by a vortex. Alternately, the NO concentration could be uniform and the PLIF intensity could be varying because of gas temperature gradients in the streaks. CFD simulations of this flowfield (though at higher Reynolds number) indicate that the temperature in the streaks downstream of the trip varies between 250 and 500 Kelvin. ${ }^{7}$ Our prior calculations for the same probed transitions ${ }^{25}$ indicate that the PLIF signal would decrease by a factor of 4 between 250 and $500 \mathrm{~K}$ at $2 \mathrm{kPa}$. Thus it is likely that the change in signal for these two images, which were acquired near the surface of the model, is caused entirely by temperature variations and not by NO concentration variations. However, as the laser sheet passes further above the surface of the model, much higher contrast structures are seen. For example, images like Fig. 5(c) and (d) typically show peak-to-valley contrasts of factors of 10 or 20. Such large variations in signal cannot be attributed only to temperature variations in the flow. In these cases, image contrast is being further enhanced by the juxtaposition of seeded and unseeded fluid. Future experiments utilizing temperature or density measurement techniques as well as computational fluid dynamics simulations and computational flow imaging simulations ${ }^{26}$ may shed further light on these flow structures.

\section{Conclusion}

Measurements have been performed in a Mach 10 wind tunnel to study the near-field flow over two protuberances on a flat plate: a BLT DTO trip and a rectangular fence of the same height, both oriented at $45^{\circ}$ to the flow. The NO PLIF flow visualization and TSP heat transfer measurement methods were used to observe the laminar flow development. PLIF was used to study the unsteady transitional flow features occurring at the higher Reynolds numbers. Two different NO PLIF measurement systems were used: a high-resolution wide-field-of-view $10 \mathrm{~Hz}$ system and a lower-resolution $500 \mathrm{kHz}$ system that could capture the time evolution of the flow. In the PLIF and TSP images, streamwise streaks were observed downstream of the trips. As the Reynolds number increased, the number of these observed streaks increased and their spacing decreased. As the Reynolds number increased, the instabilities in the streamwise streaks occurred further upstream. The flow on the right of the cameras' field of view showed an increase in jaggedness and also showed smaller structures for the higher Reynolds number cases. The sharp-edged and sharpcornered rectangular fence was observed to perturb the flow more significantly than the more streamlined BLT DTO trip when tested at the same conditions. Flow instabilities developed to a similar degree in half the distance for the fence trip compared to be BLT DTO trip. This data set should provide validation data as well as physical understanding for theoretical instability model development and computation.

\section{Acknowledgments}

We wish to acknowledge the contribution to this project from the NASA Langley Research Center 31-Inch Mach 10 Air Tunnel technicians and engineers, including Kevin Hollingsworth, Sheila Wright, Paul Tucker, Tony Robbins, Henry Fitzgerald and Johnny Ellis. This work was supported by the NASA Fundamental Aeronautics Hypersonics Program with support from both the Experimental Capabilities and Aerodynamics-Aerothermodynamics-Plasma Disciplines. Support for operation of the facility was also obtained from the Hypersonic Thermodynamic Infrared 
Measurement (HYTHIRM) project via Tom Horvath and from the Aeronautics Testing Program (ATP) and is appreciated. Thanks also to Rich Schwartz from ATK Space Division, Hampton Virginia, for assisting with the computer visualizations of the data, to Mark Kulick, also of ATK for building some of the test hardware and to Rob Andrews, from the NASA Fabrication shop, for building the BLT DTO trip. The authors from OSU and ISU also wish to acknowledge the Air Force Office of Scientific Research (Julian Tishkoff and John Schmisseur) and the Air Force Research Laboratory (James Gord) for their contributions to the development of the $\mathrm{MHz}$ laser and camera technologies.

\section{References}

${ }^{1}$ C. H. Campbell, M. T. Garske, J. Kinder, and S. A. Berry, "Orbiter Entry Boundary Layer Flight Testing," AIAA Paper Number 2008-635, 46 ${ }^{\text {th }}$ AIAA Aerospace Sciences Meeting and Exhibit, 7 - 10 January 2008, Reno, Nevada.

${ }^{2}$ B. P. Anderson, C. H. Campbell, L. A. Saucedo, G. R. Kinder, "BLT Flight Experiment Overview and In- Situ Measurements" AIAA-2010-0240, 48 ${ }^{\text {th }}$ AIAA Aerospace Sciences Meeting, Orlando, FL, January, 2010.

${ }^{3}$ S. Schneider "Effects of Roughness on Hypersonic Boundary-Layer Transition," J. of Spacecraft and Rockets, vol.45 no.2 p.193-209, Mar.-Apr. 2008.

${ }^{4}$ S. A. Berry and T. J. Horvath, R. Schwartz, M. Ross, B. Anderson and C. H. Campbell, "Infrared Imaging of Boundary Layer Transition Flight Experiments," 40th AIAA Thermophysics Conference AIAA 2008-4026, Seattle, WA, 23-26 June 2008.

${ }^{5}$ J. Everhart, "Transition Induced by Fence Geometries on Shuttle Orbiter at Mach 10," AIAA-2010-1577, 48 ${ }^{\text {th }}$ AIAA Aerospace Sciences Meeting, Orlando, FL, January, 2010.

${ }^{6}$ C-L. Chang, M. Choudhari, and F. Li, "Numerical Computations of Hypersonic Boundary-Layer over Surface Irregularities," AIAA-2010-1572, 48 ${ }^{\text {th }}$ AIAA Aerospace Sciences Meeting, Orlando, FL, January, 2010.

${ }^{7}$ S. Yoon, M. Barnhardt, "Simulations of High-Speed Flow Over an Isolated Roughness", AIAA-2010-1573

${ }^{8}$ P.M. Danehy, A.P. Garcia, S. Borg, A.A. Dyakonov, S.A. Berry, J.A. Wilkes Inman, D.W. Alderfer, "Fluorescence visualization of hypersonic flow past triangular and rectangular boundary-layer trips", AIAA-2007-0536, 45th AIAA Aerospace Sciences Meeting, Reno Nevada, January 8-11 (2007)

9 J. Olbregts, "Termolecular reaction of nitrogen monoxide and oxygen: A still unsolved problem,", Int. J. Chem. Kinet., 17, 1985.

${ }^{10}$ J. R. Micol "Langley Aerothermodynamic Facilities Complex: Enhancements and Testing Capabilities," AIAA Paper 98-0147, 36th AIAA Aerospace Sciences Meeting \& Exhibit, January 12-15, Reno, NV, 1998.

${ }^{11}$ Hollis, B.R. "Real-gas flow properties for NASA Langley Research Center Aerothermodynamics Facilities Complex Wind Tunnels," NASA Contractor Report 4755, Sept. 1996.

${ }^{12}$ C. Campbell, "Roles of Engineering Correlations in Hypersonic Entry Boundary Layer Transition Prediction," AIAA2010-0247, 48 ${ }^{\text {th }}$ AIAA Aerospace Sciences Meeting, Orlando, FL, January, 2010.

${ }^{13}$ P. M. Danehy, B. Bathel, C. Ivey, J. A. Inman, S. B. Jones, "NO PLIF study of hypersonic transition over a discrete hemispherical roughness element", AIAA-2009-0394, 47th AIAA Aerospace Sciences Meeting, Orlando, FL, January, 2009.

${ }^{14}$ P. M. Danehy, J. A. Inman, G. Brauckmann, D. W. Alderfer, S. B. Jones, and D. Patry, "Visualization of a Capsule Entry Vehicle Reaction-Control System Thruster" Journal of Spacecraft and Rockets, vol. 46 no.1 p. 93-102 (2009).

${ }^{15}$ P.M. Danehy , D.W. Alderfer, J.A. Inman , K.T. Berger, G.M. Buck and R. J. Schwartz "Fluorescence Imaging and Streamline Visualization of Hypersonic Flow over Rapid Prototype Wind-Tunnel Models," Proc. IMechE, Part G: J. Aerospace Engineering, 222(G5), 637-651 (2008).

16 J. A. Inman, P. M. Danehy, D. W. Alderfer, and G. M. Buck, and A. McCrea, "Planar Fluorescence Imaging and Three Dimensional Reconstructions of Capsule Reaction-Control-System Jets", AIAA Journal Vol. 47, No. 4, April (2009)

17 J. A. Inman, P.M. Danehy, R.J. Nowak, D.W. Alderfer, "Fluorescence Imaging Study of Impinging Underexpanded Jets" AIAA-2008-619, 46th AIAA Aerospace Sciences Meeting and Exhibit, Reno, Nevada, Jan. 7-10, 2008.

${ }^{18}$ J. A. Wilkes, D. W. Alderfer, S. B. Jones, and P. M. Danehy, "Portable Fluorescence Imaging System for Hypersonic Flow Facilities," JANNAF Interagency Propulsion Committee Meeting, Colorado Springs, Colorado, December, 2003.

19 N. Jiang, and W. Lempert, "Ultra-high frame rate Nitric Oxide Planar Laser Induced Fluorescence imaging", Optics Letters, 33, (19), 2236-2238, 2008

${ }^{20}$ N. Jiang, M. Webster, and W. Lempert, J. Miller, T. Meyer, J. Inman, B. Bathel, S. Jones, and P. Danehy, "MHz-Rate NO PLIF Imaging in a Mach 10 Hypersonic Wind Tunnel", AIAA-2010-1407, 48 ${ }^{\text {th }}$ AIAA Aerospace Sciences Meeting, Jan. 2010

${ }^{21}$ Watkins, A.N., Buck, G.M., Leighty, B.D., Lipford, W.E., and Oglesby, D.M., "Using Pressure- and TemperatureSensitive Paint on the Aftbody of a Capsule Vehicle," AIAA Journal, Vol. 47, No. 4, 2009, pp. 821-829. 
${ }^{22}$ Fay, J.A., and Riddell, F.R., "Theory of Stagnation Point Heat Transfer in Dissociated Air," J. Aero. Sci., Vol. 25, 1958, pp. 73-85.

${ }^{23}$ R. J. Schwartz, "ViDI: Virtual Diagnostics Interface Volume 1-The Future of Wind Tunnel Testing" Contractor Report NASA/CR-2003-212667, December, 2003.

${ }^{24}$ Autodesk 3ds Max Product Information, Autodesk Inc., http://usa.autodesk.com/adsk/servlet/index?id=5659302\&siteID=123112, viewed Jan 2, 2006.

25 J. A. Inman, "Fluorescence imaging study of free and impinging supersonic jets: jet structure and turbulent transition," PhD Dissertation, College of William and Mary, Williamsburg VA, 2007.

${ }^{26}$ P. M. Danehy, P. C. Palma, R. R. Boyce, A. F. P. Houwing, "Numerical simulation of laser-induced fluorescence imaging in shock-layer flows", AIAA Journal, Vol. 37 p. 715-722 (1999). 


\section{Appendix}

This appendix contains selected ViDI-processed image sequences from Runs 2-5 of Test 462 and Run 18 of Test 467 in the 31 Inch Mach 10 Wind Tunnel at NASA Langley Research Center. The table below summarizes the data contained in this appendix.

\begin{tabular}{|c|c|c|c|c|c|c|c|c|c|c|c|}
\hline $\begin{array}{c}\text { Figure } \\
\text { Number }\end{array}$ & Test & $\begin{array}{l}\text { PLIF } \\
\text { Run }\end{array}$ & $\begin{array}{l}\text { TSP } \\
\text { Run }\end{array}$ & $\begin{array}{c}\text { PLIF } \\
\text { Framing } \\
\text { Rate }\end{array}$ & Trip Type & $\begin{array}{c}\text { Trip } \\
\text { Height }\end{array}$ & $\begin{array}{c}\text { Trip } \\
\text { Width }\end{array}$ & $\begin{array}{c}\text { Stagnation } \\
\text { Pressure }\end{array}$ & $\begin{array}{l}\text { Stagnation } \\
\text { Temperature } \\
\end{array}$ & \begin{tabular}{|c|} 
Unit \\
Reynolds \\
Number
\end{tabular} & $\begin{array}{c}\text { NO flow } \\
\text { rate }\end{array}$ \\
\hline & & & & & & $(\mathrm{mm})$ & $(\mathrm{mm})$ & $(\mathrm{MPa})$ & $\begin{array}{l}\mathrm{K}) \\
\end{array}$ & $(1 / \mathrm{m})$ & (sccm) \\
\hline A1 & 462 & 2 & -- & $10 \mathrm{~Hz}$ & BLT DTO & 1.00 & 10.36 & 2.40 & 988 & 1.71 & 150 \\
\hline $\mathrm{A} 2$ & 462 & 2 & -- & $10 \mathrm{~Hz}$ & BLT DTO & 1.00 & 10.36 & 2.40 & 988 & 1.71 & 150 \\
\hline A3 & 462 & 2 & -- & $10 \mathrm{~Hz}$ & BLT DTO & 1.00 & 10.36 & 2.40 & 988 & 1.71 & 150 \\
\hline A4 & 462 & 2 & -- & $10 \mathrm{~Hz}$ & BLT DTO & 1.00 & 10.36 & 2.40 & 988 & 1.71 & 150 \\
\hline A5 & 462 & 2 & 36 & $10 \mathrm{~Hz}$ & BLT DTO & 1.00 & 10.36 & 2.40 & 988 & 1.71 & 150 \\
\hline A6 & 462 & 3 & -- & $10 \mathrm{~Hz}$ & BLT DTO & 1.00 & 10.36 & 4.97 & 1002 & 3.35 & 300 \\
\hline A7 & 462 & 3 & -- & $10 \mathrm{~Hz}$ & BLT DTO & 1.00 & 10.36 & 4.97 & 1002 & 3.35 & 300 \\
\hline A8 & 462 & 3 & -- & $10 \mathrm{~Hz}$ & BLT DTO & 1.00 & 10.36 & 4.97 & 1002 & 3.35 & 300 \\
\hline A9 & 462 & 3 & -- & $10 \mathrm{~Hz}$ & BLT DTO & 1.00 & 10.36 & 4.97 & 1002 & 3.35 & 300 \\
\hline A10 & 462 & 3 & 35 & $10 \mathrm{~Hz}$ & BLT DTO & 1.00 & 10.36 & 4.97 & 1002 & 3.35 & 300 \\
\hline $\mathrm{A} 11$ & 462 & 4 & -- & $10 \mathrm{~Hz}$ & rectangular fence @ 45 deg & 1.00 & 8.35 & 4.97 & 997 & 3.38 & 300 \\
\hline A12 & 462 & 4 & -- & $10 \mathrm{~Hz}$ & rectangular fence @ 45 deg & 1.00 & 8.35 & 4.97 & 997 & 3.38 & 300 \\
\hline A13 & 462 & 4 & -- & $10 \mathrm{~Hz}$ & rectangular fence @ 45 deg & 1.00 & 8.35 & 4.97 & 997 & 3.38 & 300 \\
\hline A14 & 462 & 4 & -- & $10 \mathrm{~Hz}$ & rectangular fence @ 45 deg & 1.00 & 8.35 & 4.97 & 997 & 3.38 & 300 \\
\hline A15 & 462 & 5 & -- & $10 \mathrm{~Hz}$ & BLT DTO & 1.00 & 10.36 & 9.33 & 1002 & 6.12 & 300 \\
\hline A16 & 462 & 5 & -- & $10 \mathrm{~Hz}$ & BLT DTO & 1.00 & 10.36 & 9.33 & 1002 & 6.12 & 300 \\
\hline $\mathrm{A} 17$ & 462 & 5 & -- & $10 \mathrm{~Hz}$ & BLT DTO & 1.00 & 10.36 & 9.33 & 1002 & 6.12 & 300 \\
\hline A18 & 462 & 5 & -- & $10 \mathrm{~Hz}$ & BLT DTO & 1.00 & 10.36 & 9.33 & 1002 & 6.12 & 300 \\
\hline A19 & 467 & 18 & -- & $500 \mathrm{kHz}$ & BLT DTO & 1.00 & 10.36 & 9.31 & 990 & 6.17 & 300 \\
\hline A20 & 467 & 18 & -- & $500 \mathrm{kHz}$ & BLT DTO & 1.00 & 10.36 & 9.31 & 990 & 6.17 & 300 \\
\hline A21 & 467 & 18 & -- & $500 \mathrm{kHz}$ & BLT DTO & 1.00 & 10.36 & 9.31 & 990 & 6.17 & 300 \\
\hline A22 & 467 & 18 & -- & $500 \mathrm{kHz}$ & BLT DTO & 1.00 & 10.36 & 9.31 & 990 & 6.17 & 300 \\
\hline A23 & 467 & 18 & -- & $500 \mathrm{kHz}$ & BLT DTO & 1.00 & 10.36 & 9.31 & 990 & 6.17 & 300 \\
\hline
\end{tabular}

Table A1: Test matrix and figure summary. 
(a)

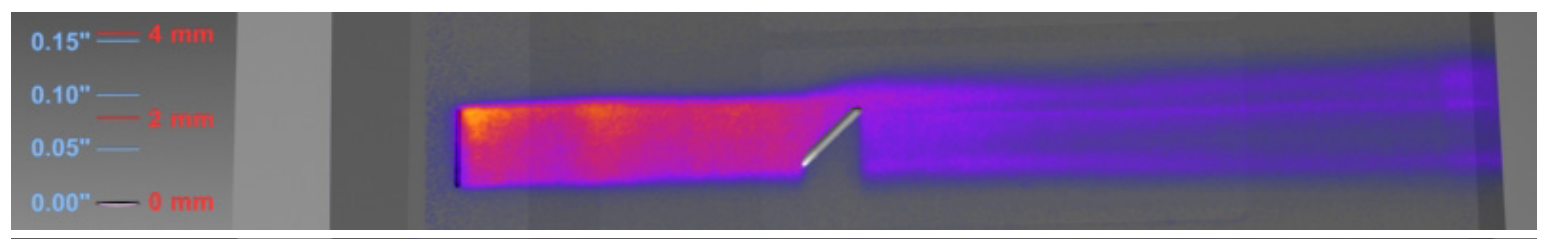

(b)

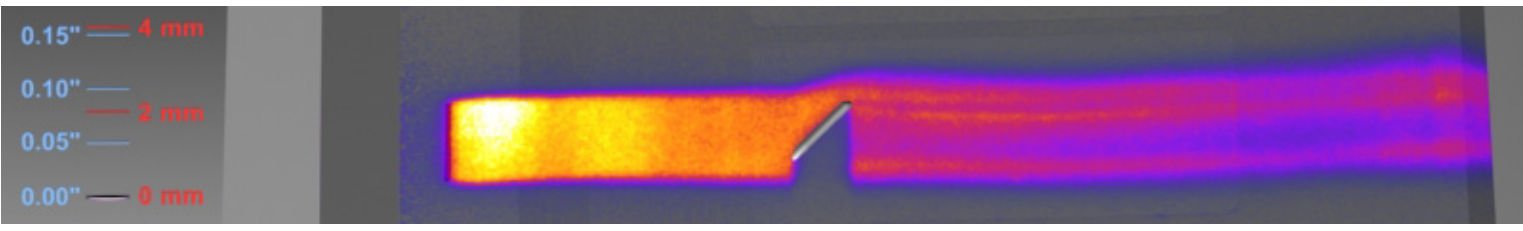

(c)
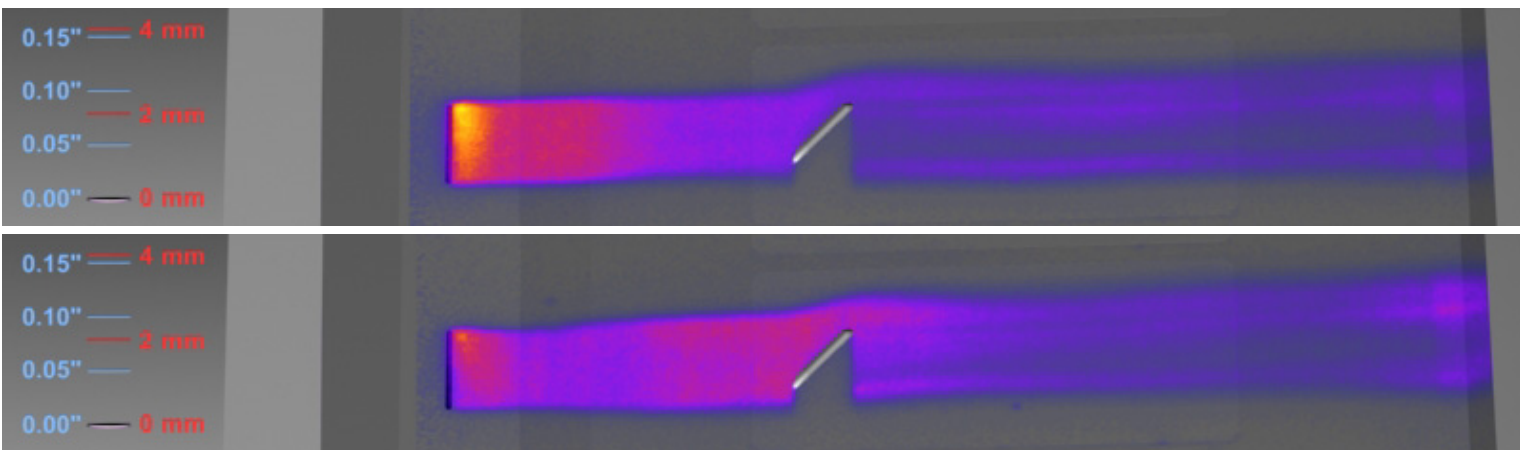

(d)

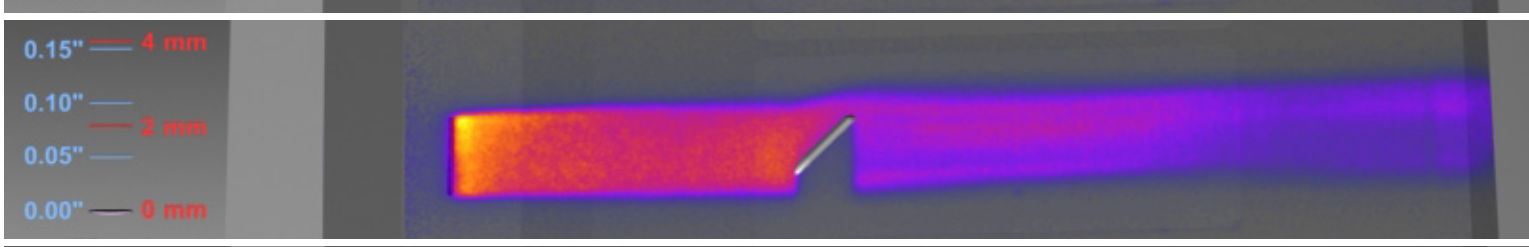

(e)

(f)

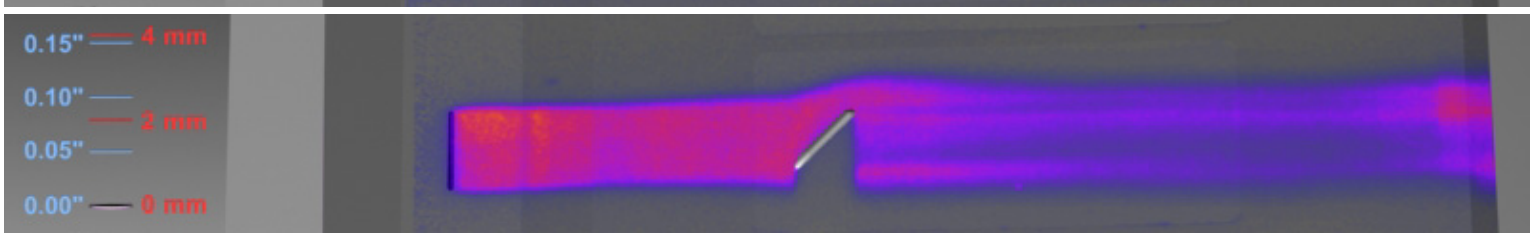

(g)

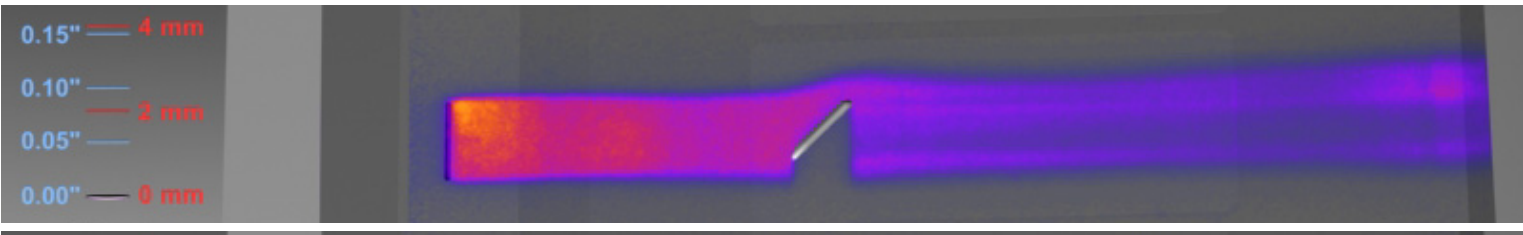

(h)
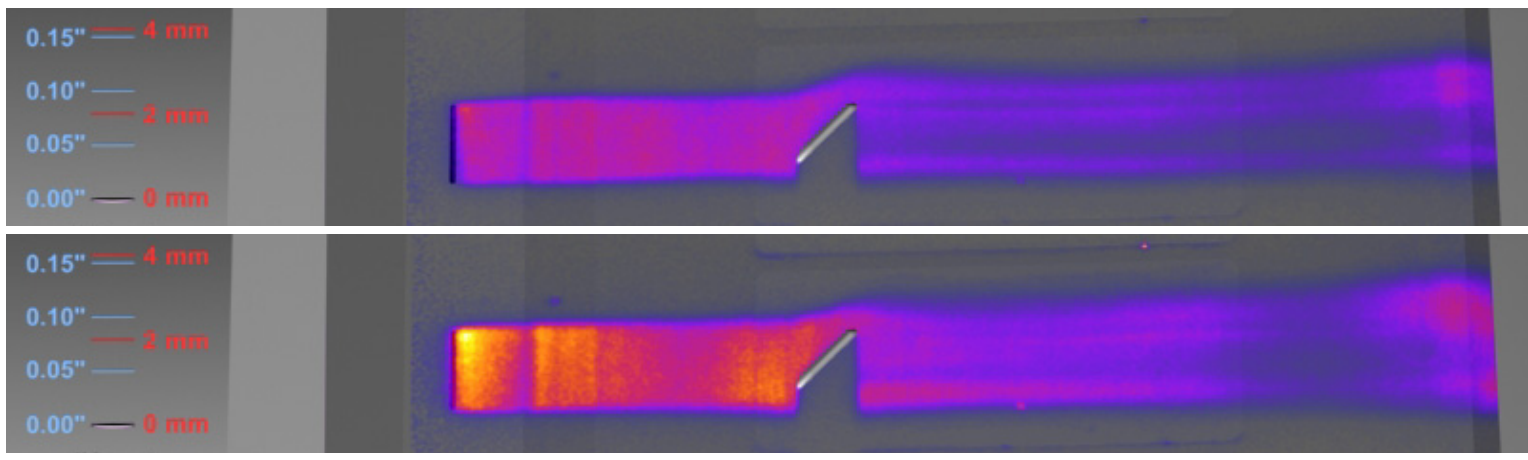

Figure A1: Test 462, Run 2, 1-mm tall BLT DTO trip, plate angle $=20^{\circ}, 11-\mathrm{mm}$ wide slot seeding, $\dot{m}=$ $300 \mathrm{sccm}, \mathrm{P}_{0}=2.4 \mathrm{MPa}$, sheet position $=0.1 \mathrm{~mm}$ above surface, framing rate $=10 \mathrm{~Hz}$. 
(a)

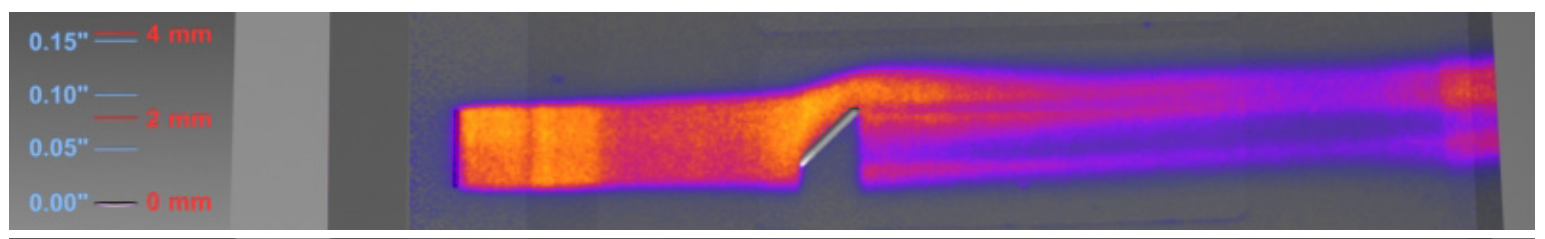

(b)

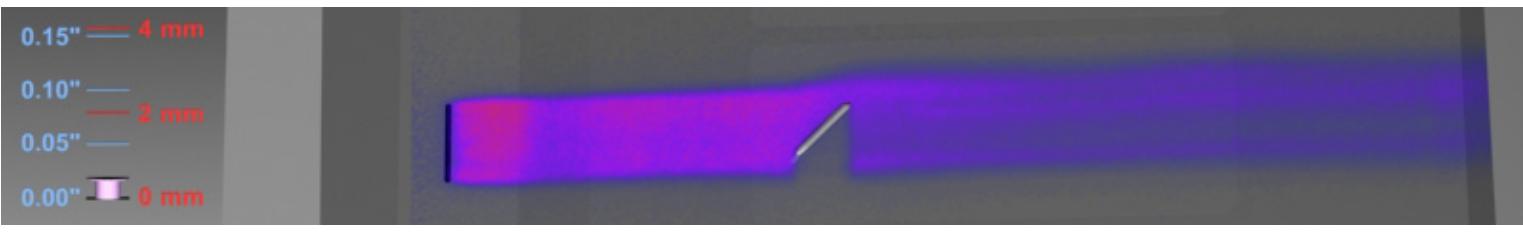

(c)
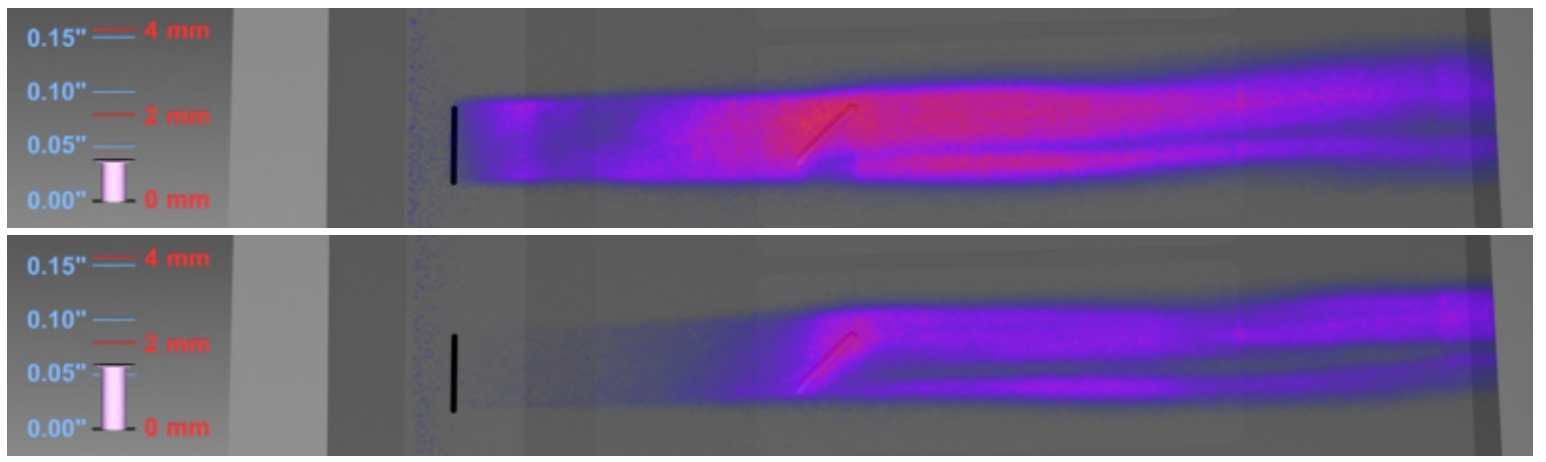

(e)
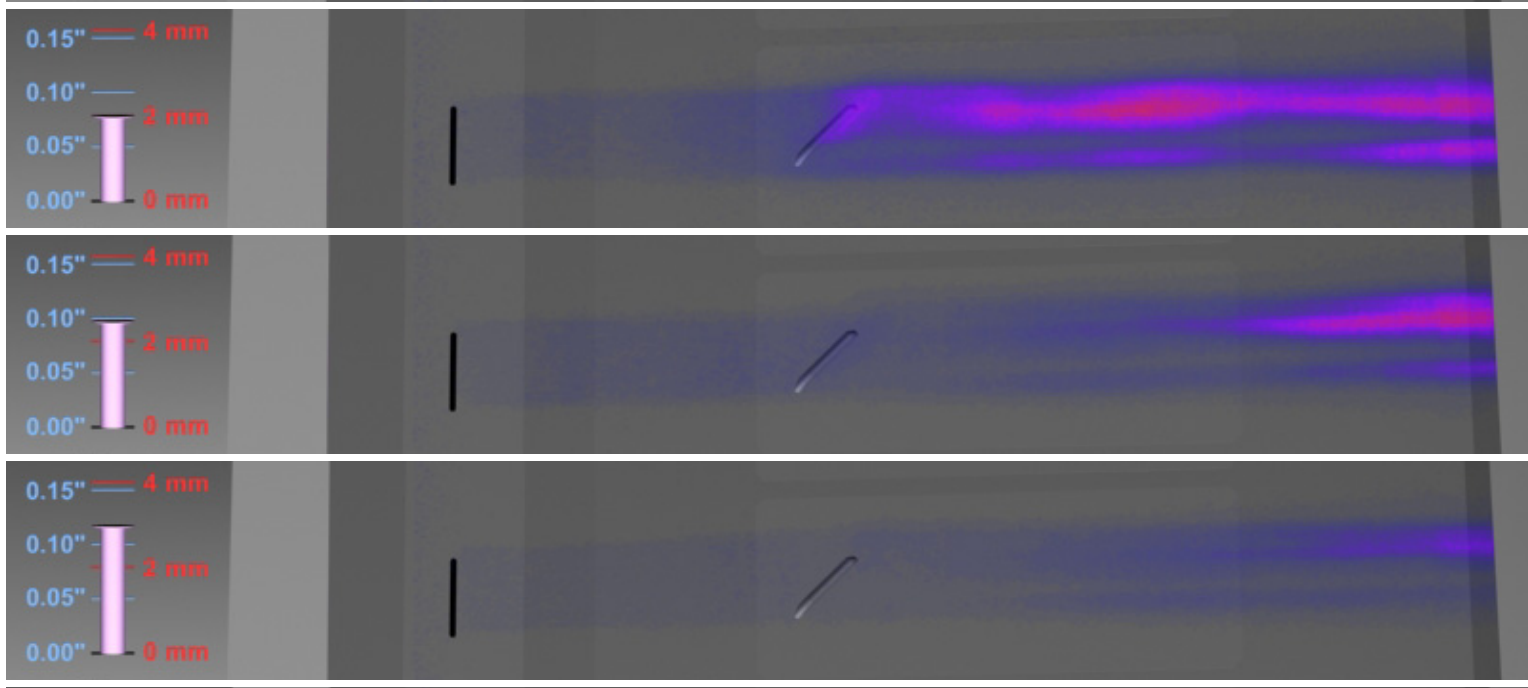

$(\mathrm{g})$

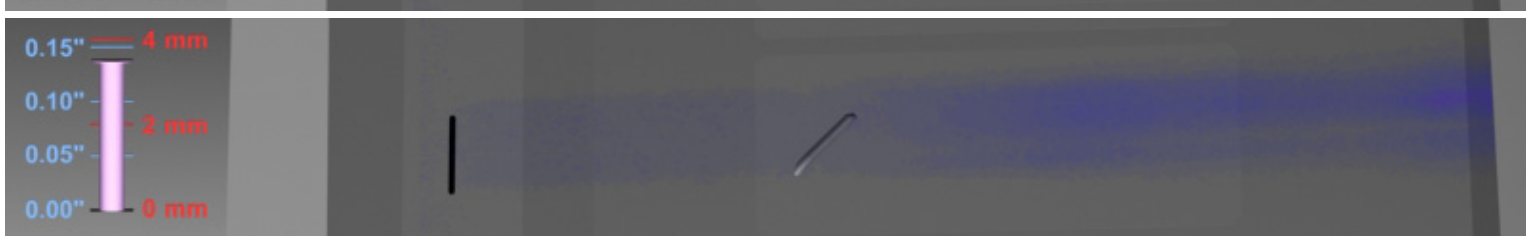

(h)

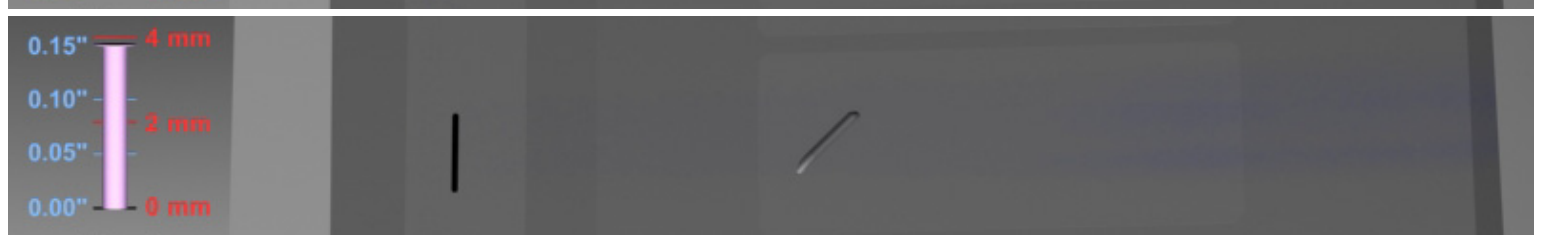

Figure A2: Test 462, Run 2, 1-mm tall BLT DTO trip, plate angle $=20^{\circ}, 11-\mathrm{mm}$ wide slot seeding, $\dot{m}=$ $300 \mathrm{sccm}, \mathrm{P}_{0}=2.4 \mathrm{MPa}$, sheet position $=$ scan $\mathrm{mm}$ above surface, framing rate $=10 \mathrm{~Hz}$. 
(a)

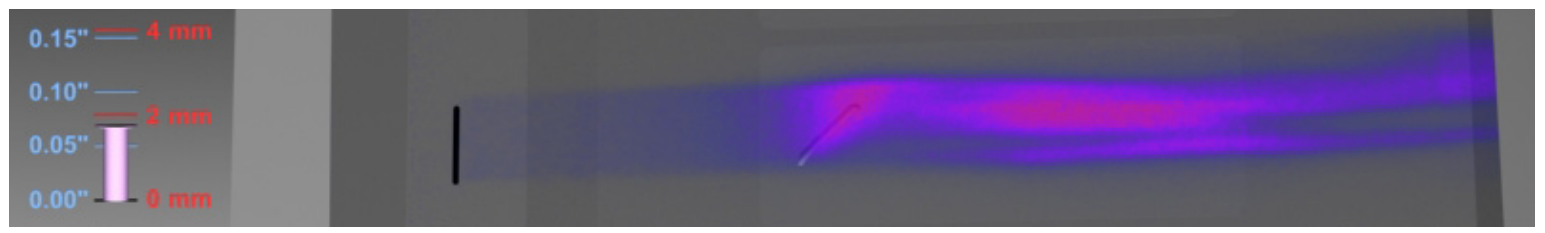

(b)

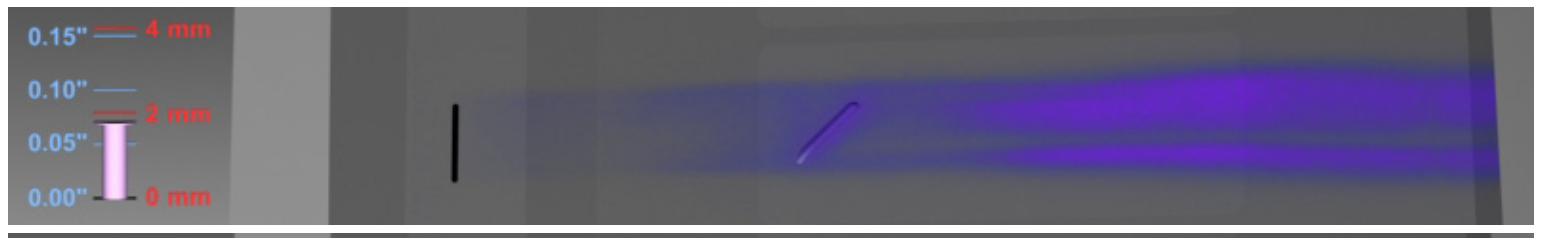

(c)
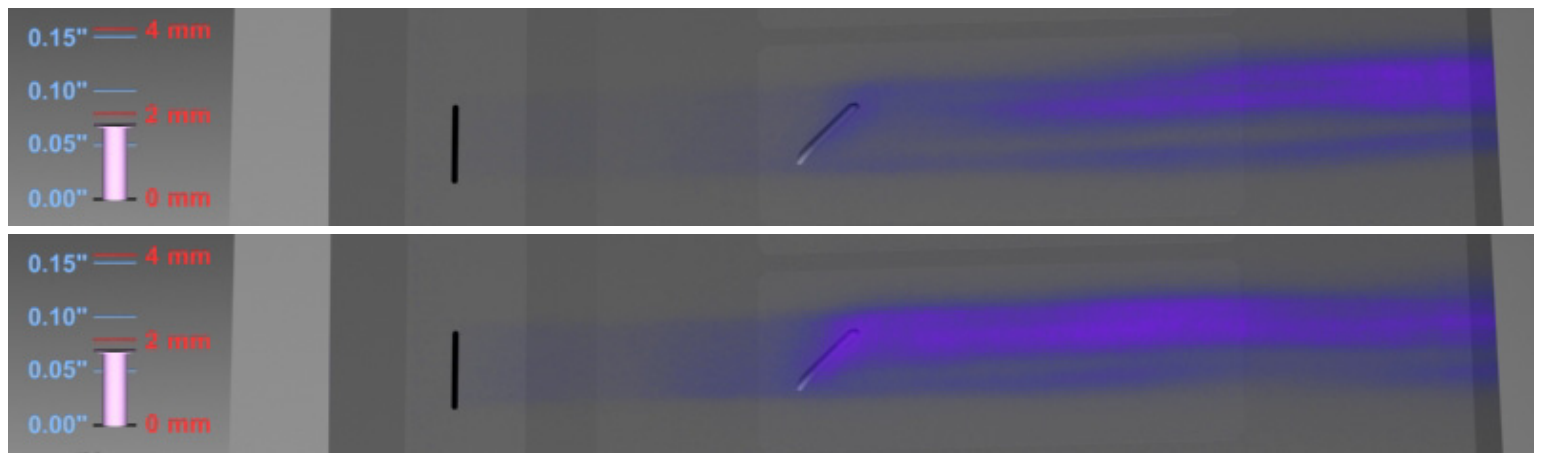

(d)

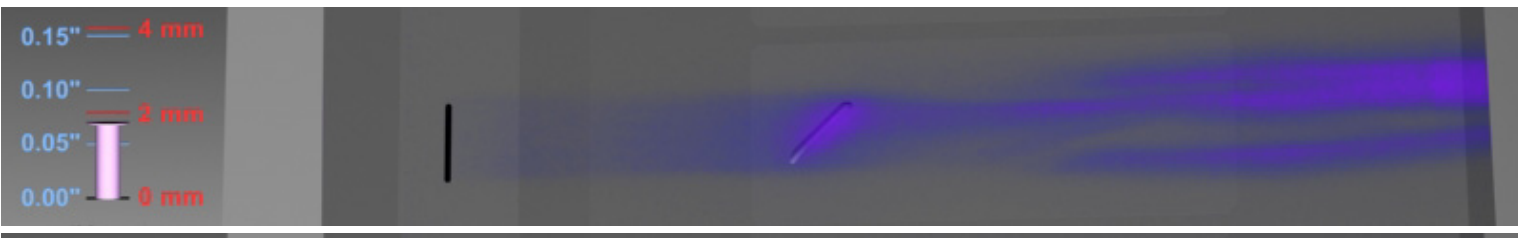

(e)

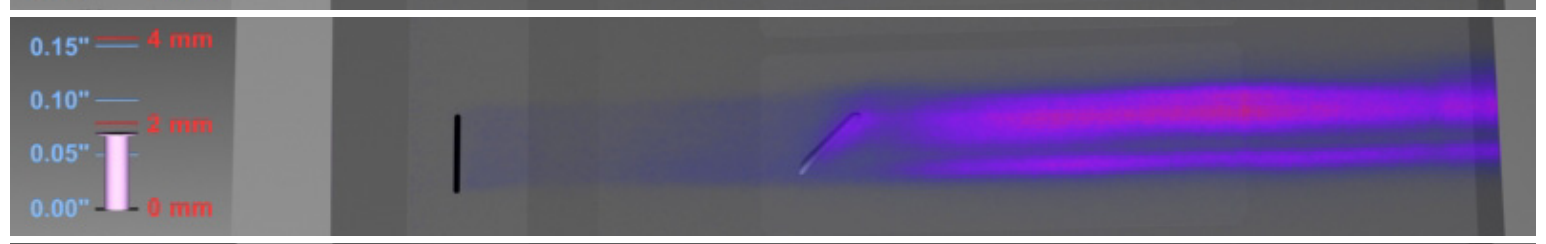

(f)

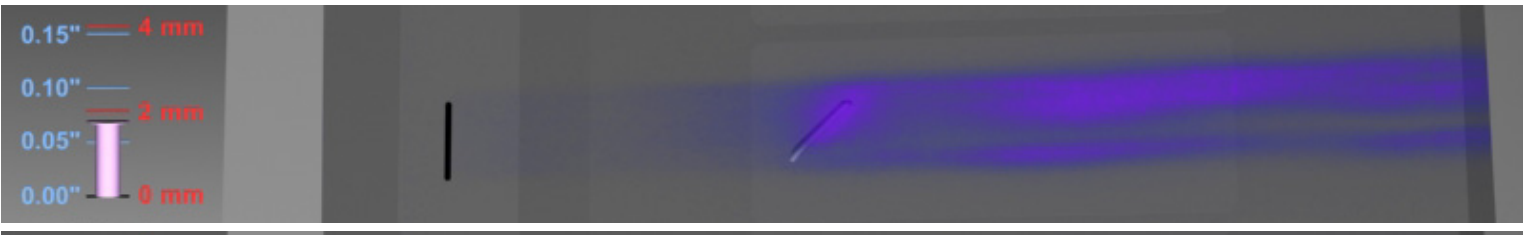

(h)

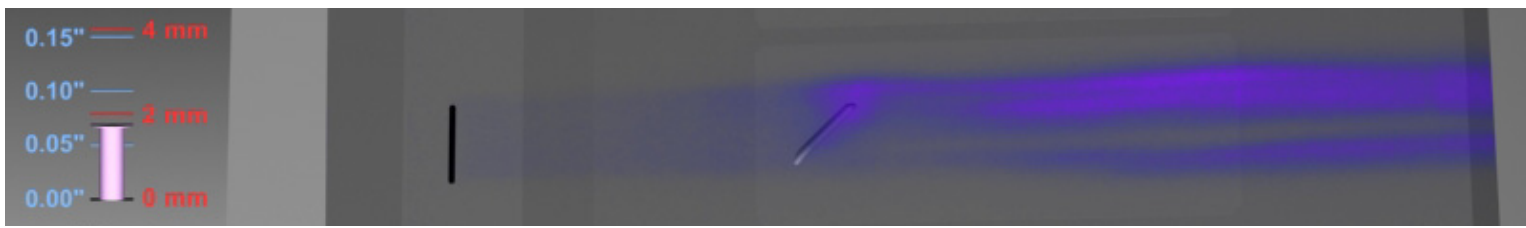

(1)

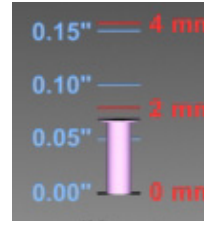

Figure A3: Test 462, Run 2, 1-mm tall BLT DTO trip, plate angle $=20^{\circ}, 11-\mathrm{mm}$ wide slot seeding, $\dot{m}=$ $300 \mathrm{sccm}, \mathrm{P}_{0}=2.4 \mathrm{MPa}$, sheet position $=1.8 \mathrm{~mm}$ above surface, framing rate $=10 \mathrm{~Hz}$. 
(a)

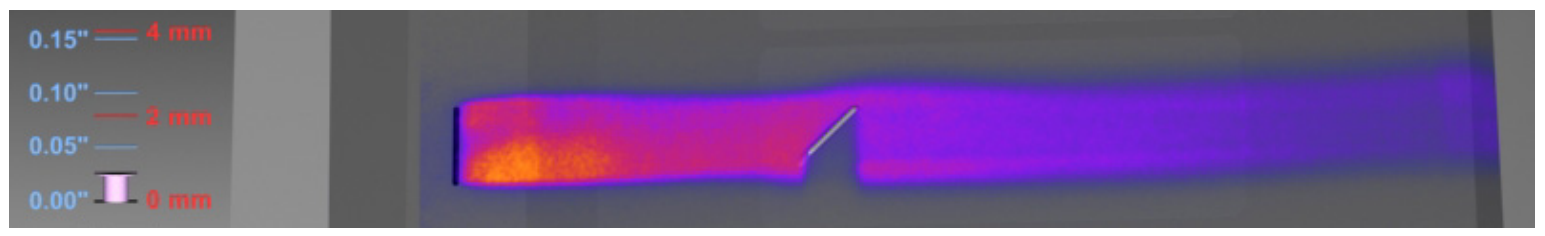

(b)

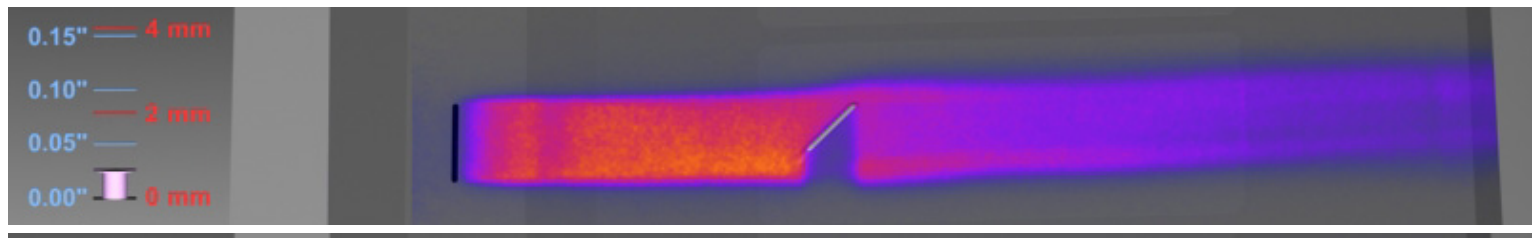

(c)
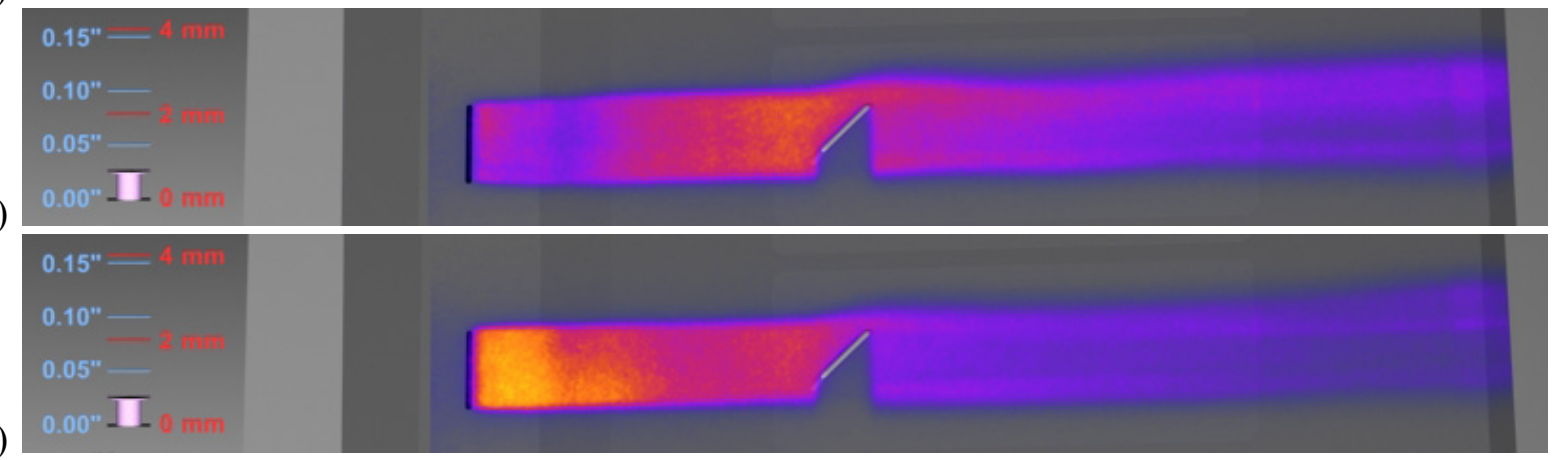

(e)

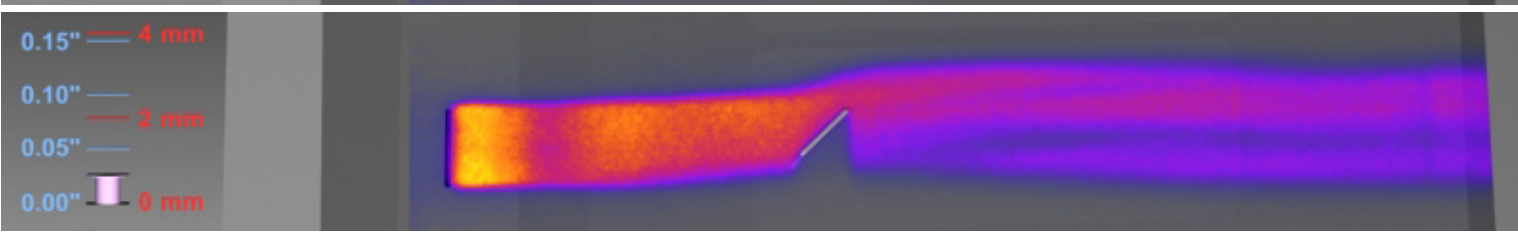

(1)

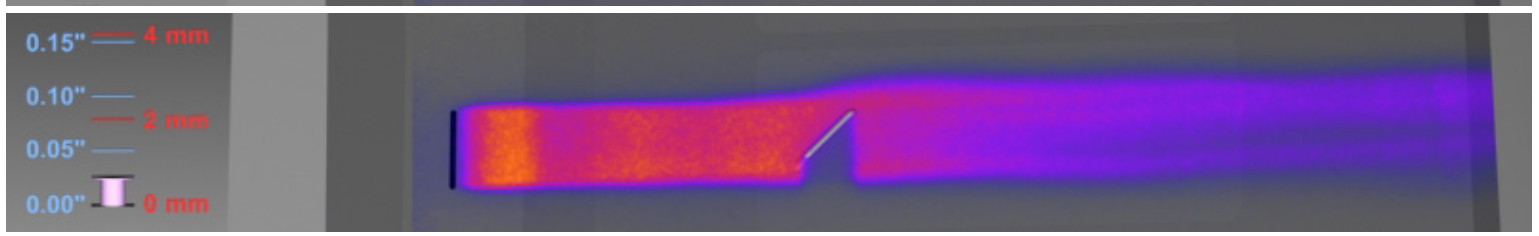

(g)

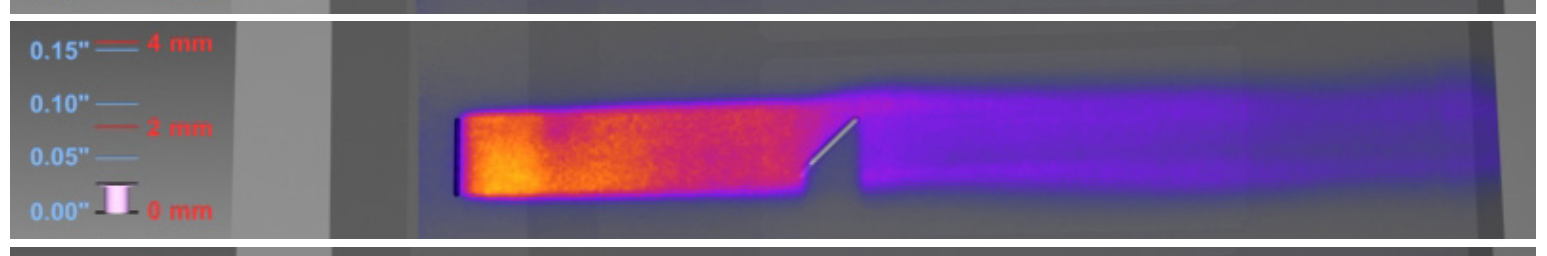

(h)
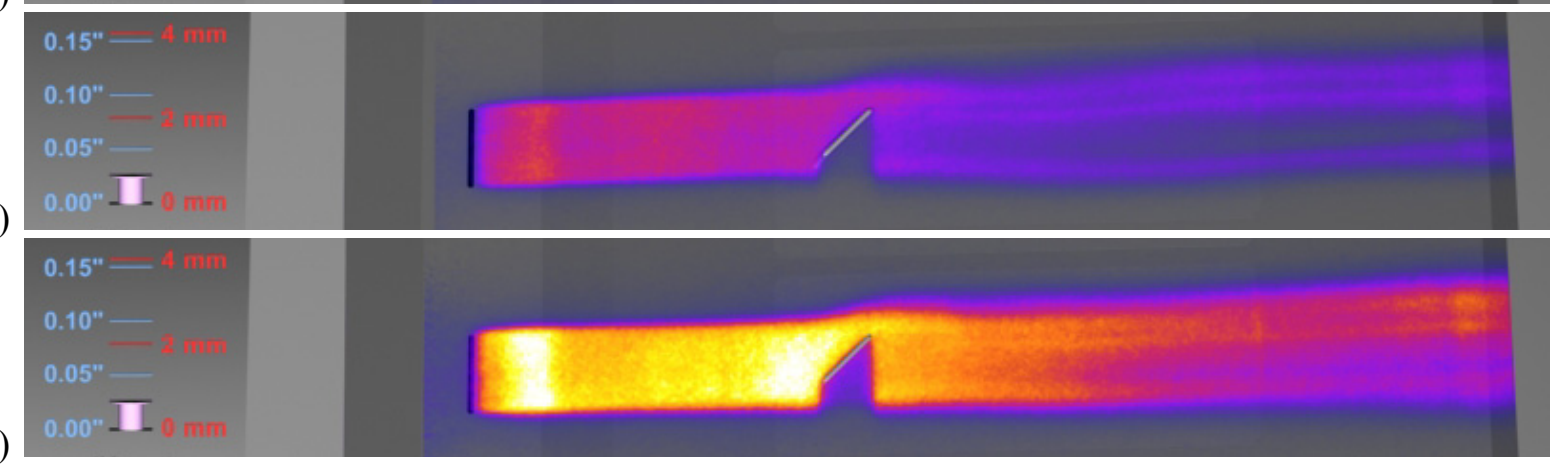

Figure A4: Test 462, Run 2, 1-mm tall BLT DTO trip, plate angle $=20^{\circ}, 11-\mathrm{mm}$ wide slot seeding, $\dot{m}=$ $300 \mathrm{sccm}, \mathrm{P}_{0}=2.4 \mathrm{MPa}$, sheet position $=0.7 \mathrm{~mm}$ above surface, framing rate $=10 \mathrm{~Hz}$. 
(a)

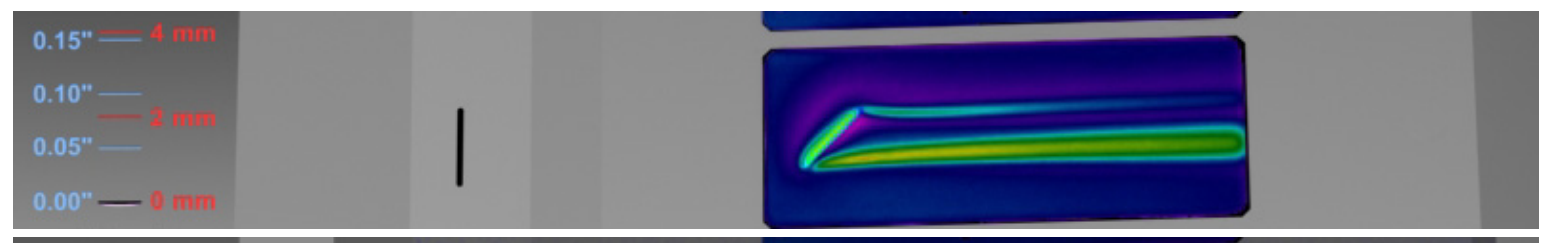

(b)

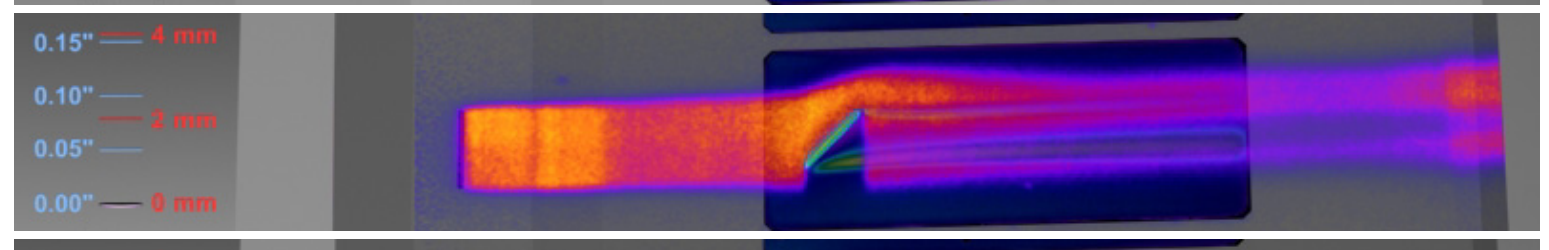

(c)

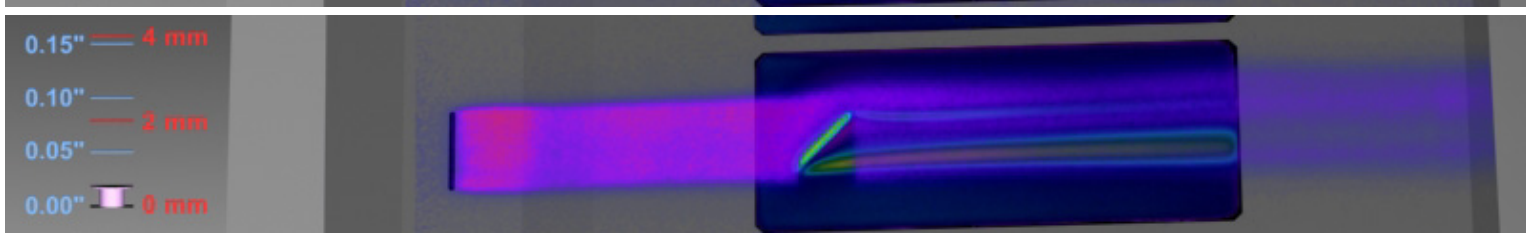

(d)

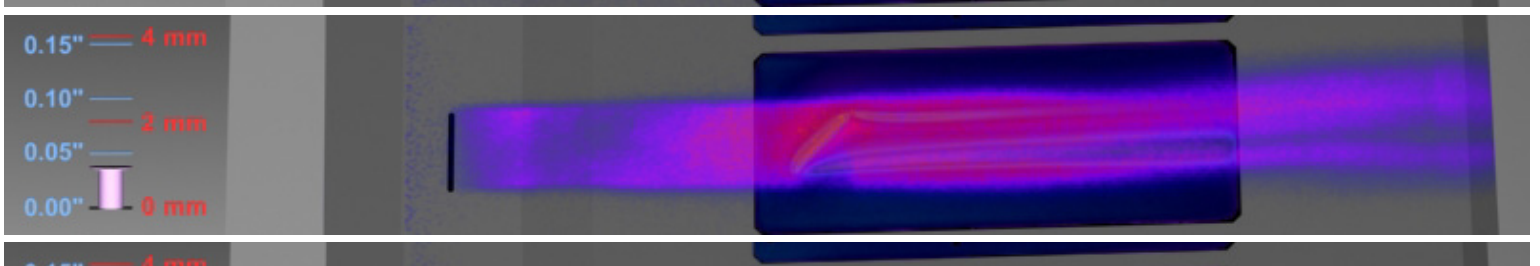

(e)

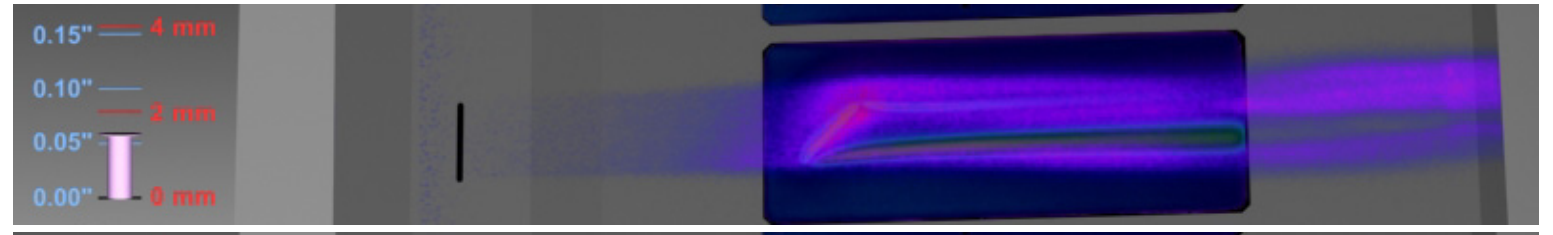

(f)

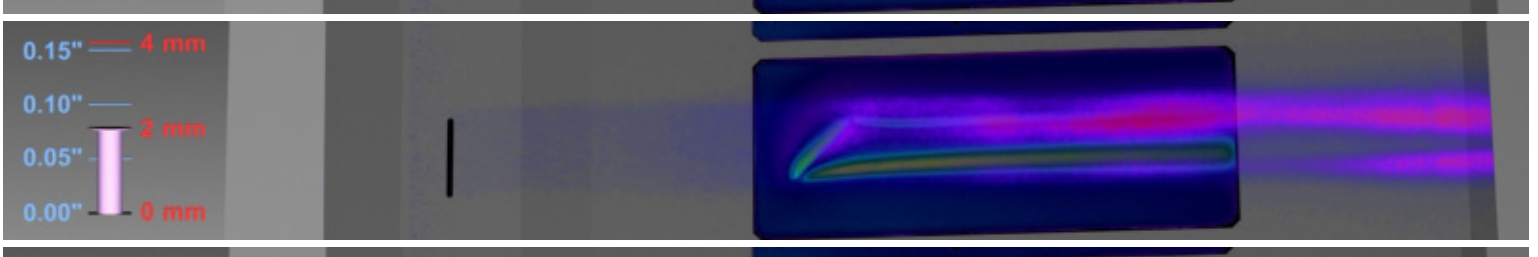

(g)

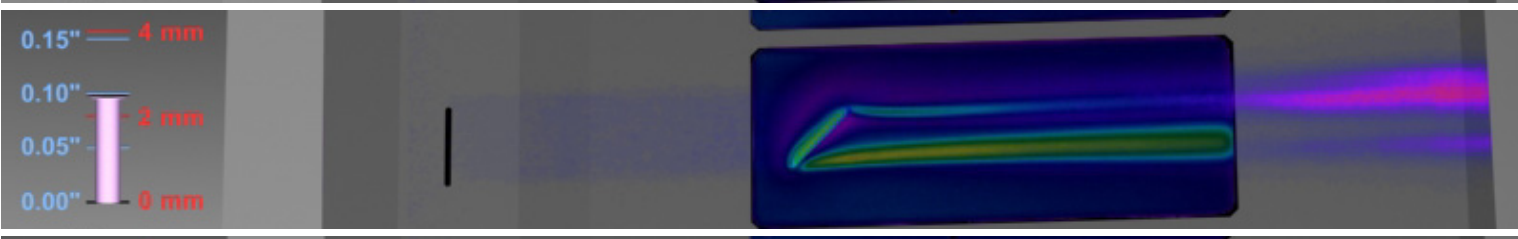

(h)

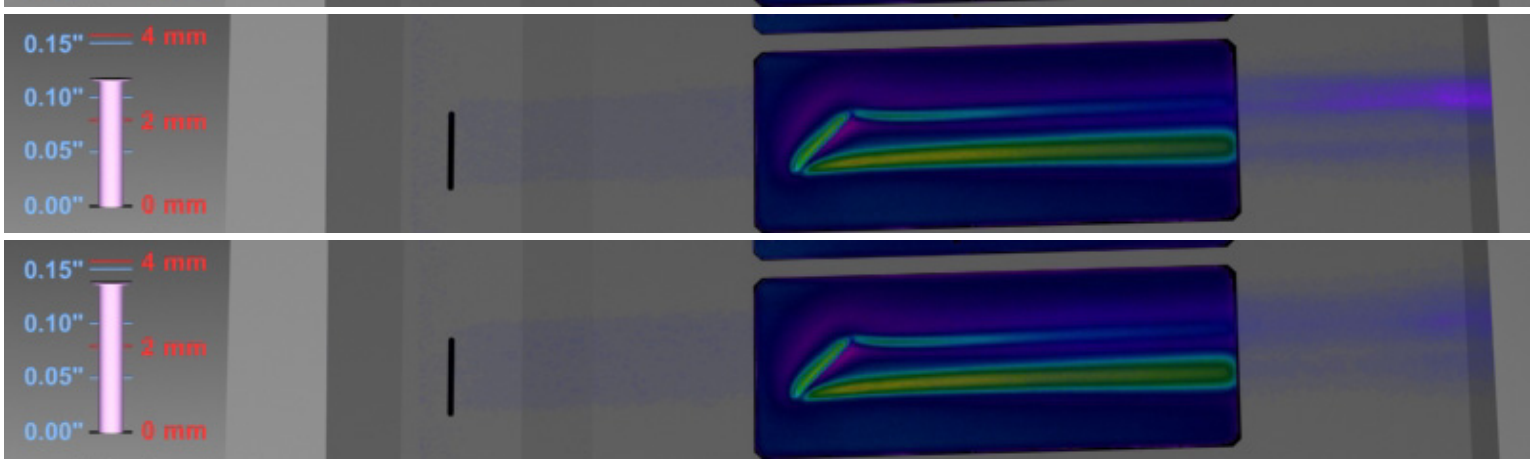

Figure A5: Test 462, PLIF Run 2, TSP Run 36,1-mm tall BLT DTO trip, plate angle $=20^{\circ}$, 11 -mm wide slot seeding, $\dot{m}=300 \mathrm{sccm}, \mathrm{P}_{0}=2.4 \mathrm{MPa}$, sheet position $=$ TSP Run 36 scan $\mathrm{mm}$ above surface, framing rate $=10 \mathrm{~Hz}$. 
(a)

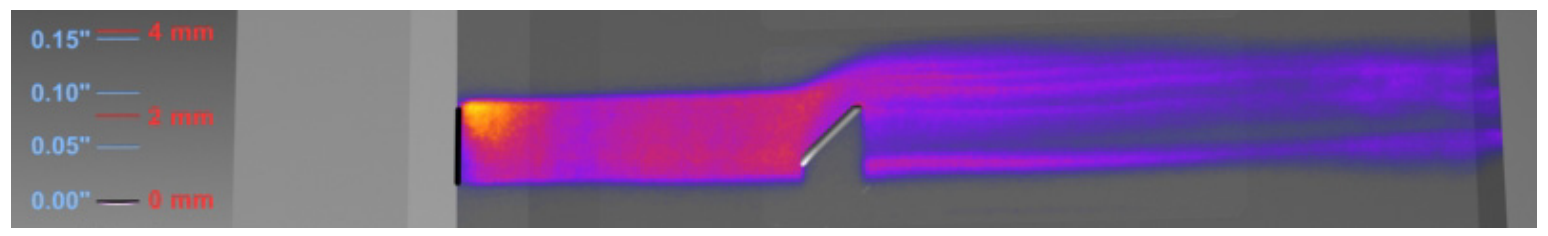

(b)

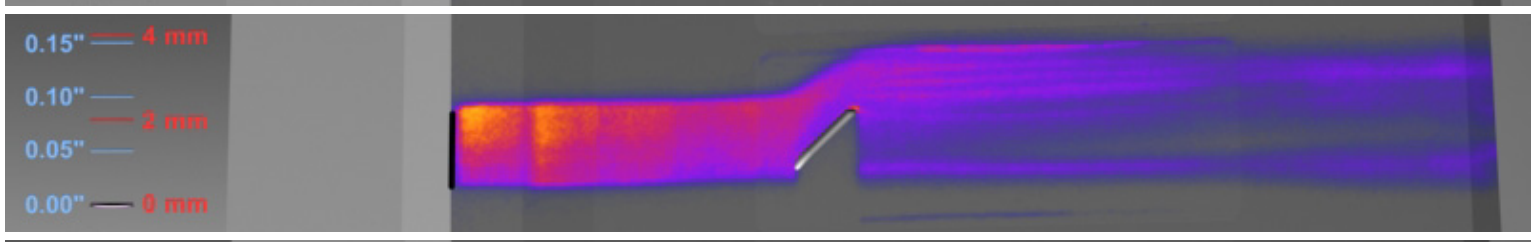

(c)
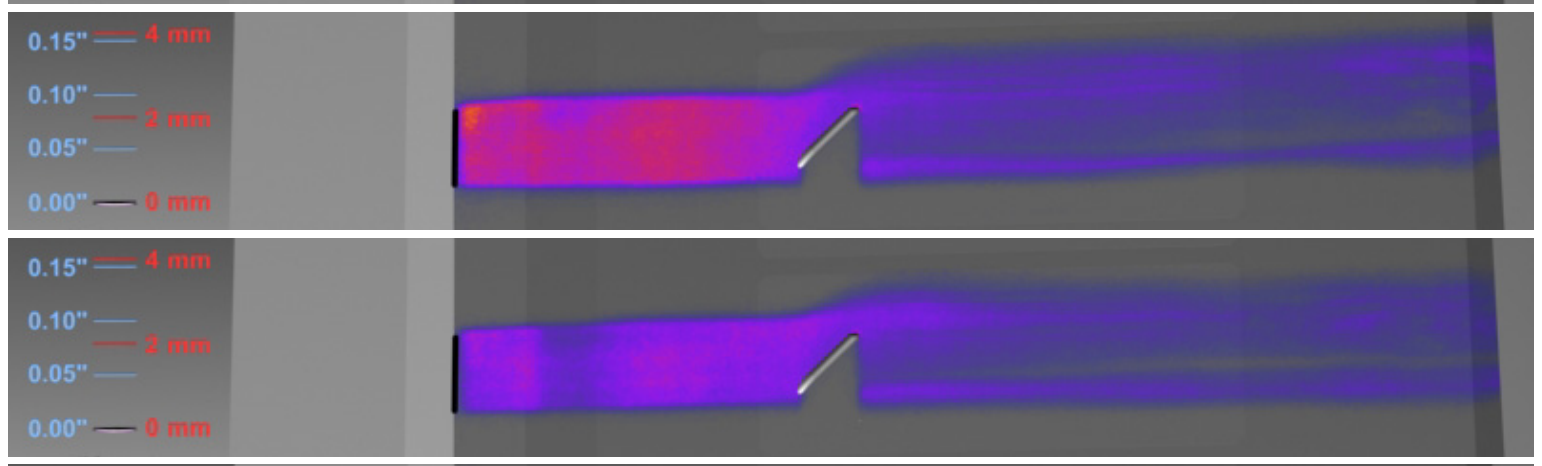

(d)

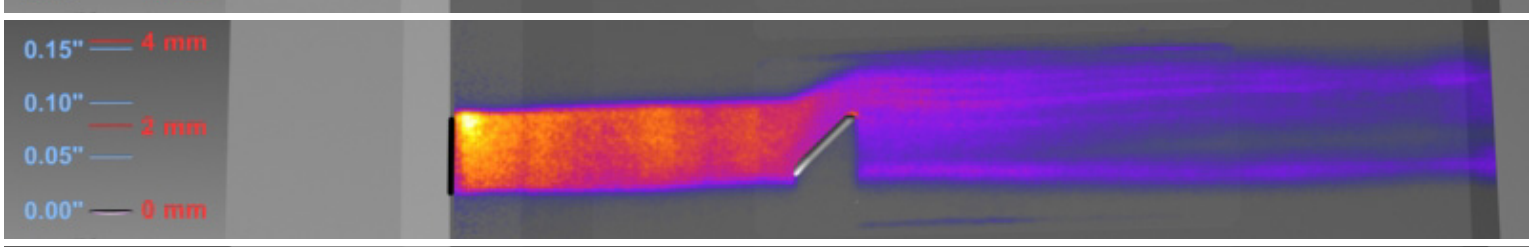

(e)

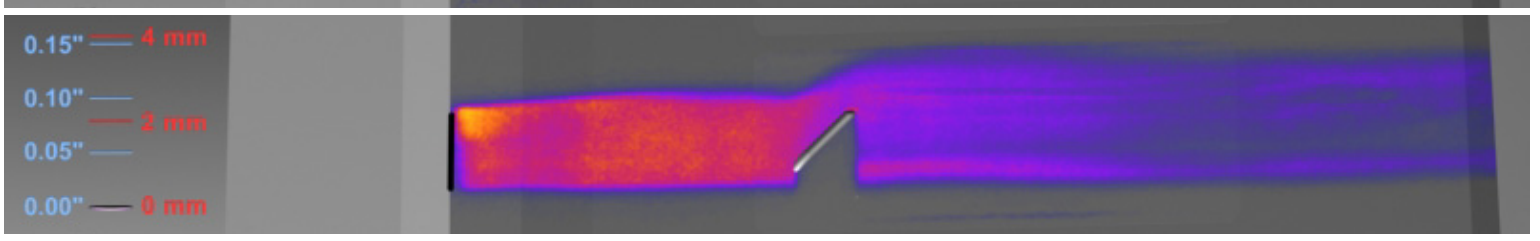

(f)

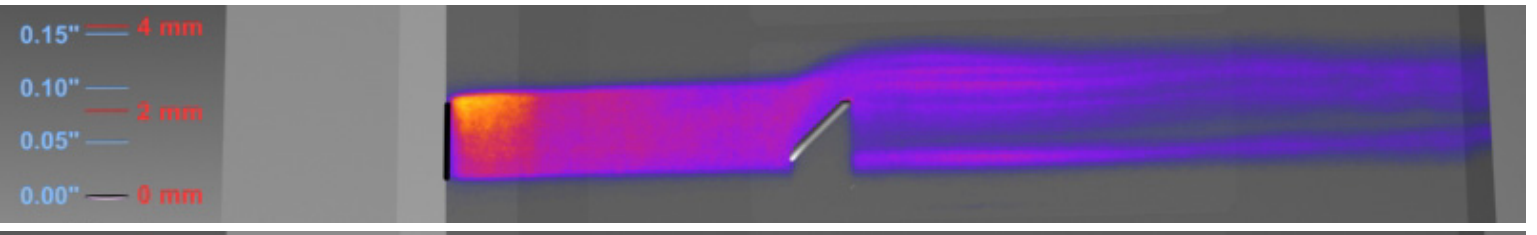

(h)
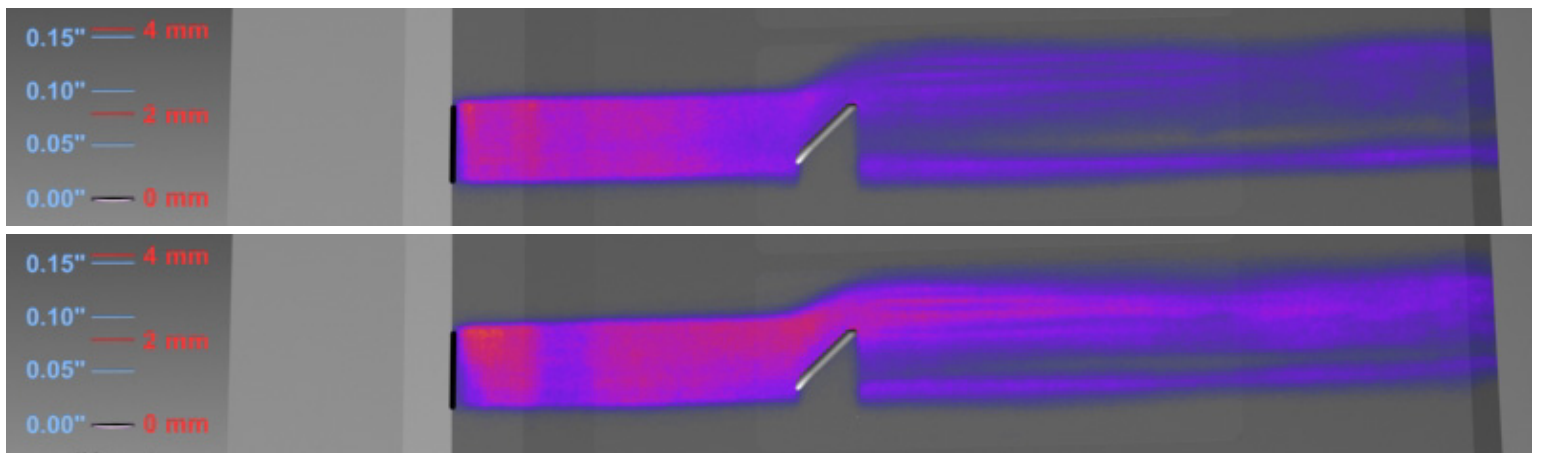

(i)

Figure A6: Test 462, Run 3, 1-mm tall BLT DTO trip, plate angle $=20^{\circ}, 11-\mathrm{mm}$ wide slot seeding, $\dot{\mathrm{m}}=$ $300 \mathrm{sccm}, \mathrm{P}_{0}=4.97 \mathrm{MPa}$, sheet position $=0.1 \mathrm{~mm}$ above surface, framing rate $=10 \mathrm{~Hz}$. 
(a)

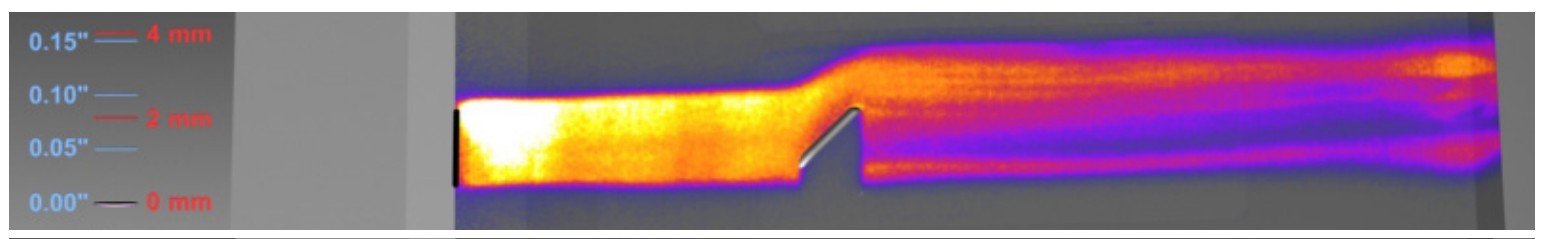

(b)

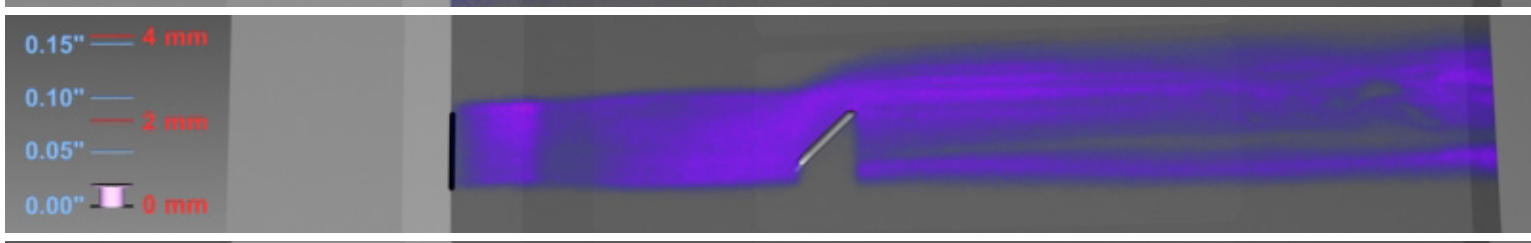

(c)

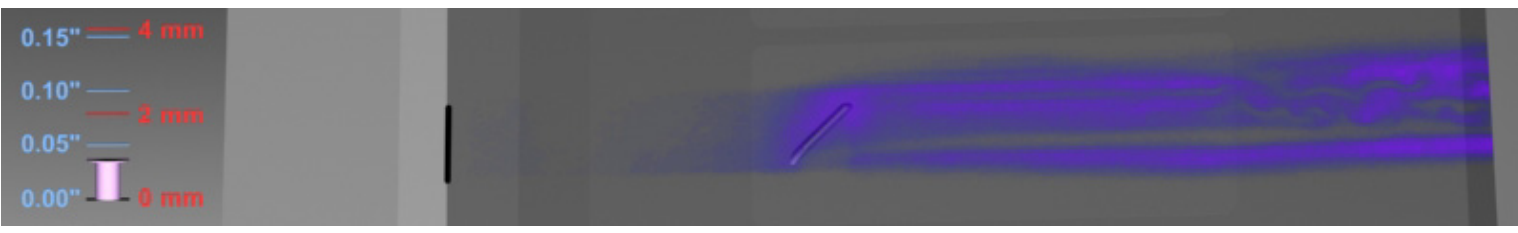

(d)

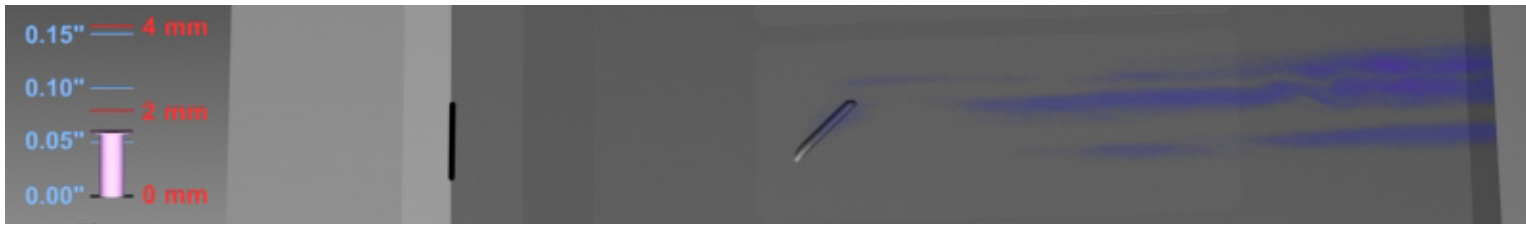

(e)

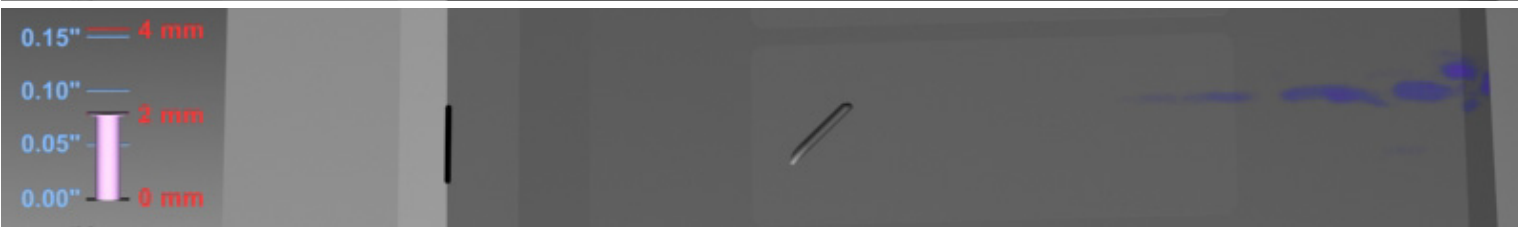

(f)

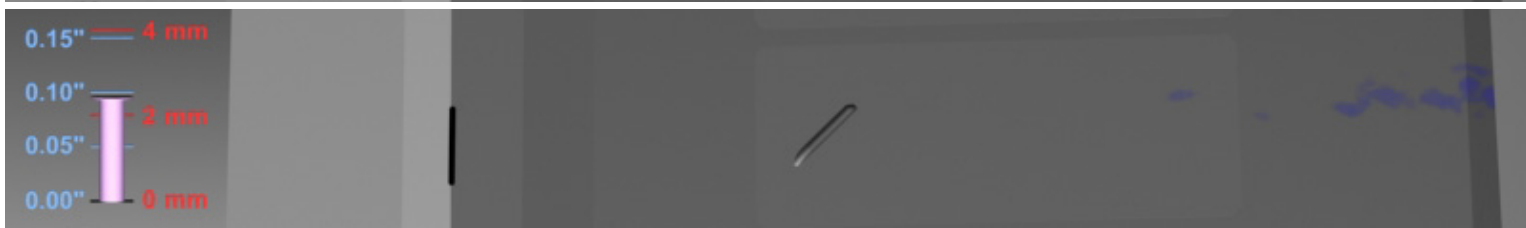

(g)

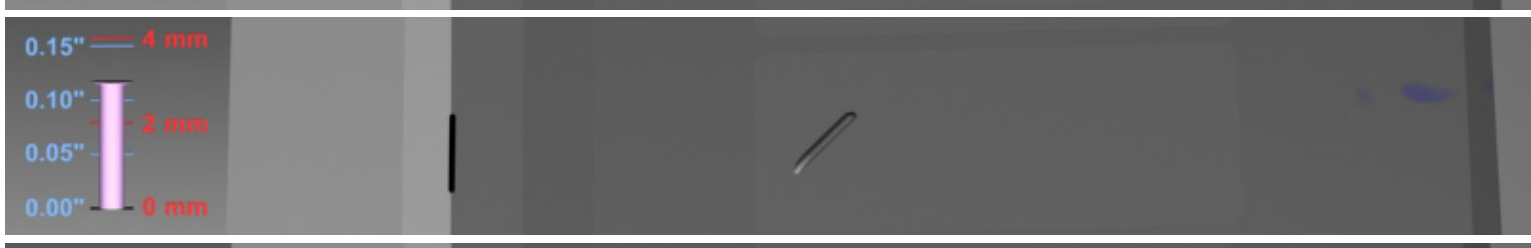

(h)

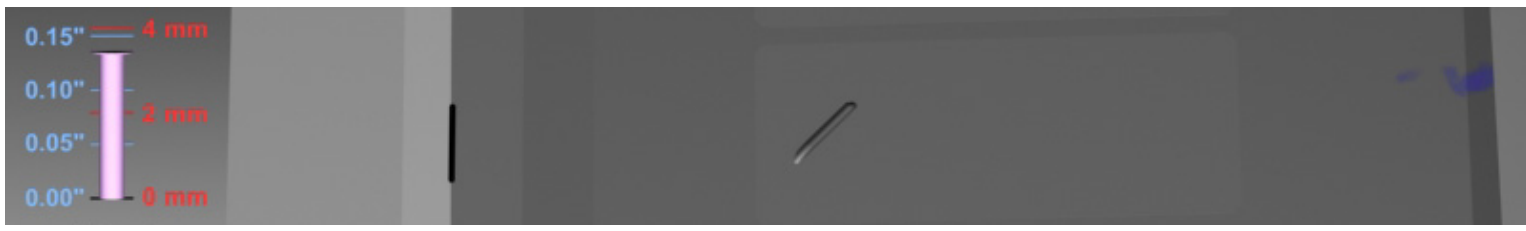

(1)

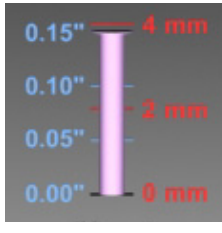

Figure A7: Test 462, Run 3, 1-mm tall BLT DTO trip, plate angle $=20^{\circ}, 11$-mm wide slot seeding, $\dot{m}=$ $300 \mathrm{sccm}, \mathrm{P}_{0}=4.97 \mathrm{MPa}$, sheet position $=$ scan mm above surface, framing rate $=10 \mathrm{~Hz}$. 
(a)

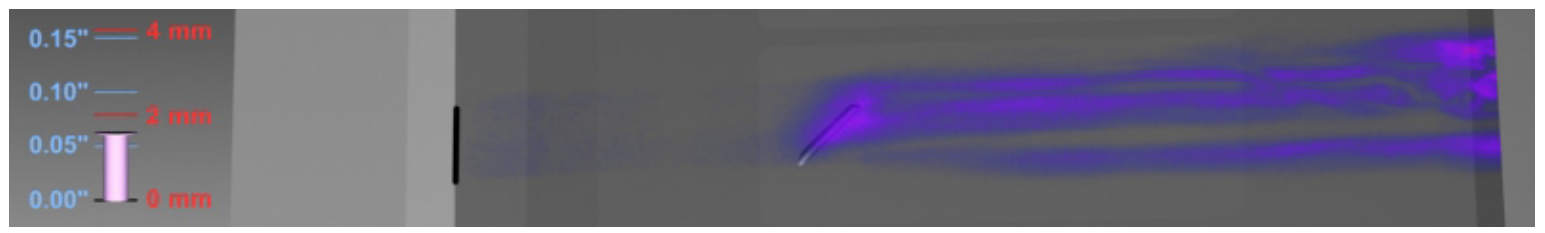

(b)

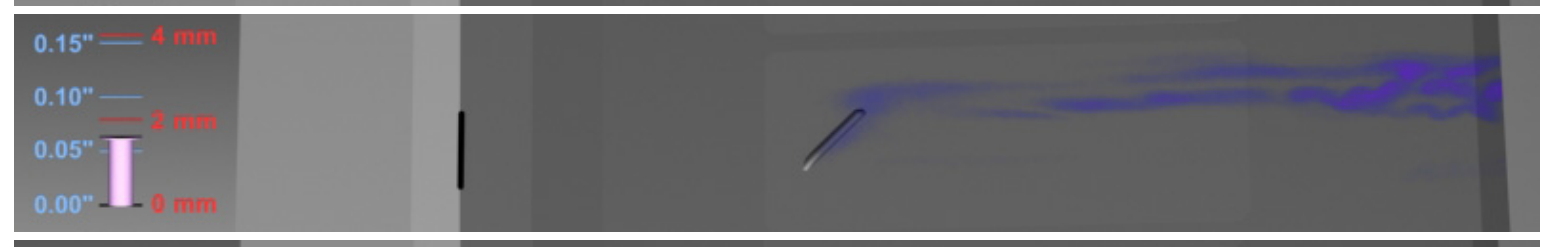

(c)

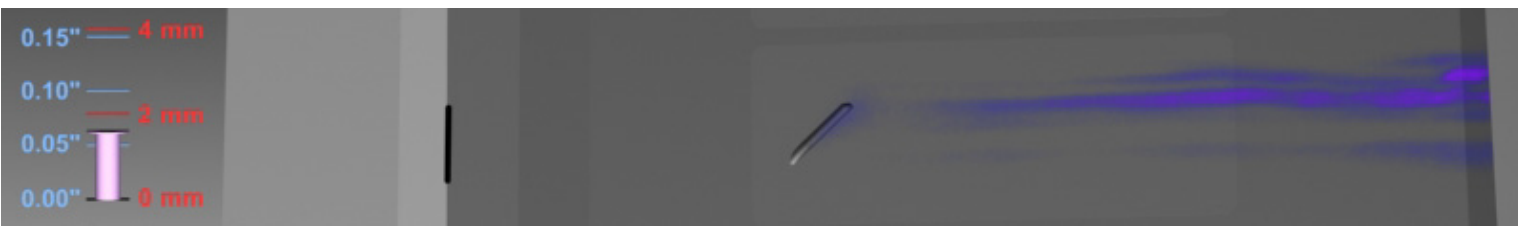

(d)

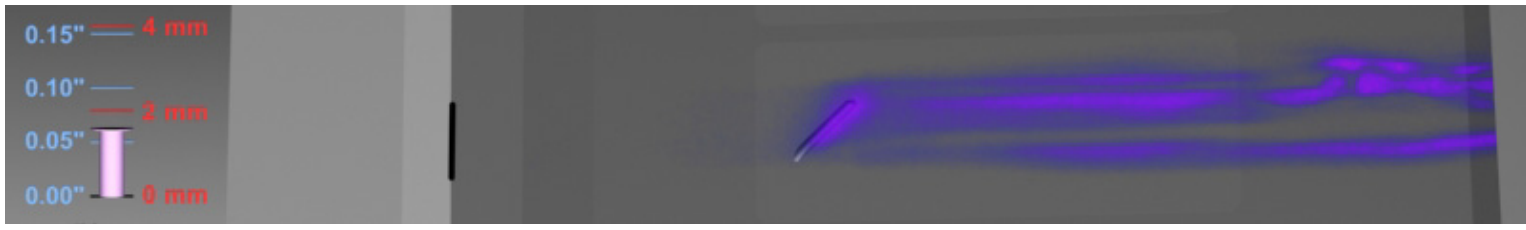

(e)

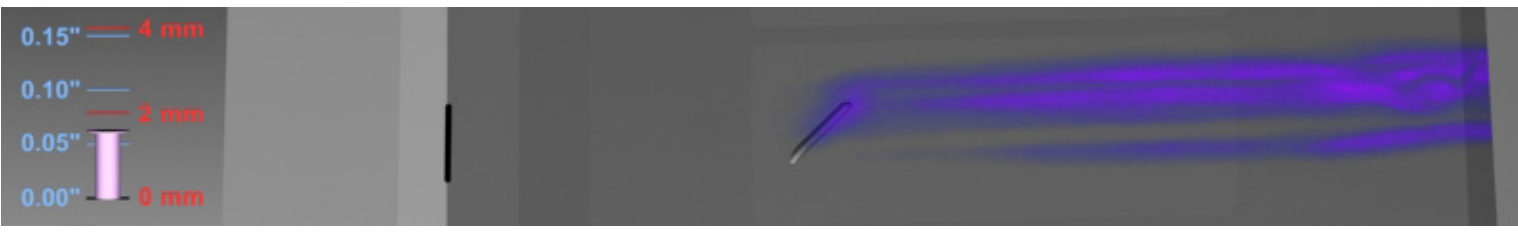

(f)

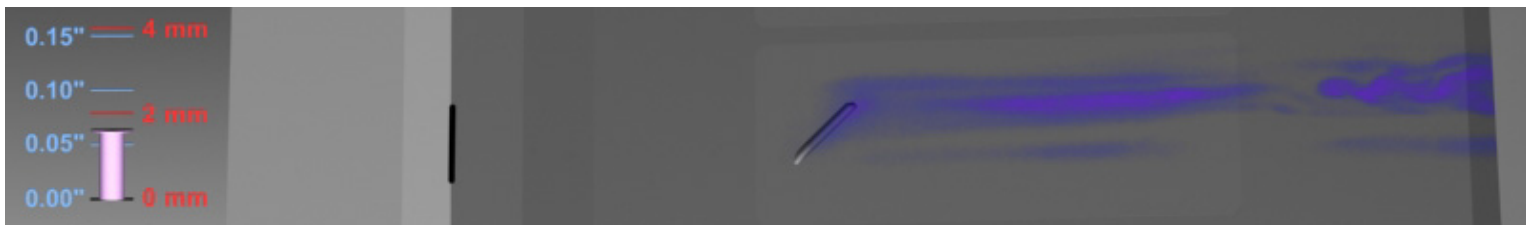

(g)

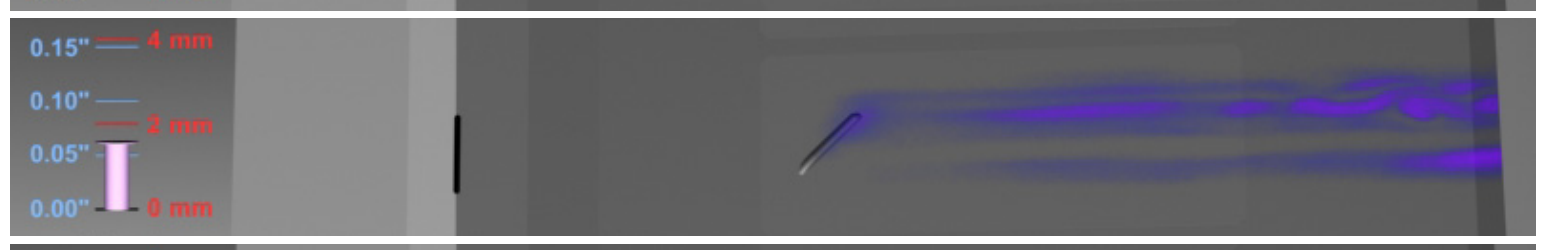

(h)

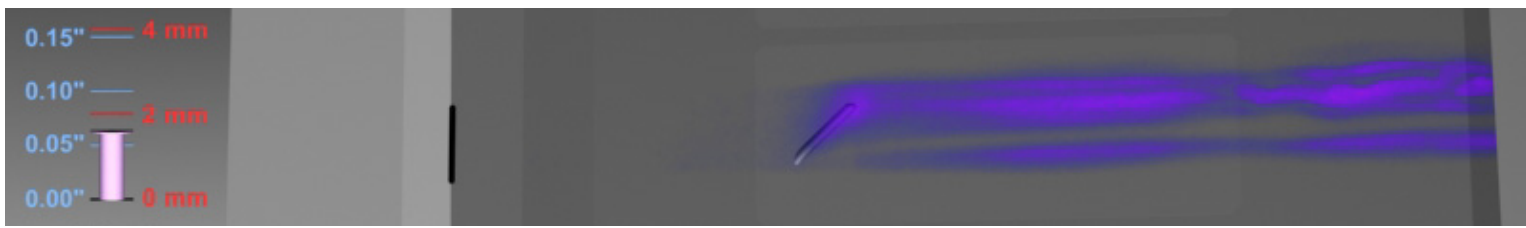

(1)

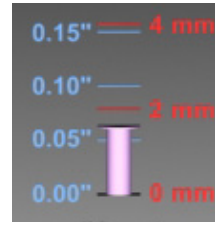

Figure A8: Test 462, Run 3, 1-mm tall BLT DTO trip, plate angle $=20^{\circ}, 11-\mathrm{mm}$ wide slot seeding, $\dot{m}=$ $300 \mathrm{sccm}, \mathrm{P}_{0}=4.97 \mathrm{MPa}$, sheet position $=1.6 \mathrm{~mm}$ above surface, framing rate $=10 \mathrm{~Hz}$. 
(a)

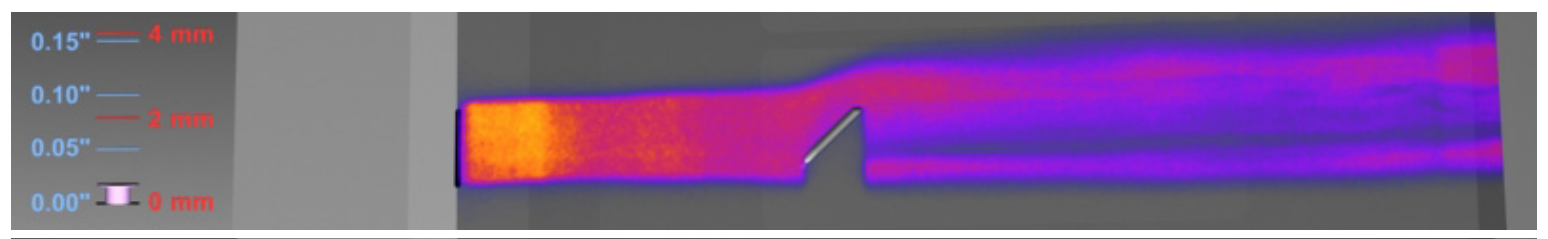

(b)

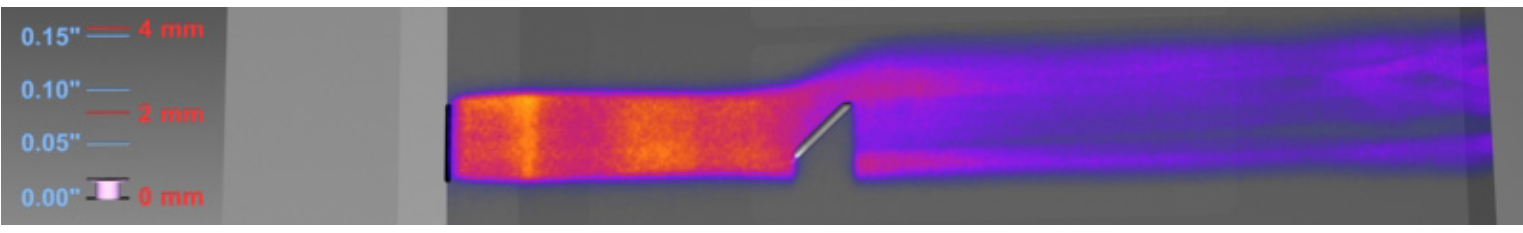

(c)
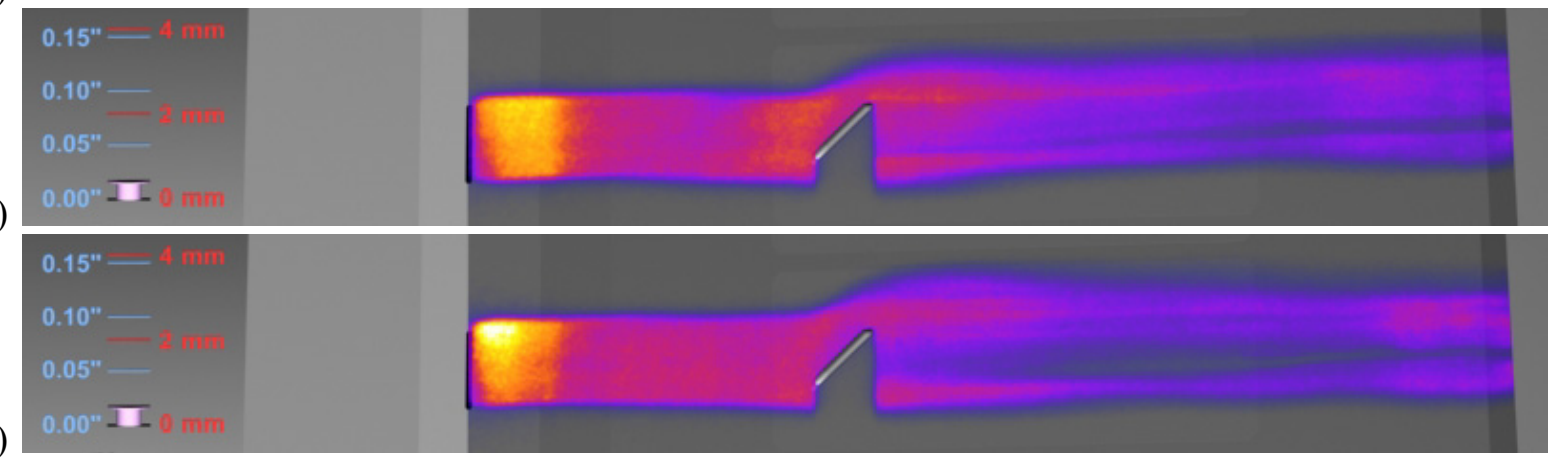

(d)

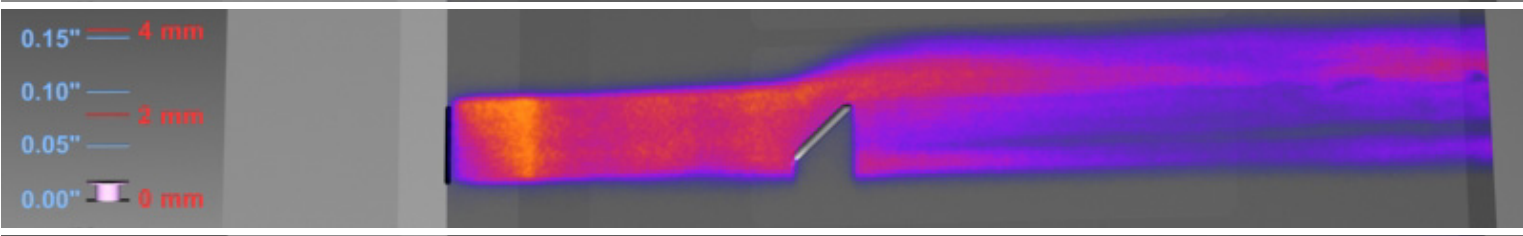

(e)

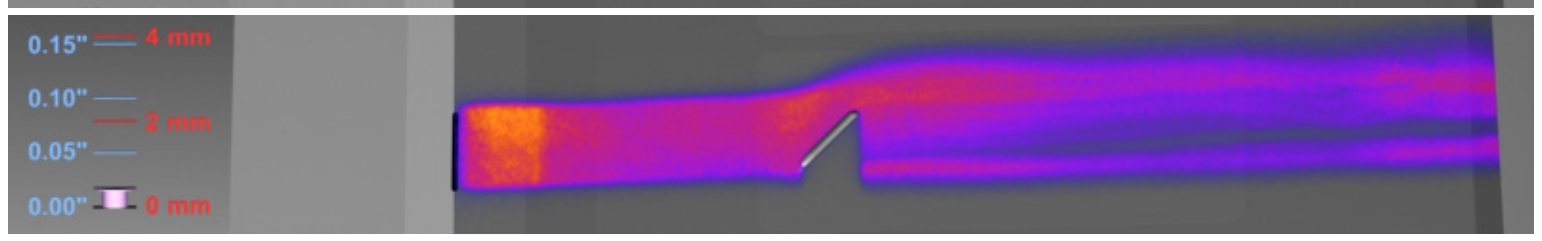

(f)

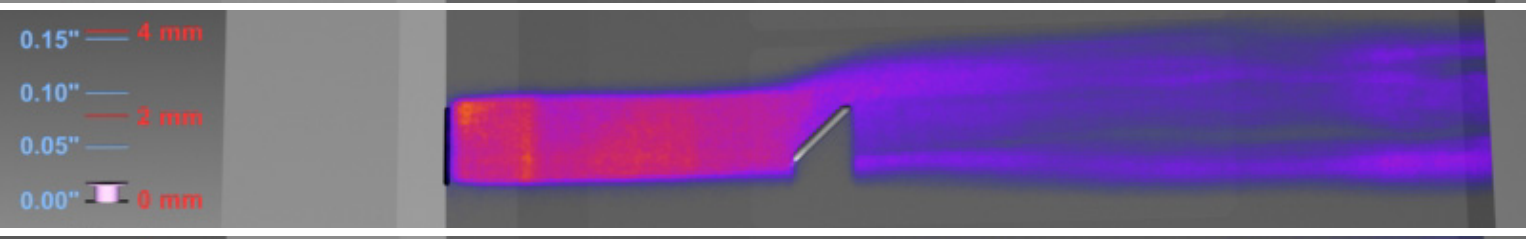

(h)
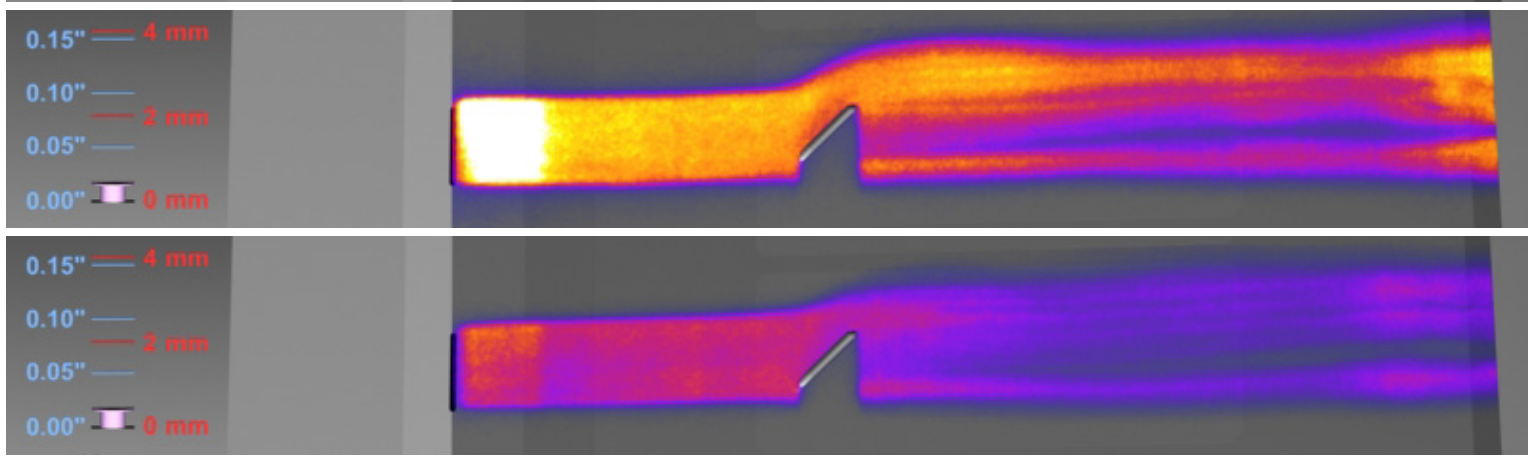

Figure A9: Test 462, Run 3, 1-mm tall BLT DTO trip, plate angle $=20^{\circ}, 11-\mathrm{mm}$ wide slot seeding, $\dot{m}=$ $300 \mathrm{sccm}, \mathrm{P}_{0}=4.97 \mathrm{MPa}$, sheet position $=0.5 \mathrm{~mm}$ above surface, framing rate $=10 \mathrm{~Hz}$. 
(a)

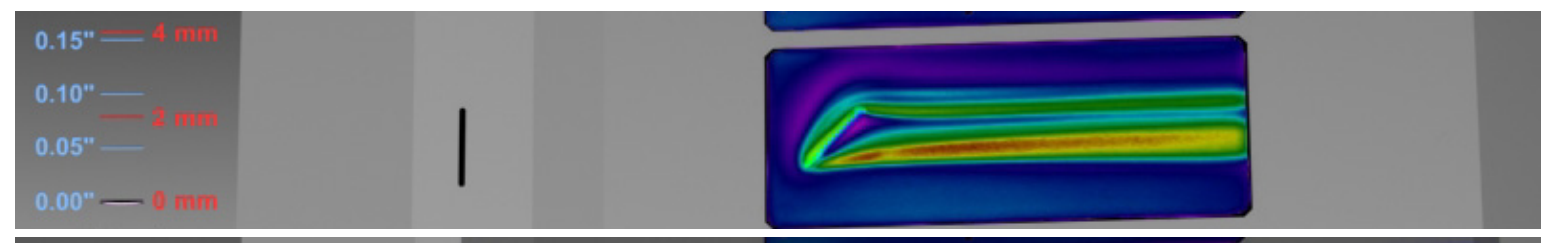

(b)

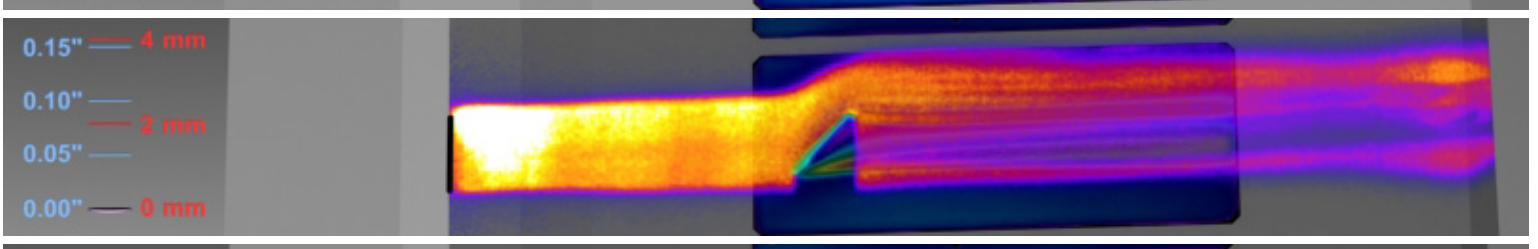

(c)

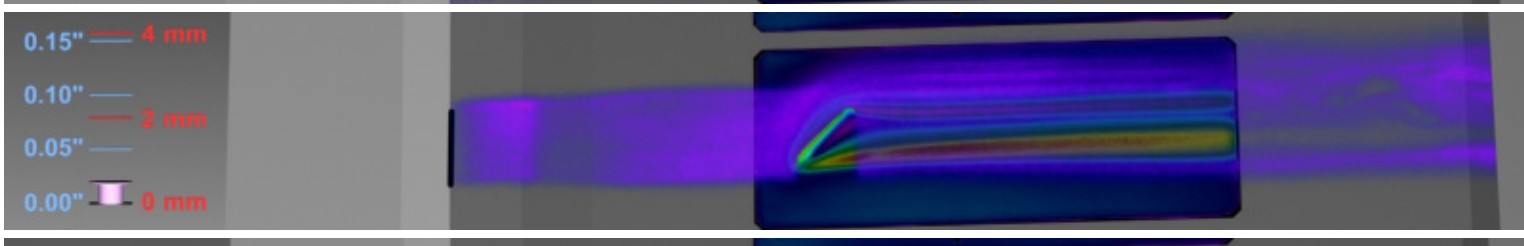

(d)

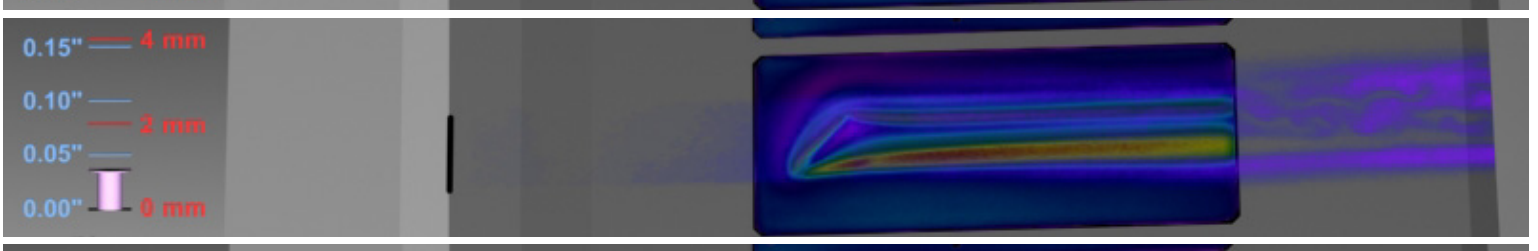

(e)

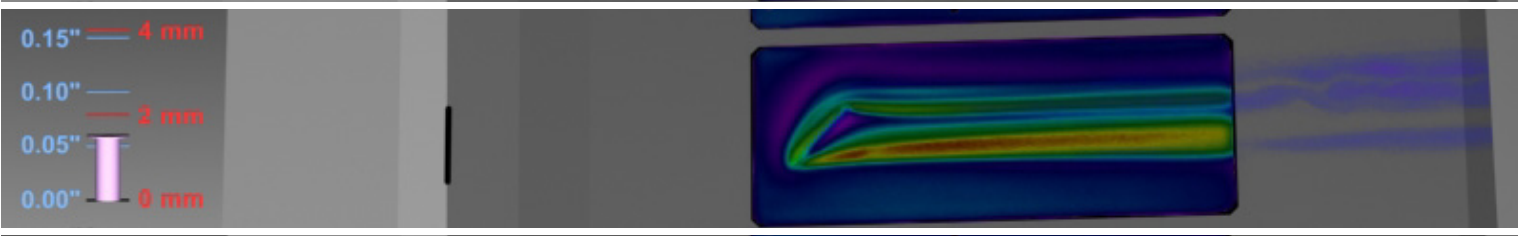

(f)

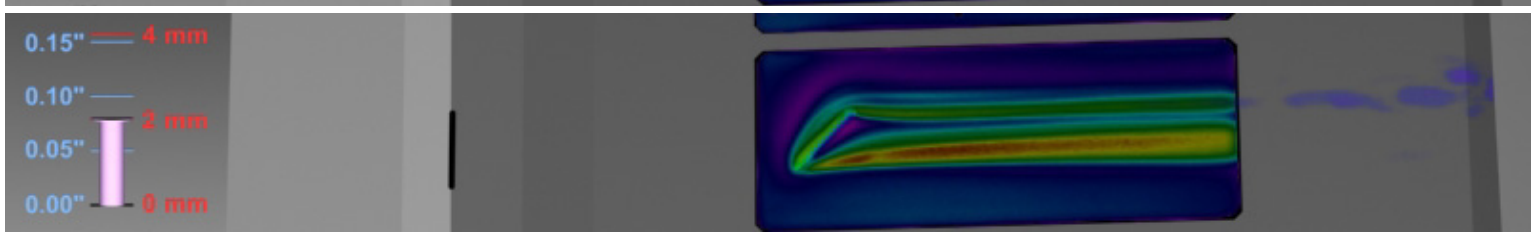

(g)

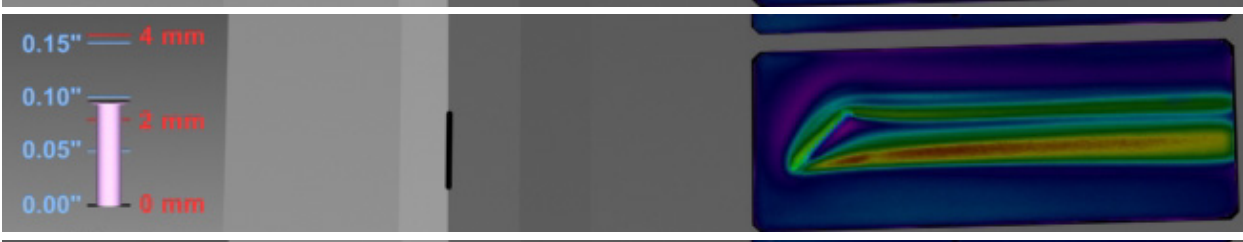

(h)

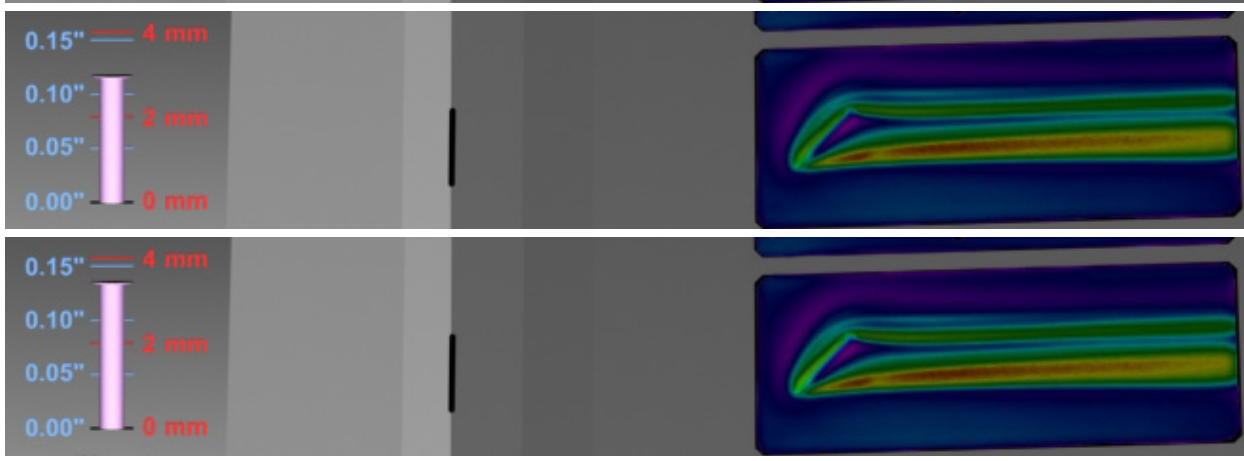

(i)

Figure A10: Test 462, PLIF Run 3, TSP Run 35,1-mm tall BLT DTO trip, plate angle $=20^{\circ}, 11$-mm wide slot seeding, $\dot{m}=300 \mathrm{sccm}, \mathrm{P}_{0}=4.97 \mathrm{MPa}$, sheet position $=$ TSP Run $35 \mathrm{scan} \mathrm{mm}$ above surface, framing rate $=10 \mathrm{~Hz}$. 
(a)

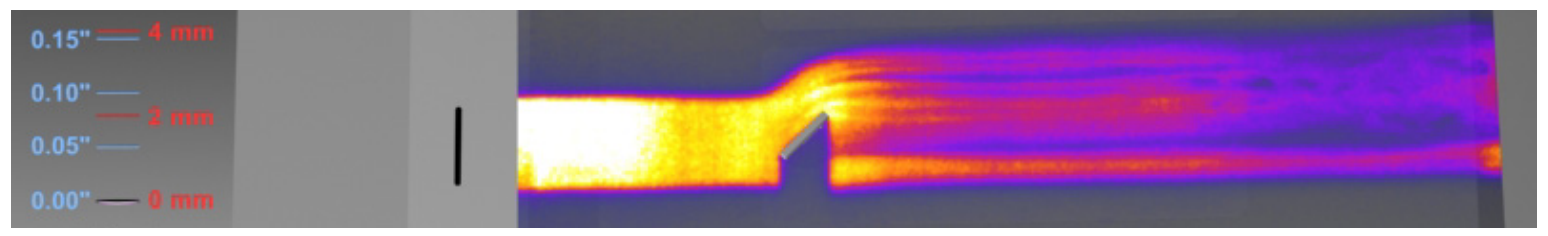

(b)

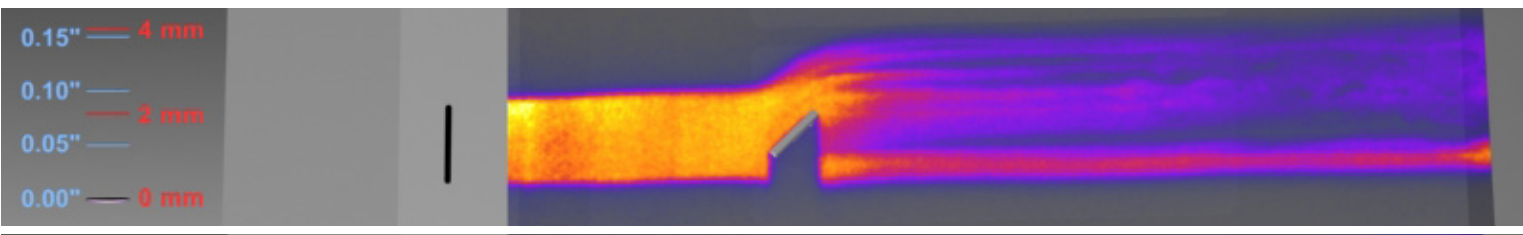

(c)

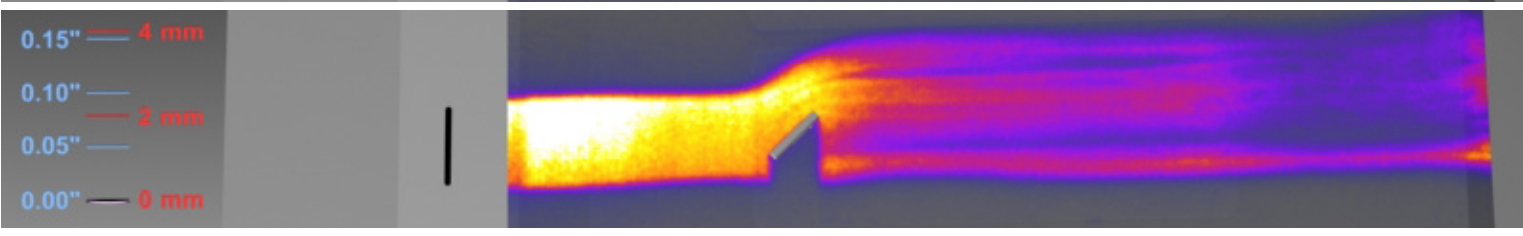

(d)

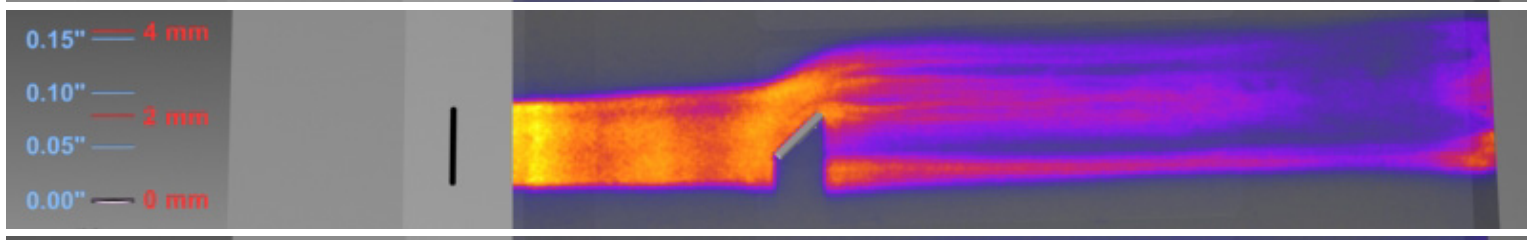

(e)

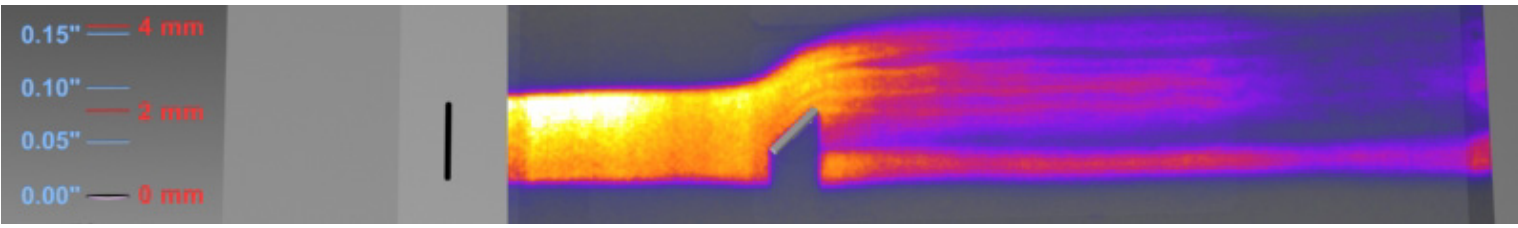

(f)

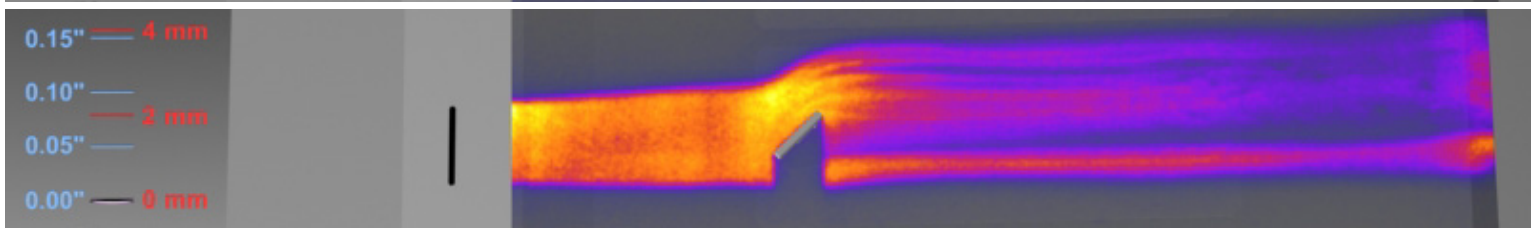

(g)

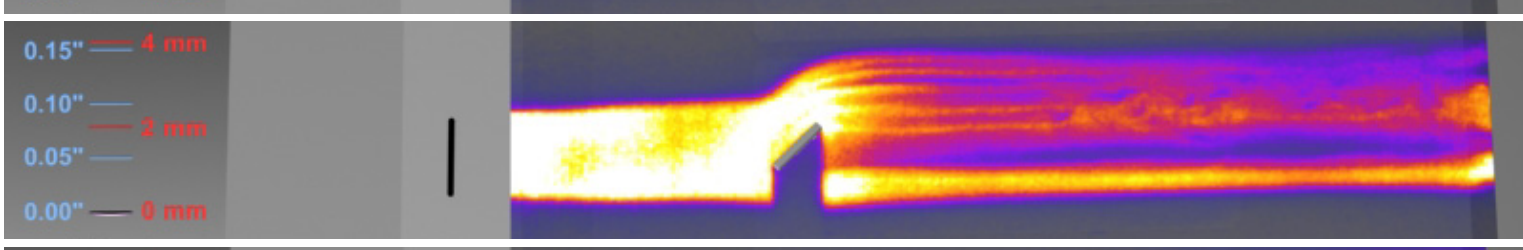

(h)

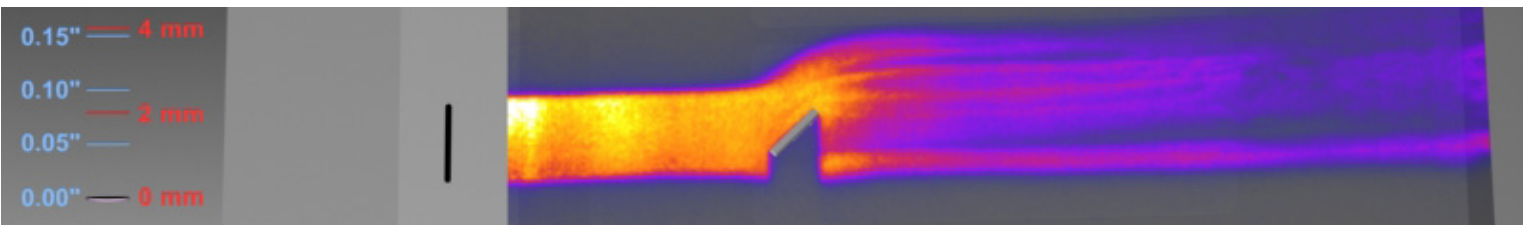

(1)

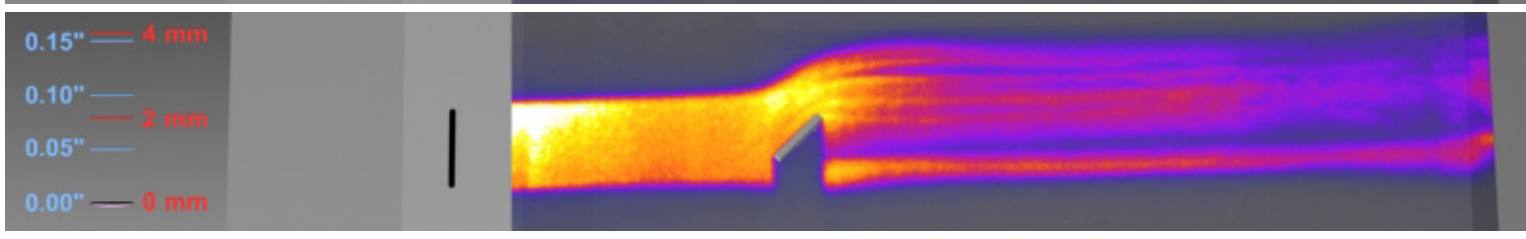

Figure A11: Test 462 , Run 4, 1 -mm tall by $8 \mathrm{~mm}$ wide fence trip at $45^{\circ}$, plate angle $=20^{\circ}, 11-\mathrm{mm}$ wide slot seeding, $\dot{m}=300 \mathrm{sccm}, \mathrm{P}_{0}=4.97 \mathrm{MPa}$, sheet position $=0.1 \mathrm{~mm}$ above surface, framing rate $=10 \mathrm{~Hz}$. 
(a)

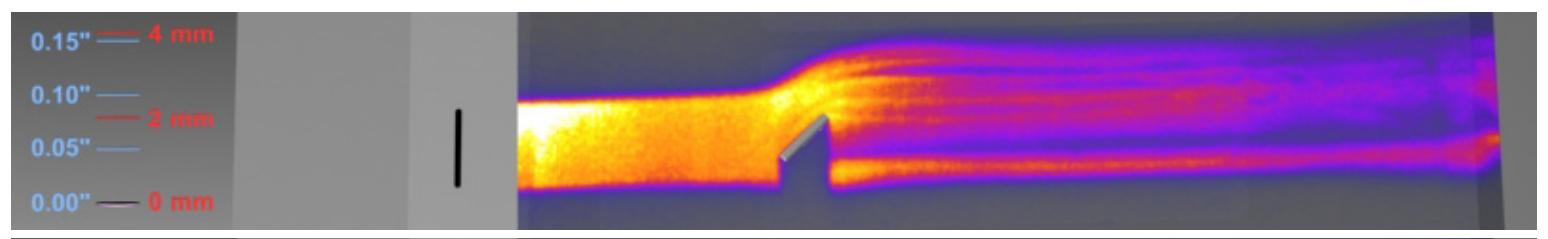

(b)

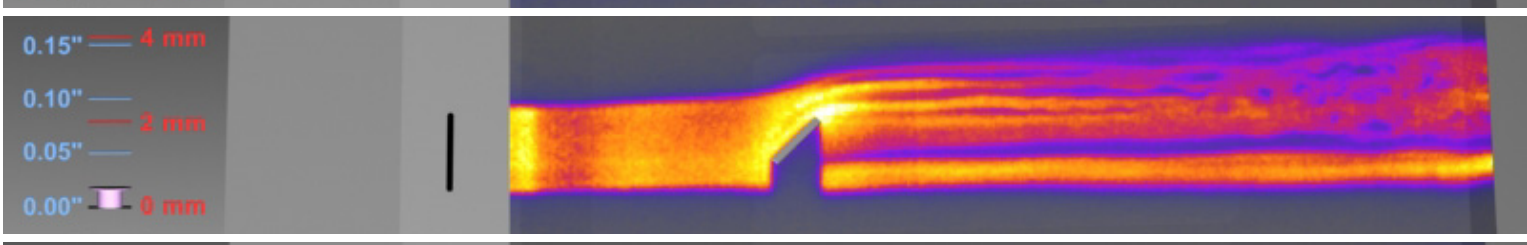

(c)

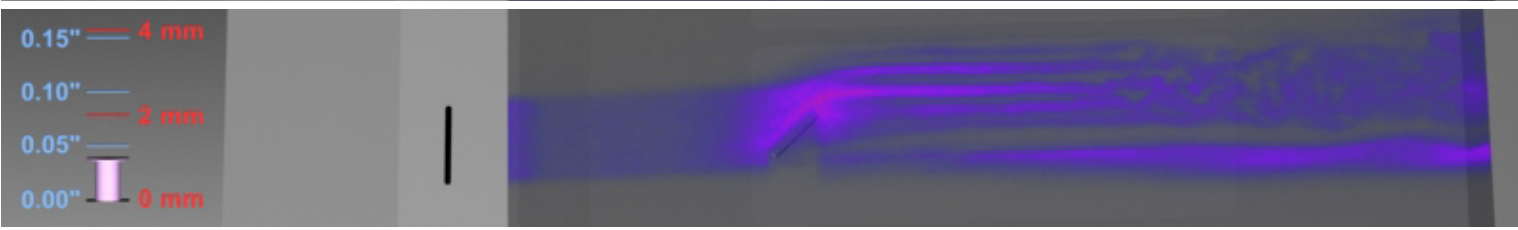

(d)

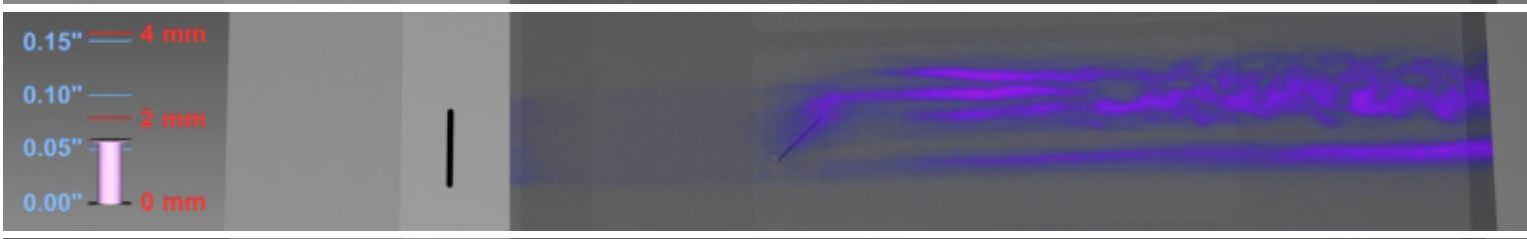

(e)

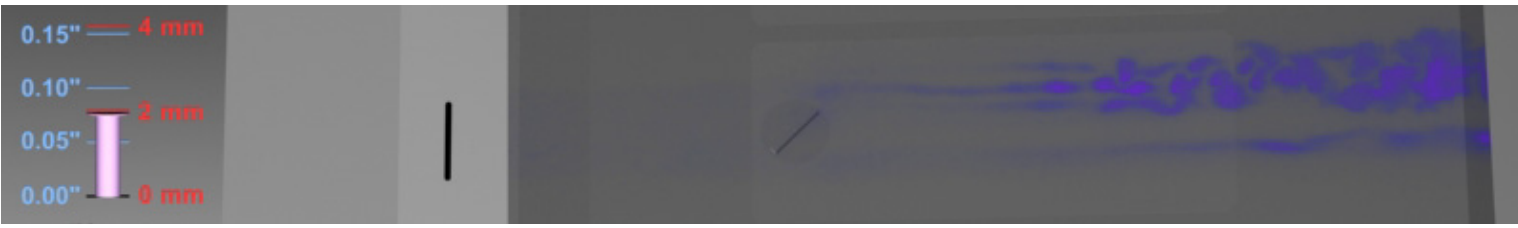

(f)

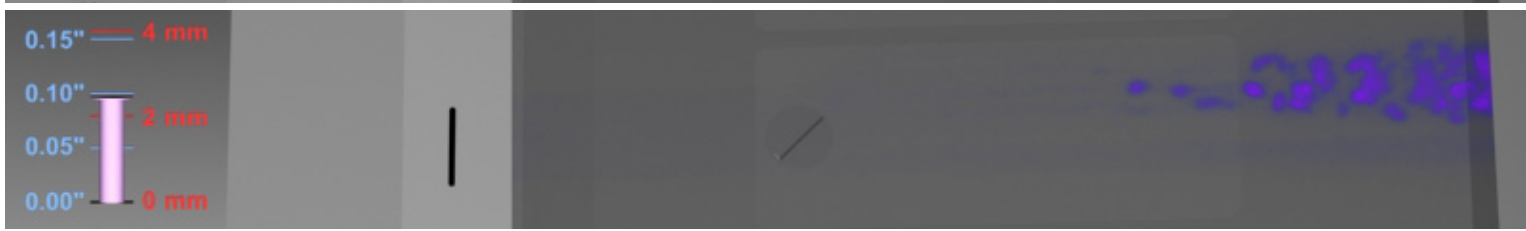

(g)

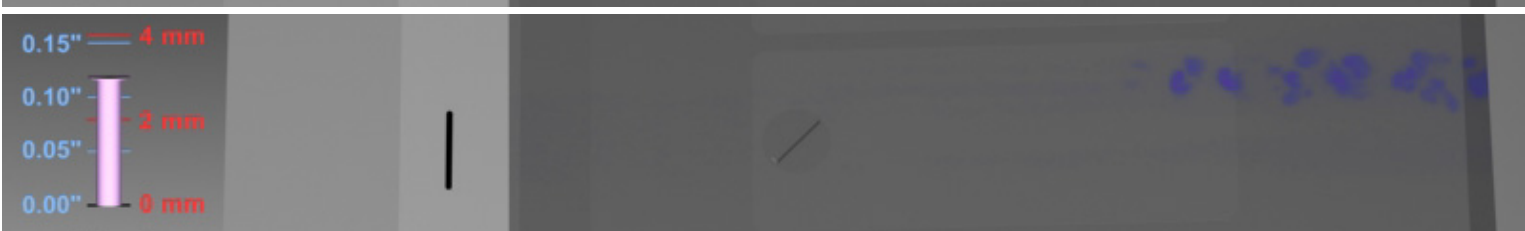

(h)

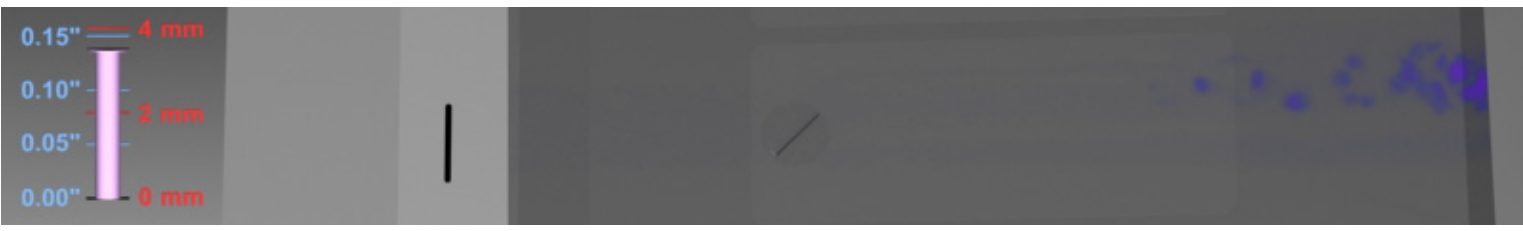

(1)

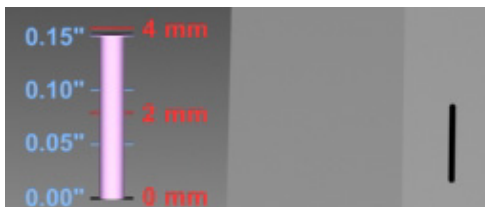

Figure A12: Test 462 , Run 4, 1-mm tall by $8 \mathrm{~mm}$ wide fence trip at $45^{\circ}$, plate angle $=20^{\circ}, 11-\mathrm{mm}$ wide slot seeding, $\dot{m}=300 \mathrm{sccm}, \mathrm{P}_{0}=4.97 \mathrm{MPa}$, sheet position $=$ scan $\mathrm{mm}$ above surface, framing rate $=10$ $\mathrm{Hz}$. 
(a)

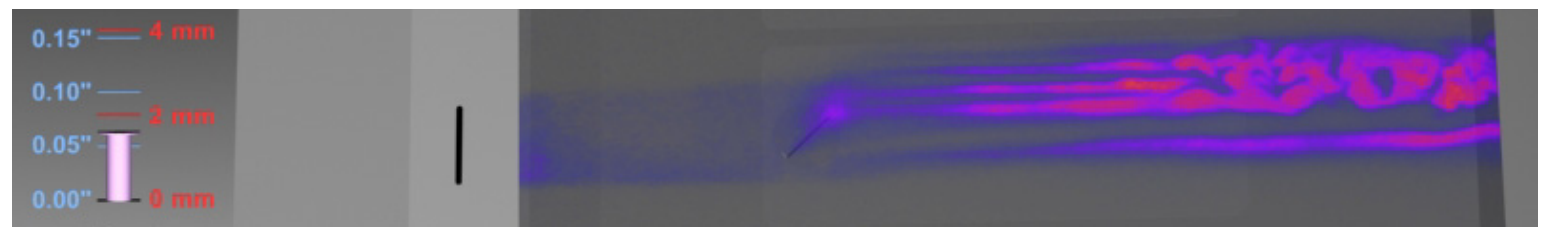

(b)

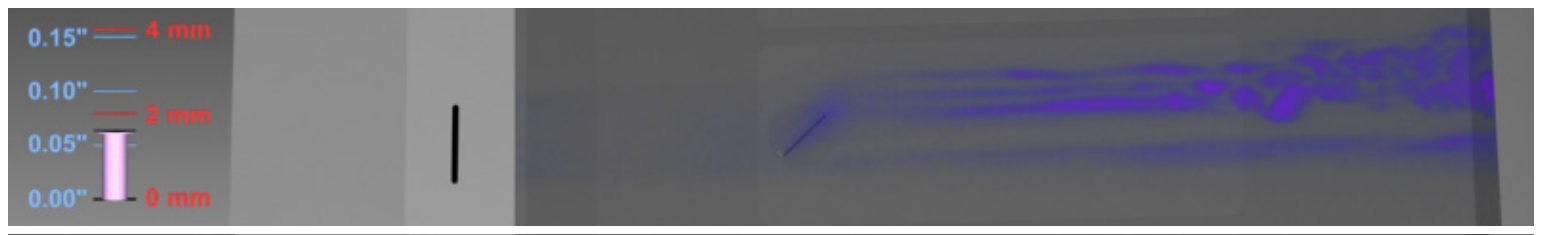

(c)

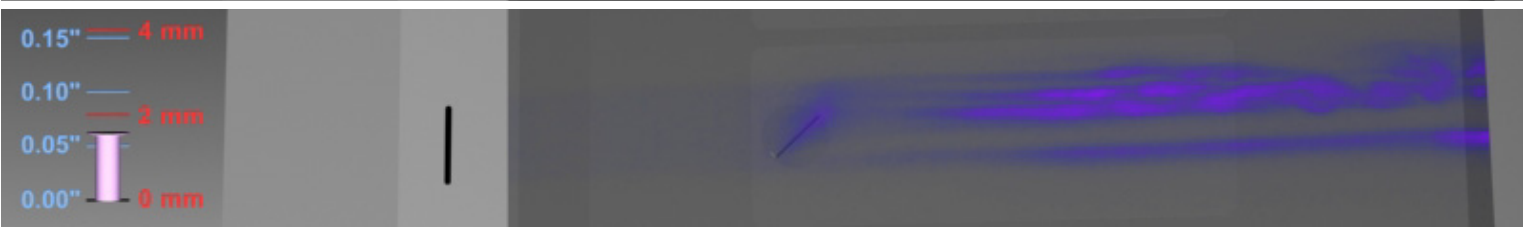

(d)

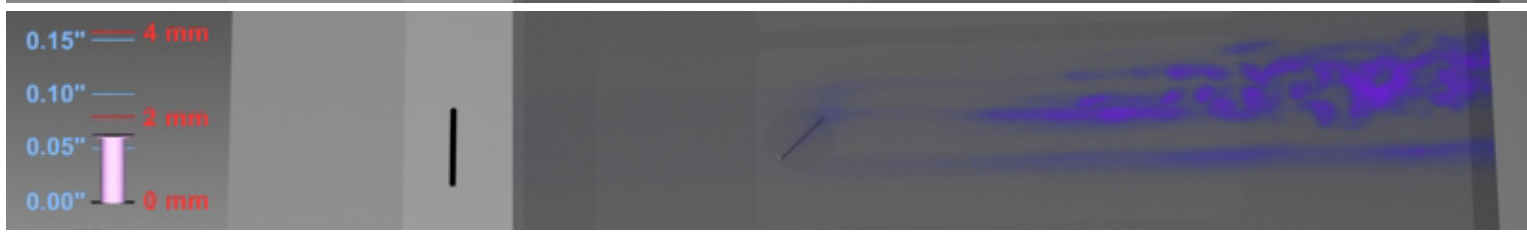

(e)

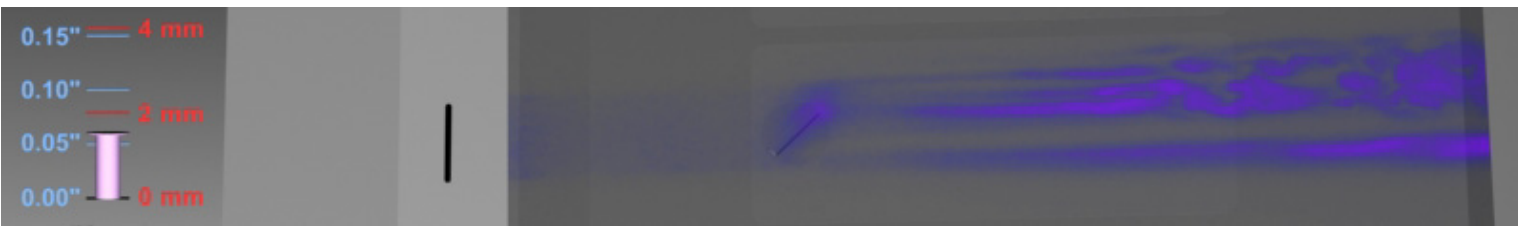

(f)

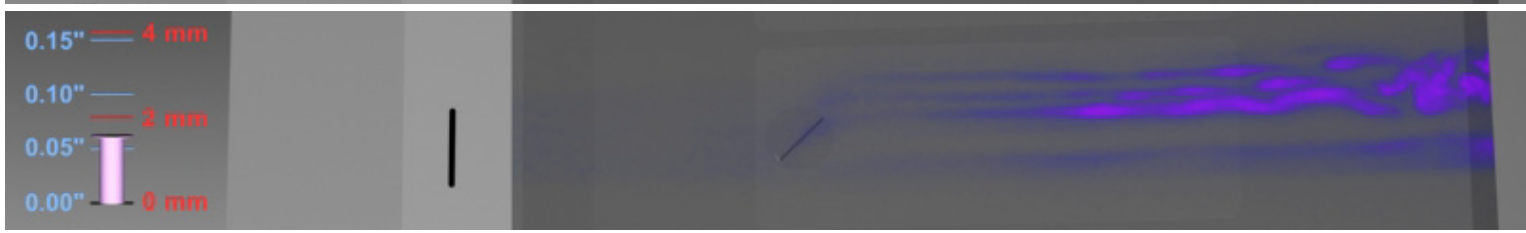

(g)

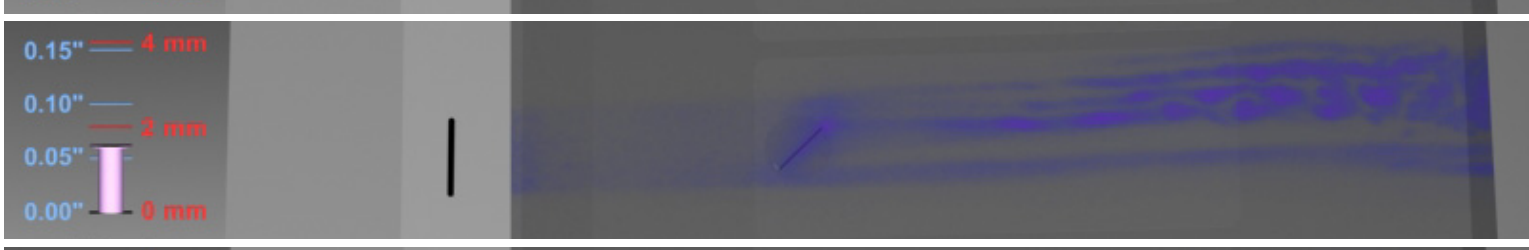

(h)

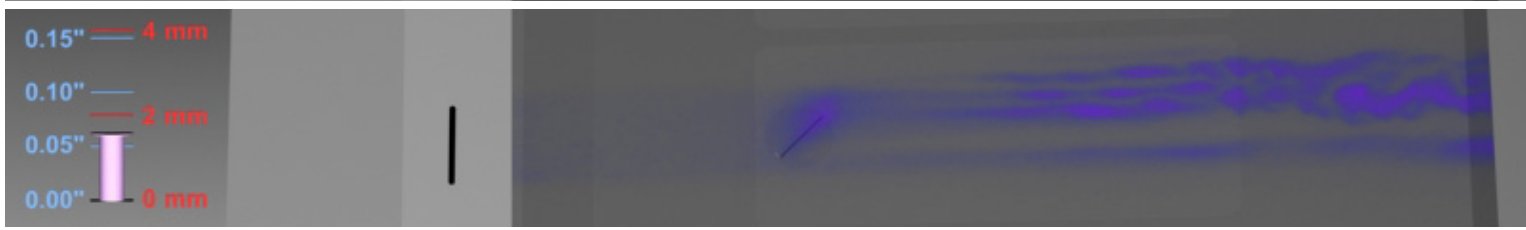

(1)

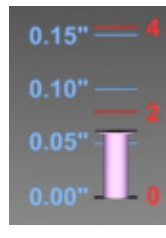

Figure A13: Test 462 , Run 4, $1-\mathrm{mm}$ tall by $8 \mathrm{~mm}$ wide fence trip at $45^{\circ}$, plate angle $=20^{\circ}, 11-\mathrm{mm}$ wide slot seeding, $\dot{m}=300 \mathrm{sccm}, \mathrm{P}_{0}=4.97 \mathrm{MPa}$, sheet position $=1.6 \mathrm{~mm}$ above surface, framing rate $=10 \mathrm{~Hz}$. 
(a)

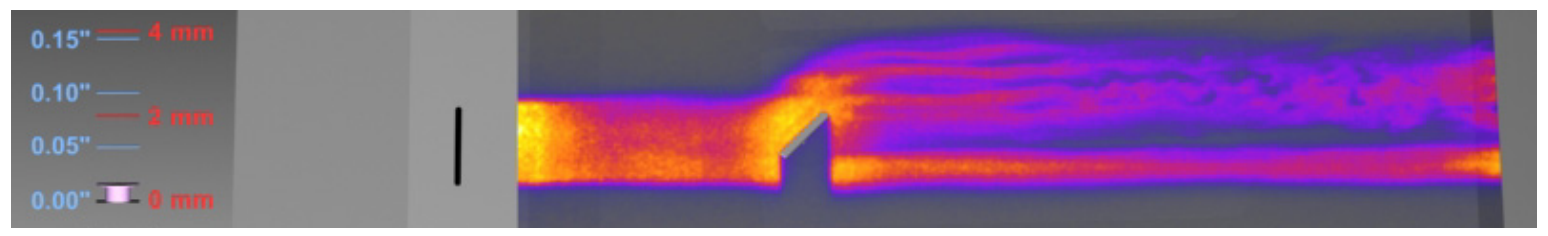

(b)

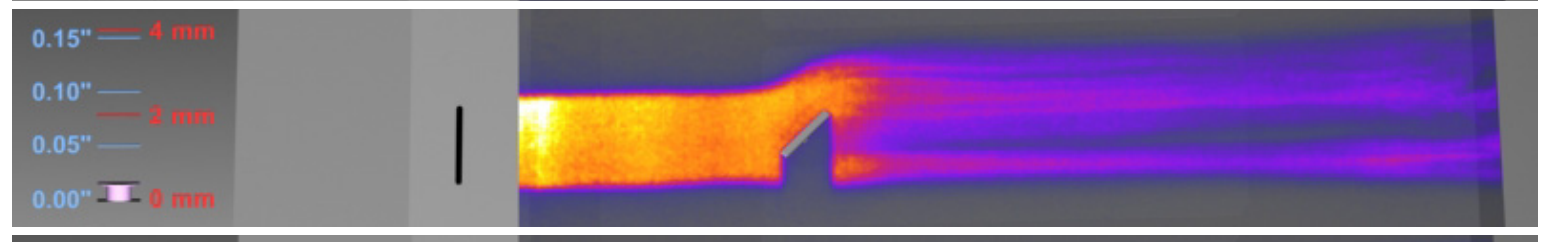

(c)

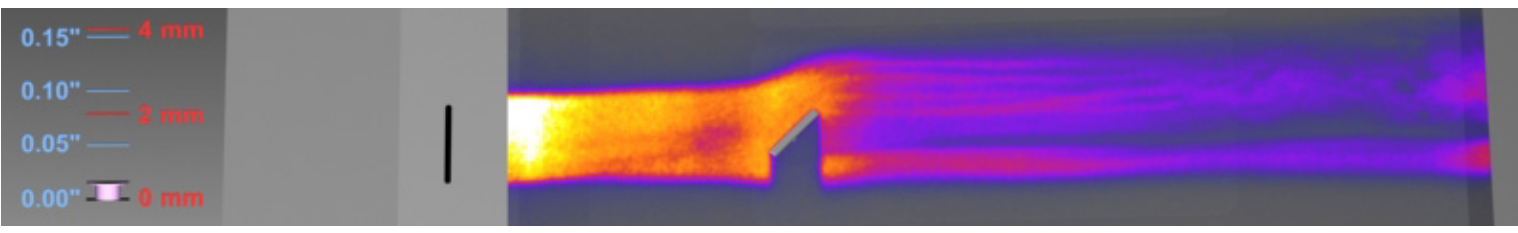

(d)

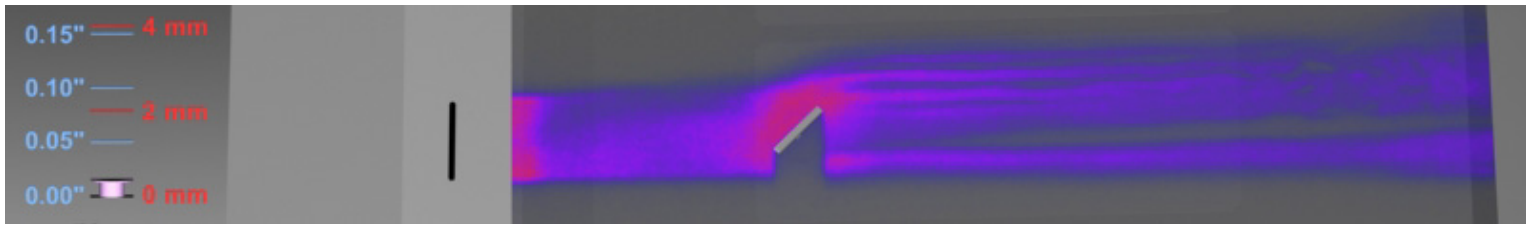

(e)

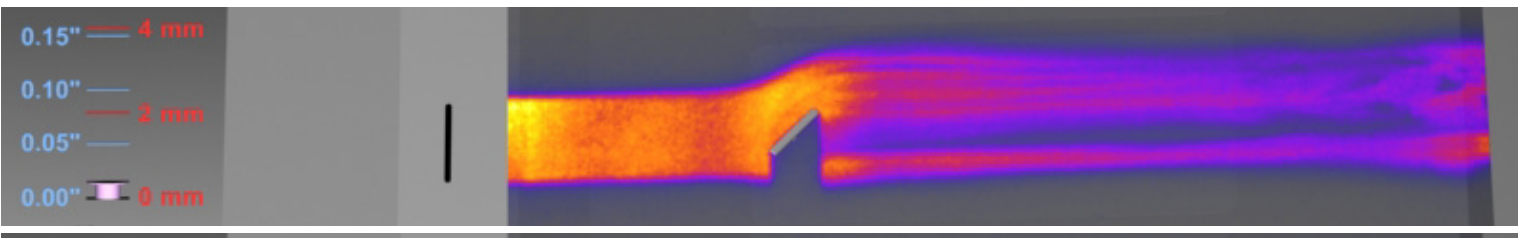

(f)

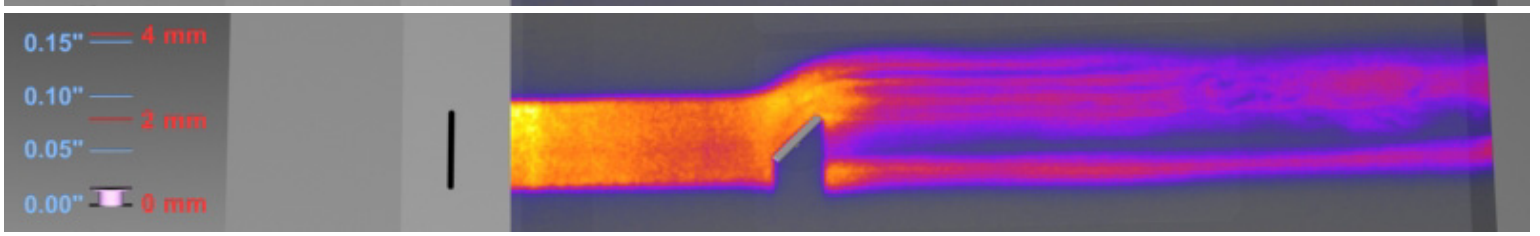

(g)

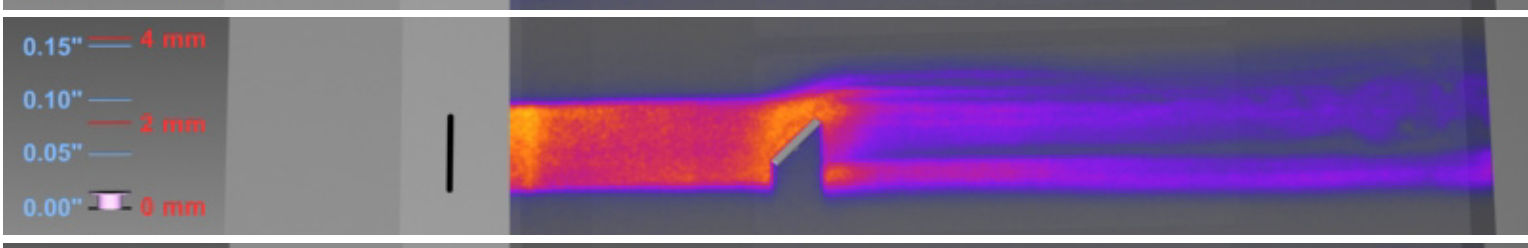

(h)

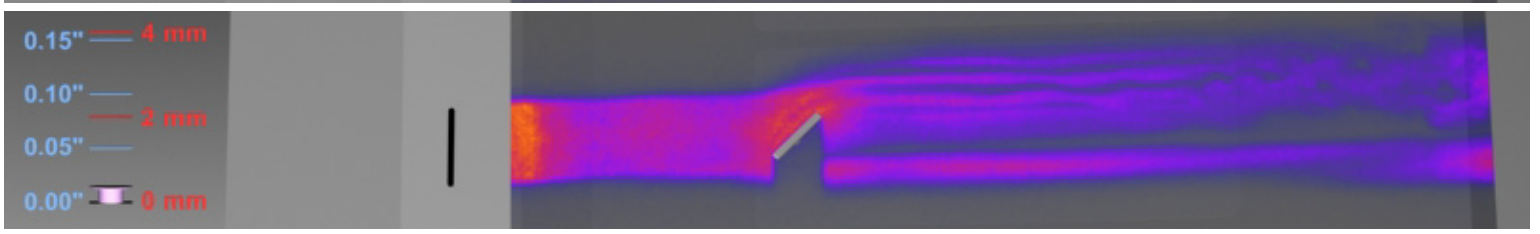

(1)

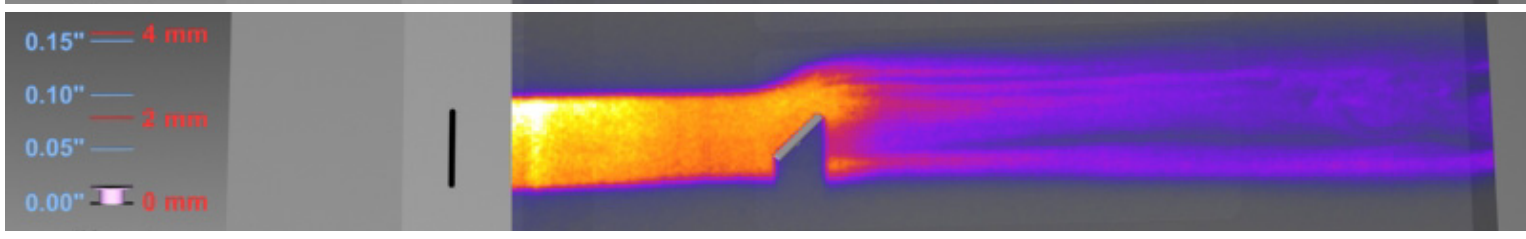

Figure A14: Test 462 , Run 4, 1 -mm tall by $8 \mathrm{~mm}$ wide fence trip at $45^{\circ}$, plate angle $=20^{\circ}, 11-\mathrm{mm}$ wide slot seeding, $\dot{m}=300 \mathrm{sccm}, \mathrm{P}_{0}=4.97 \mathrm{MPa}$, sheet position $=0.5 \mathrm{~mm}$ above surface, framing rate $=10 \mathrm{~Hz}$. 
(a)

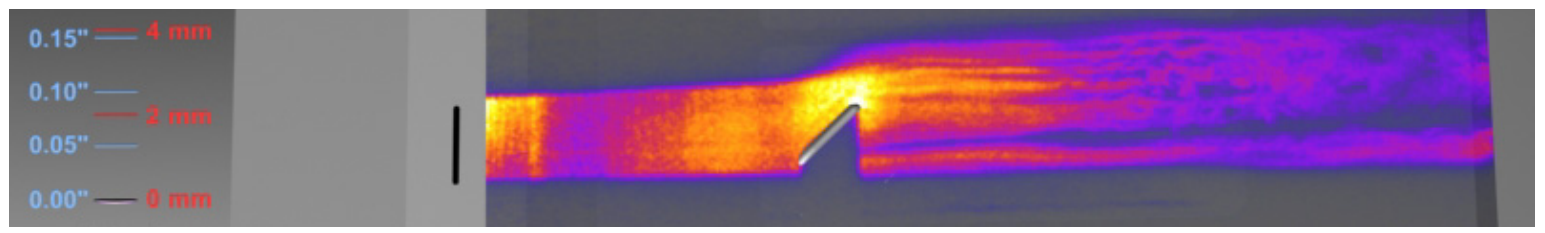

(b)

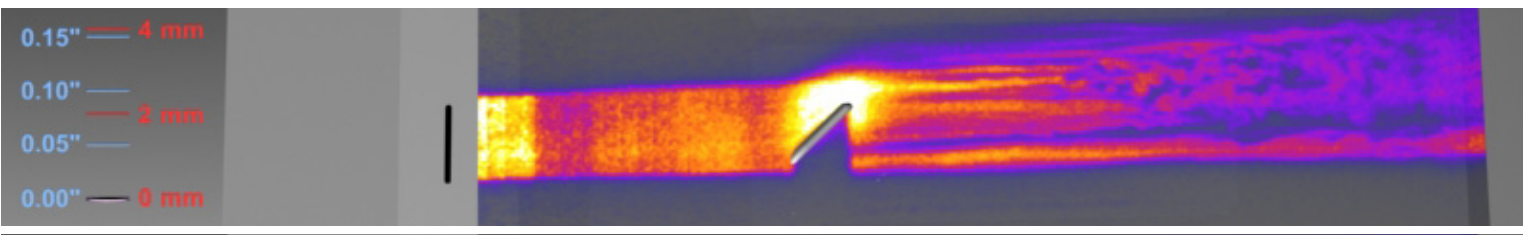

(c)

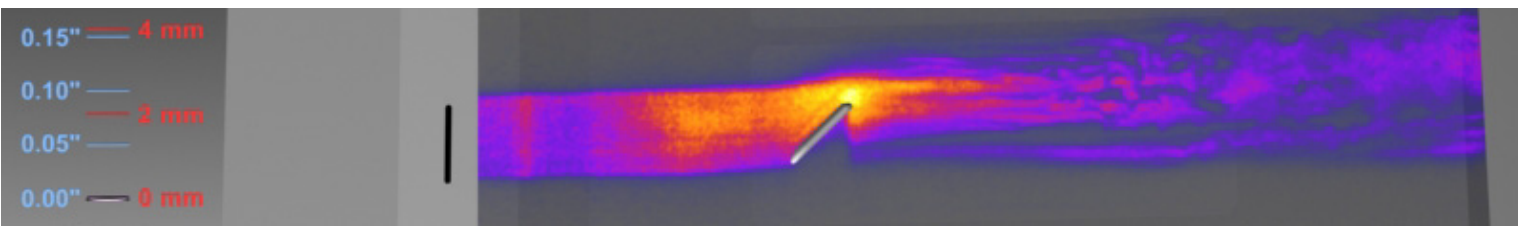

(d)

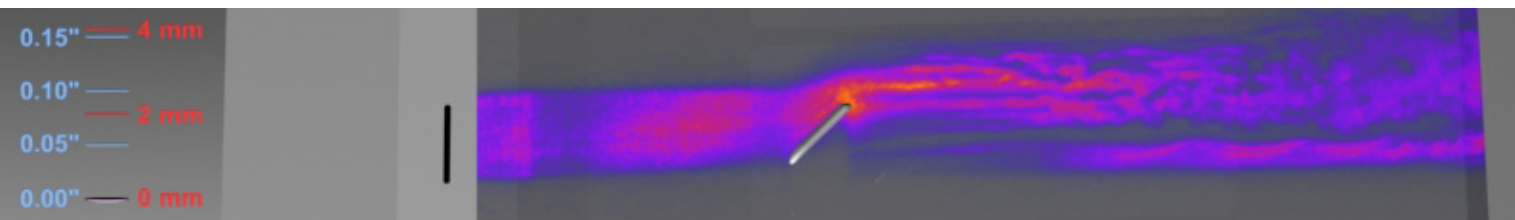

(e)

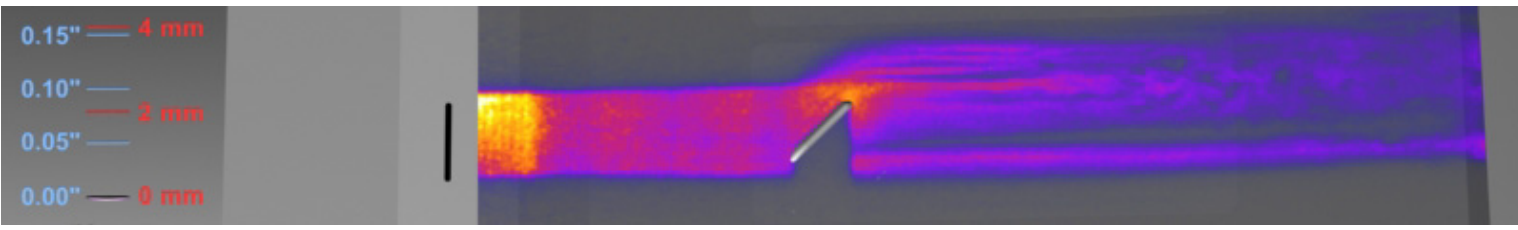

(I)

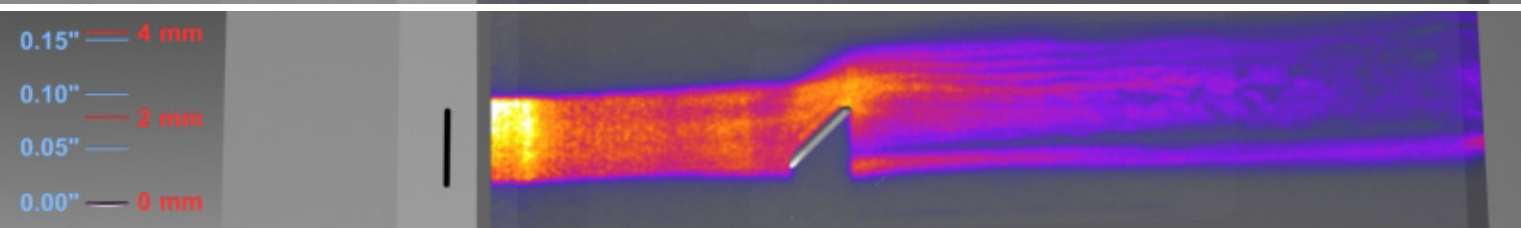

(g)

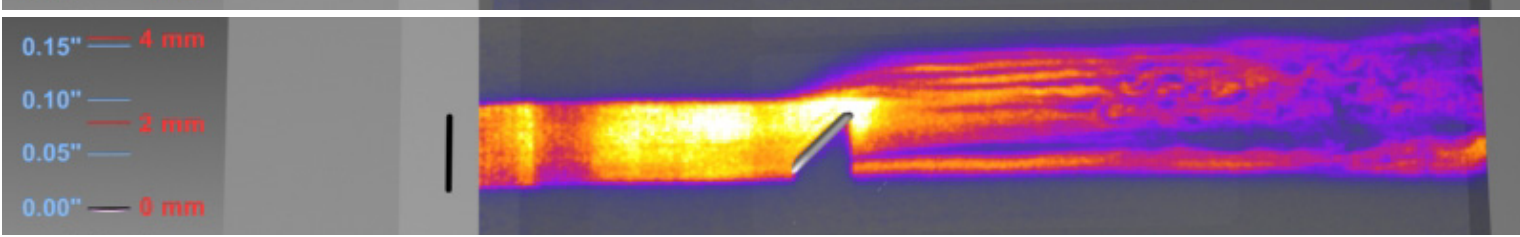

(h)
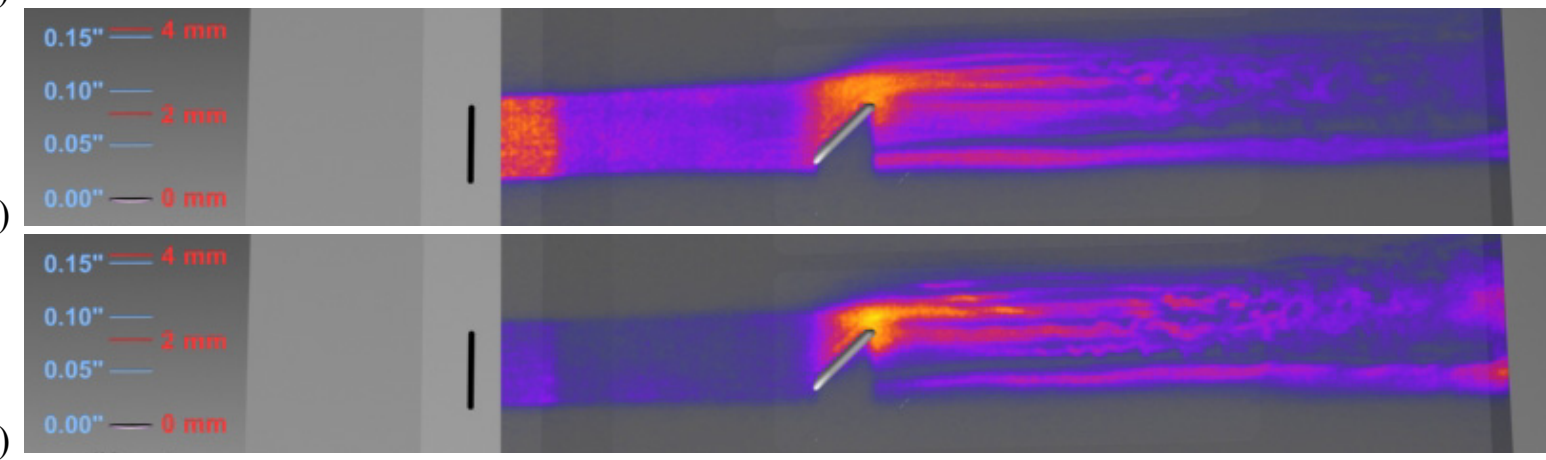

Figure A15: Test 462, Run 5, 1-mm tall BLT DTO trip, plate angle $=20^{\circ}, 11-\mathrm{mm}$ wide slot seeding, $\dot{m}=$ $300 \mathrm{sccm}, \mathrm{P}_{0}=9.33 \mathrm{MPa}$, sheet position $=0.1 \mathrm{~mm}$ above surface, framing rate $=10 \mathrm{~Hz}$. 
(a)

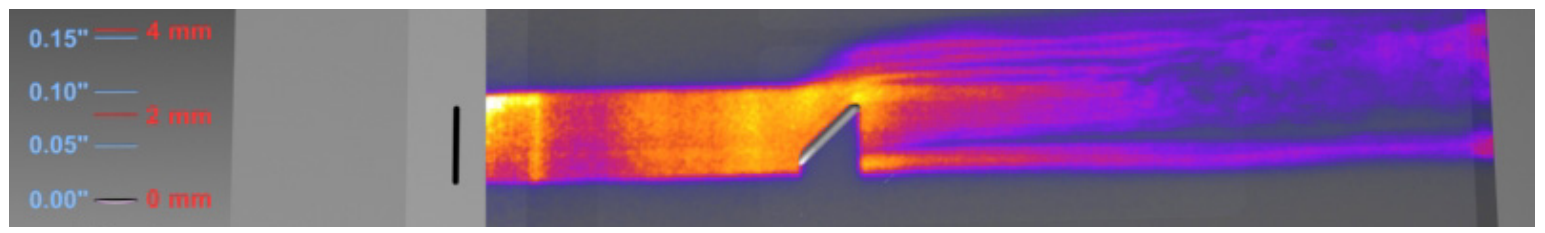

(b)

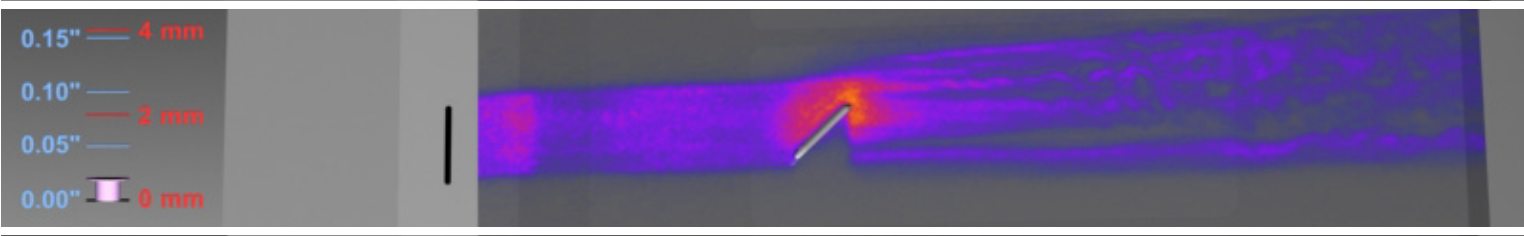

(c)

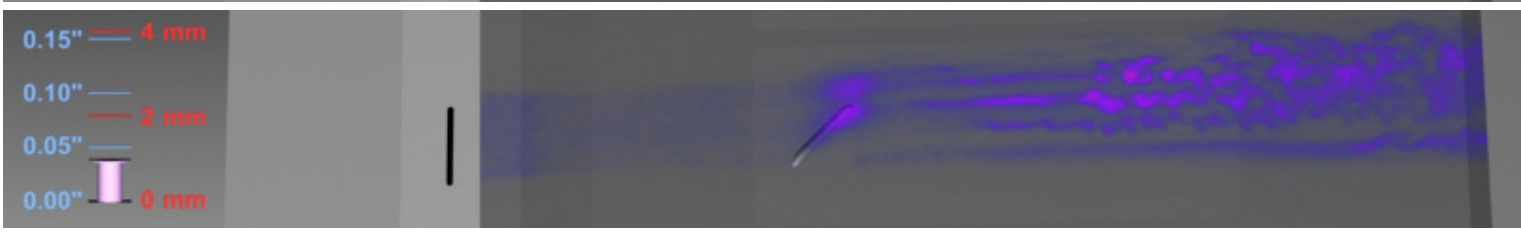

(d)

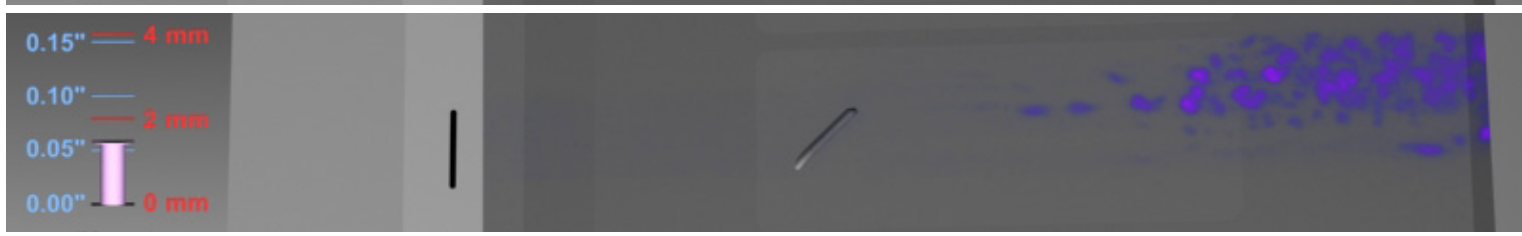

(e)
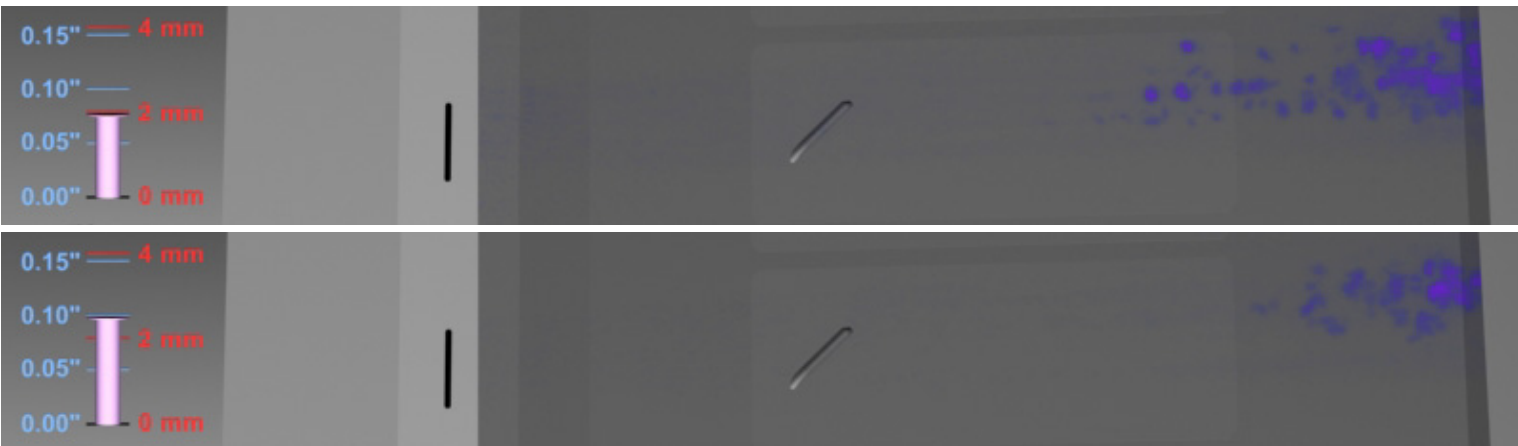

(f)

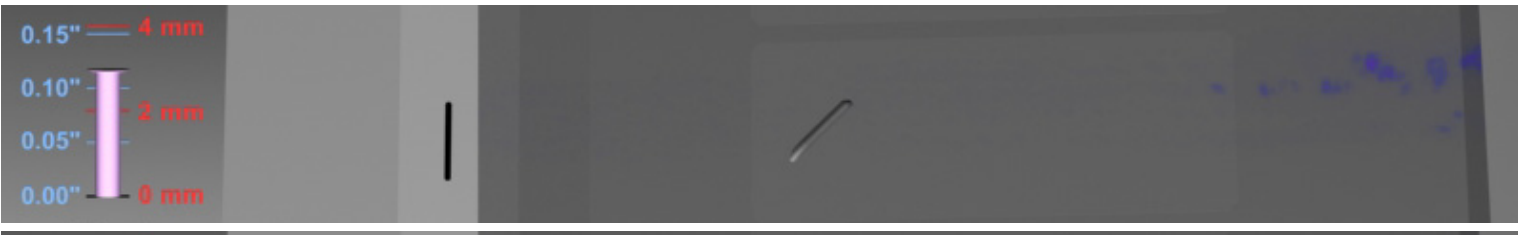

(g)

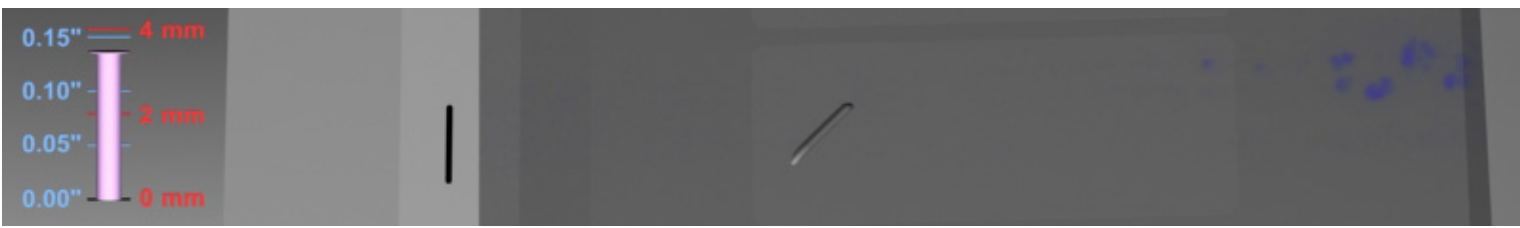

(h)

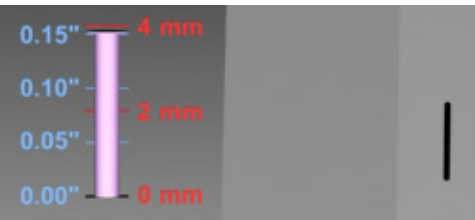

Figure A16: Test 462, Run 5, 1-mm tall BLT DTO trip, plate angle $=20^{\circ}, 11-\mathrm{mm}$ wide slot seeding, $\dot{m}=$ $300 \mathrm{sccm}, \mathrm{P}_{0}=9.33 \mathrm{MPa}$, sheet position $=$ scan $\mathrm{mm}$ above surface, framing rate $=10 \mathrm{~Hz}$. 
(a)

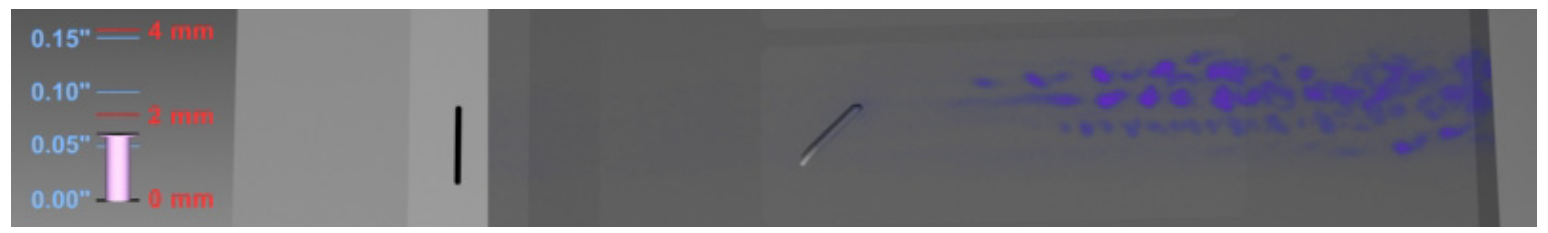

(b)

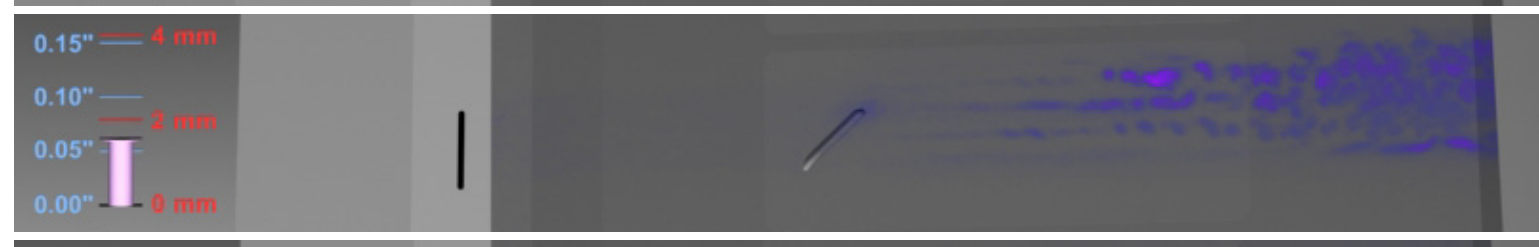

(c)

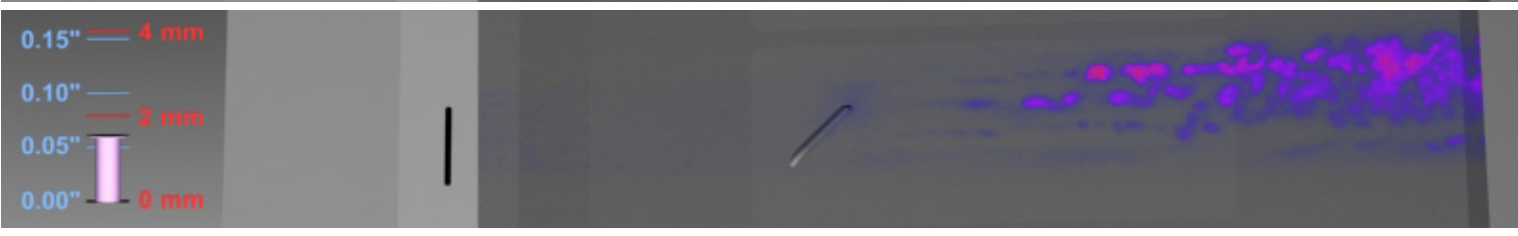

(d)

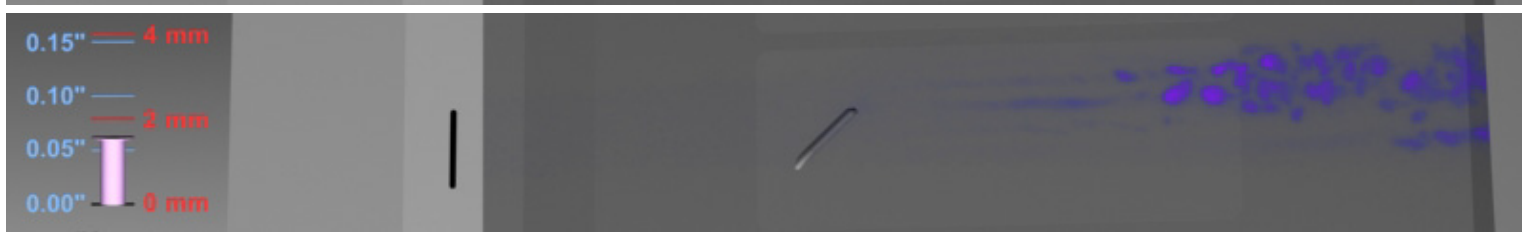

(e)

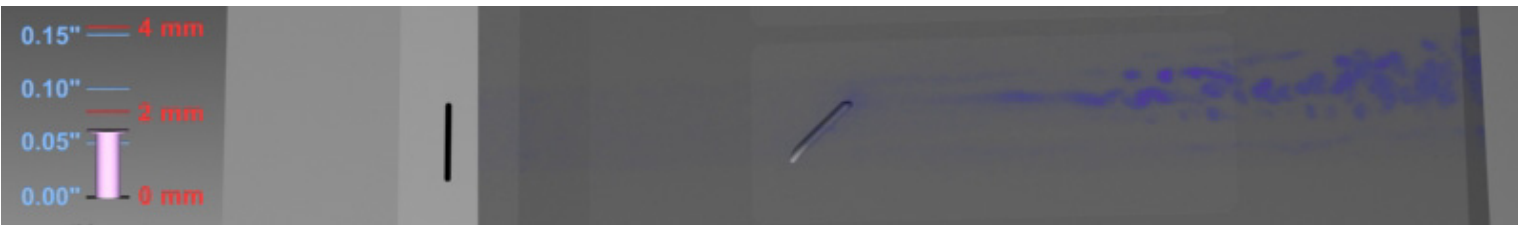

(f)

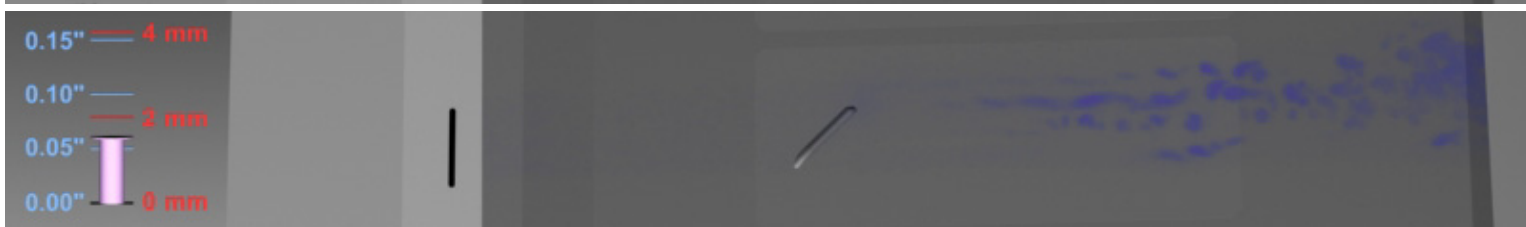

(g)

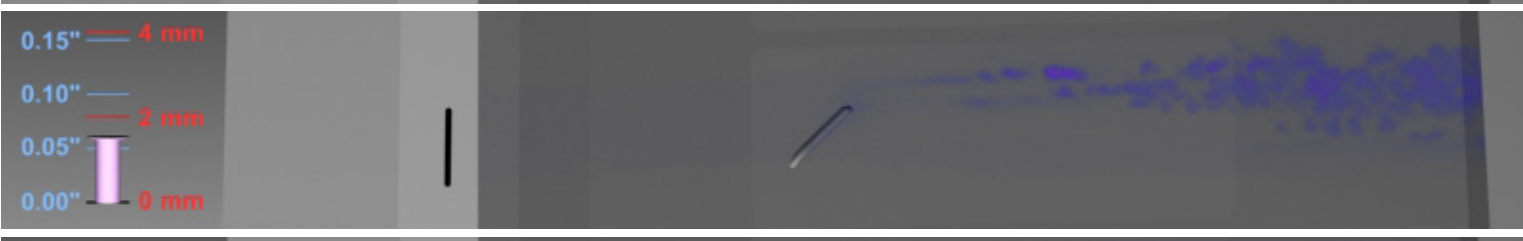

(h)

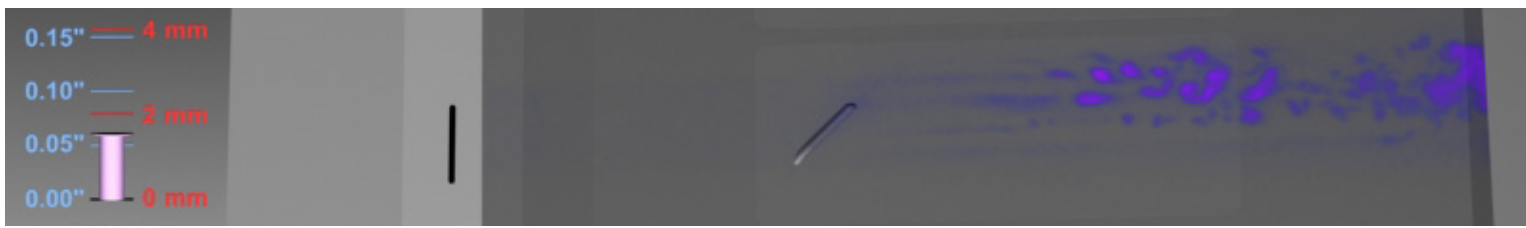

(1)

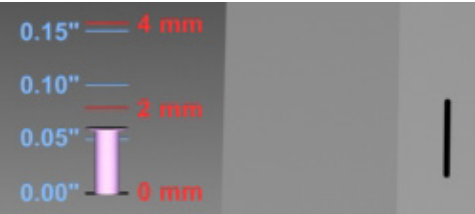

Figure A17: Test 462, Run 5, 1-mm tall BLT DTO trip, plate angle $=20^{\circ}, 11-\mathrm{mm}$ wide slot seeding, $\dot{m}=$ $300 \mathrm{sccm}, \mathrm{P}_{0}=9.33 \mathrm{MPa}$, sheet position $=1.6 \mathrm{~mm}$ above surface, framing rate $=10 \mathrm{~Hz}$. 
(a)

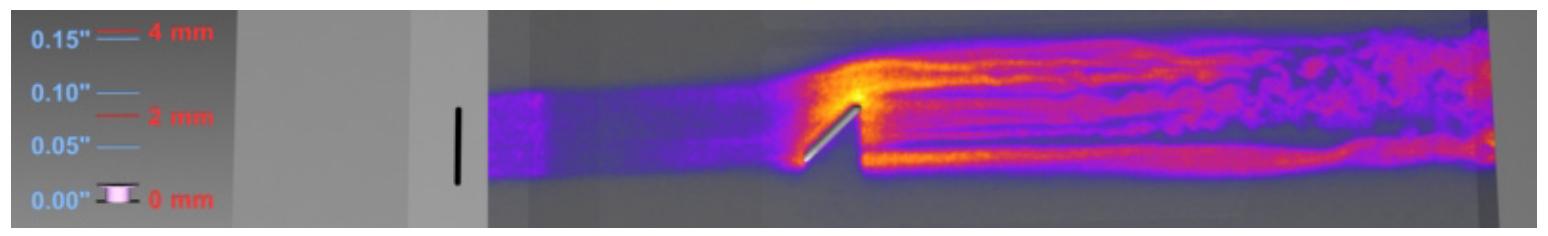

(b)

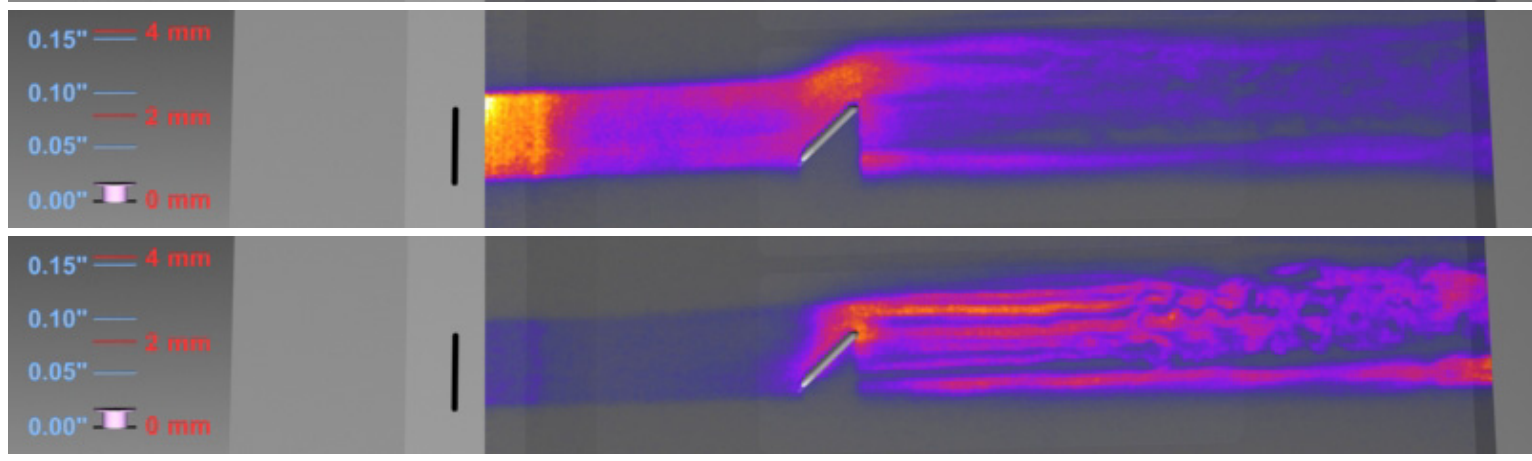

(c)

(d)

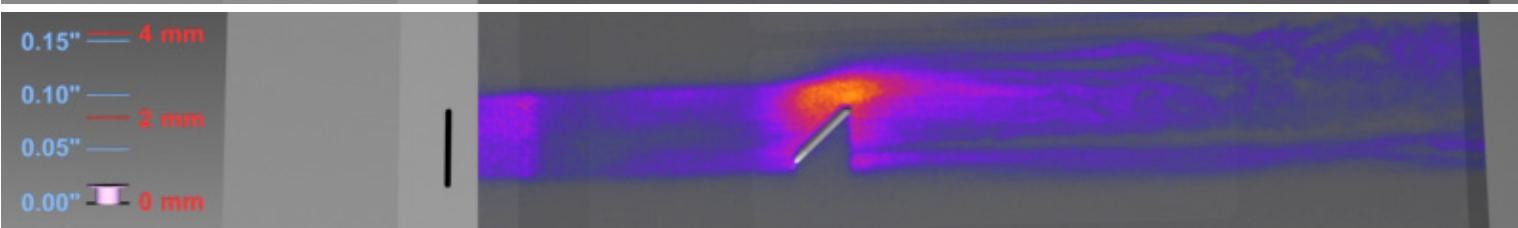

(e)

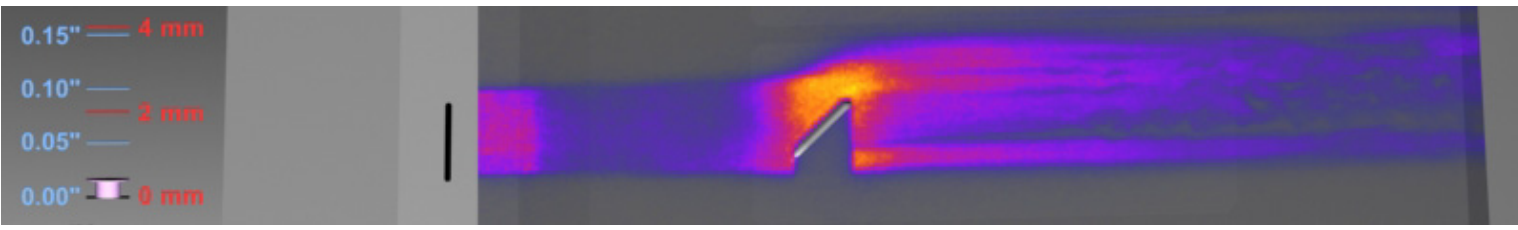

(f)

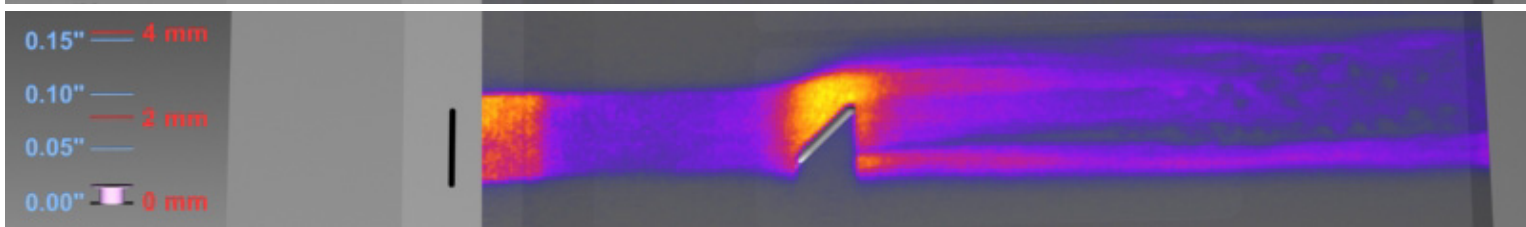

(g)

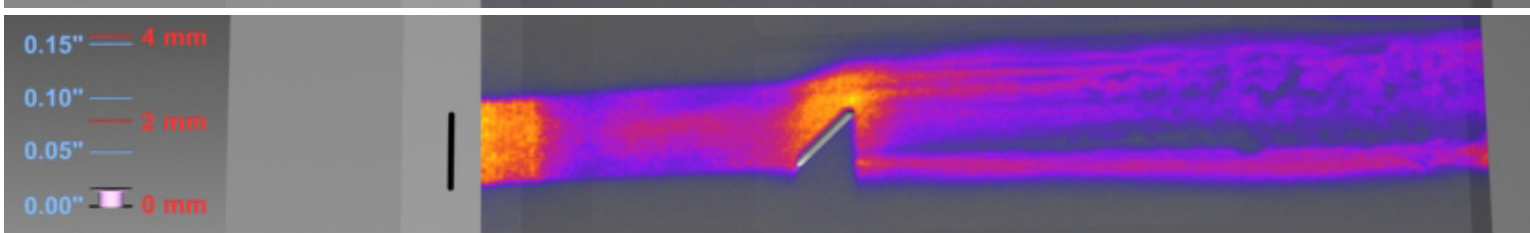

(h)

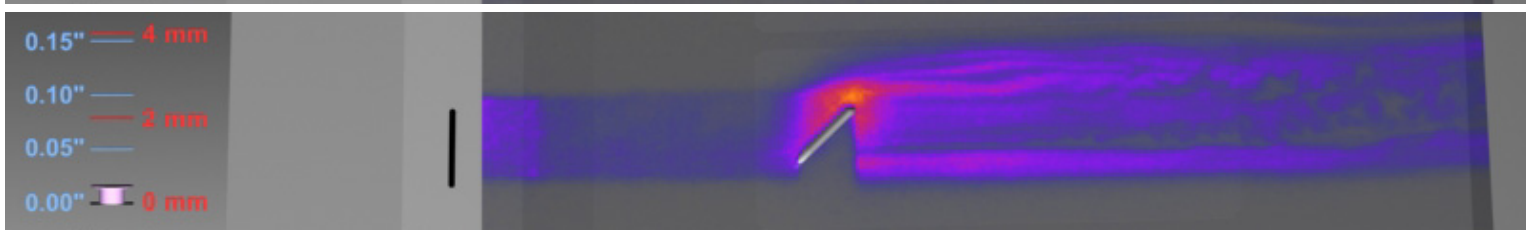

(1)

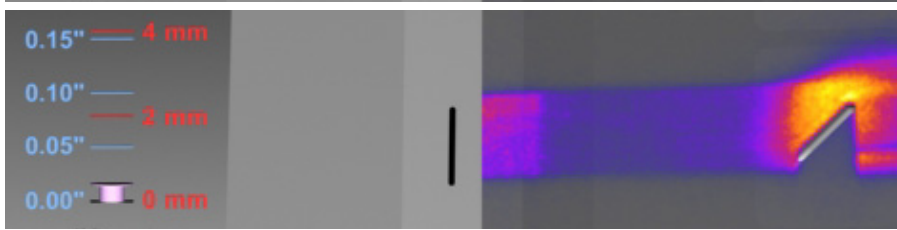

Figure A18: Test 462, Run 5, 1-mm tall BLT DTO trip, plate angle $=20^{\circ}, 11-\mathrm{mm}$ wide slot seeding, $\dot{m}=$ $300 \mathrm{sccm}, \mathrm{P}_{0}=9.33 \mathrm{MPa}$, sheet position $=0.5 \mathrm{~mm}$ above surface, framing rate $=10 \mathrm{~Hz}$. 


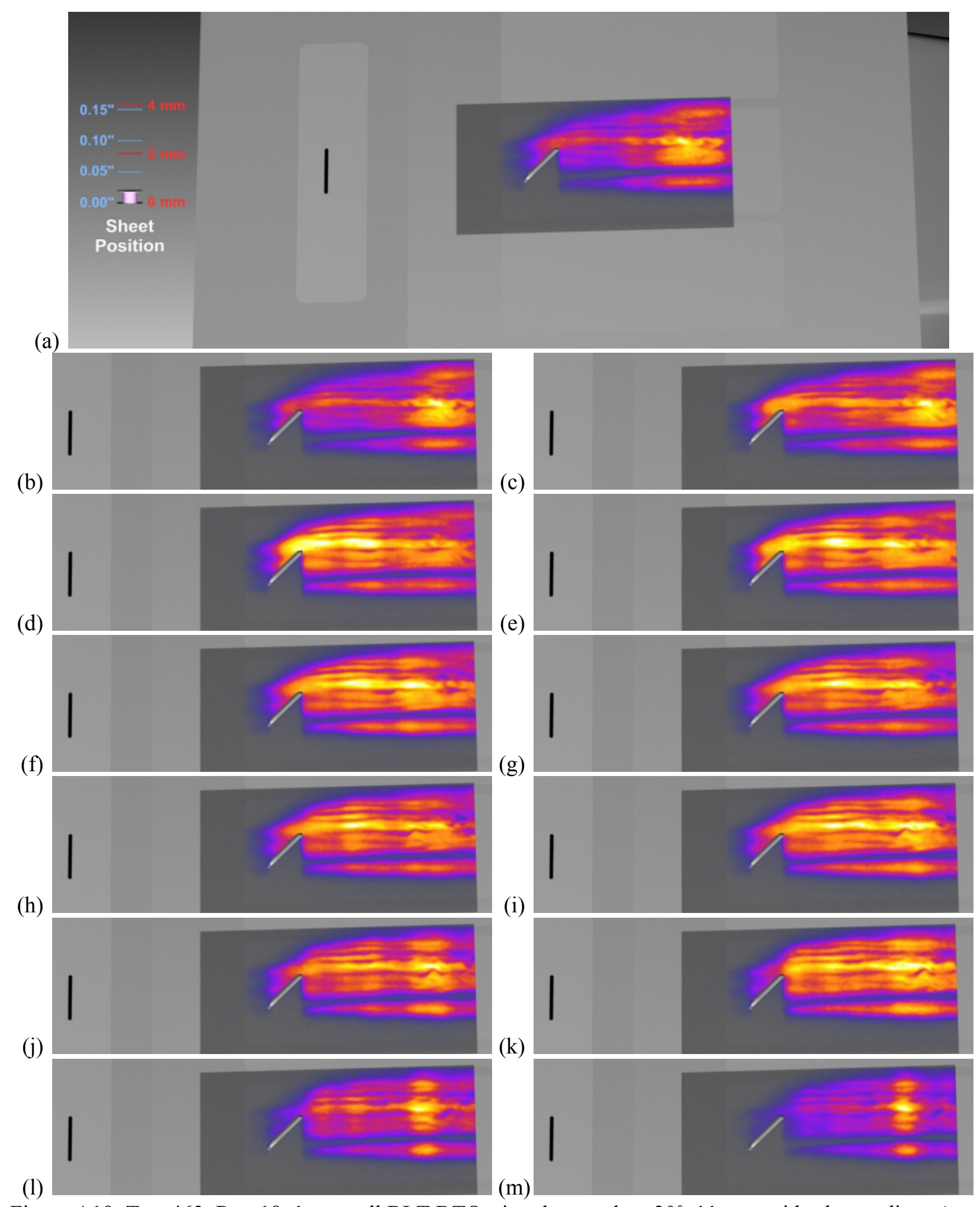

Figure A19: Test 463, Run 18, 1-mm tall BLT DTO trip, plate angle $=20^{\circ}, 11-\mathrm{mm}$ wide slot seeding, $\dot{m}=$ $300 \mathrm{sccm}, \mathrm{P}_{0}=9.31 \mathrm{MPa}$, sheet position $=0.5 \mathrm{~mm}$ above surface, framing rate $=500 \mathrm{kHz}$. 


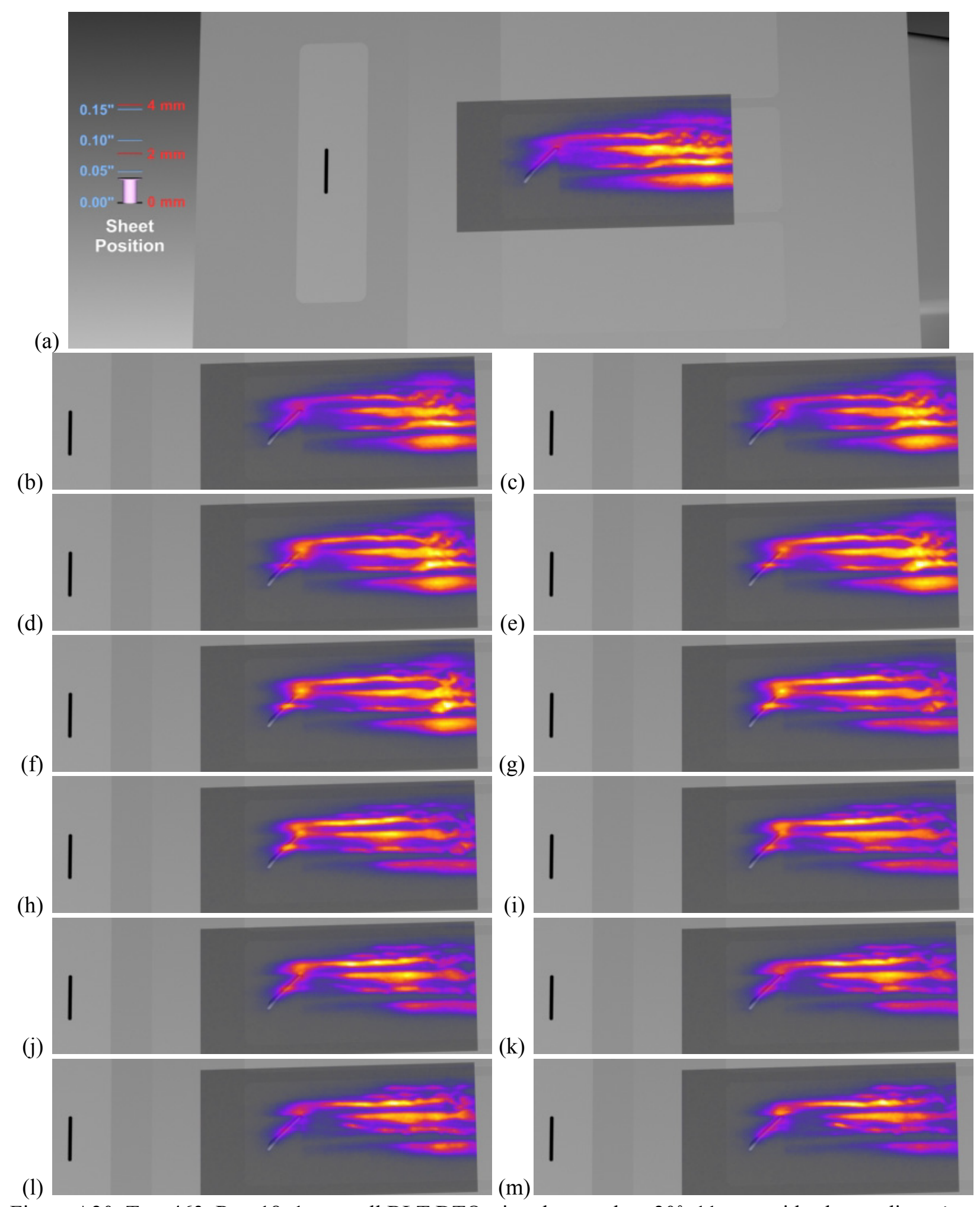

Figure A20: Test 463, Run 18, 1-mm tall BLT DTO trip, plate angle $=20^{\circ}, 11-\mathrm{mm}$ wide slot seeding, $\dot{m}=$ $300 \mathrm{sccm}, \mathrm{P}_{0}=9.31 \mathrm{MPa}$, sheet position $=1 \mathrm{~mm}$ above surface, framing rate $=500 \mathrm{kHz}$. 


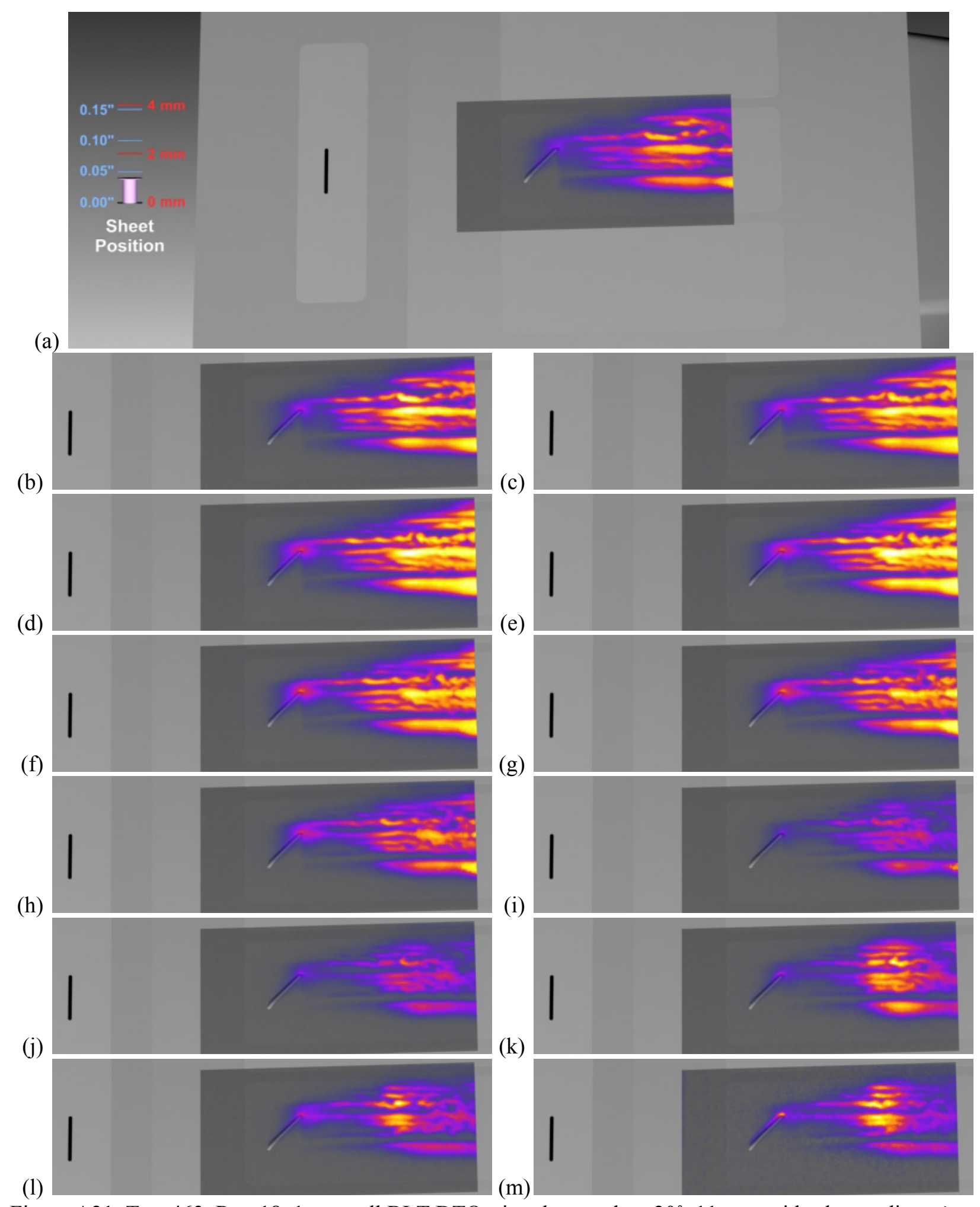

Figure A21: Test 463, Run 18, 1-mm tall BLT DTO trip, plate angle $=20^{\circ}, 11-\mathrm{mm}$ wide slot seeding, $\dot{m}=$ $300 \mathrm{sccm}, \mathrm{P}_{0}=9.31 \mathrm{MPa}$, sheet position $=1 \mathrm{~mm}$ above surface, framing rate $=500 \mathrm{kHz}$. 


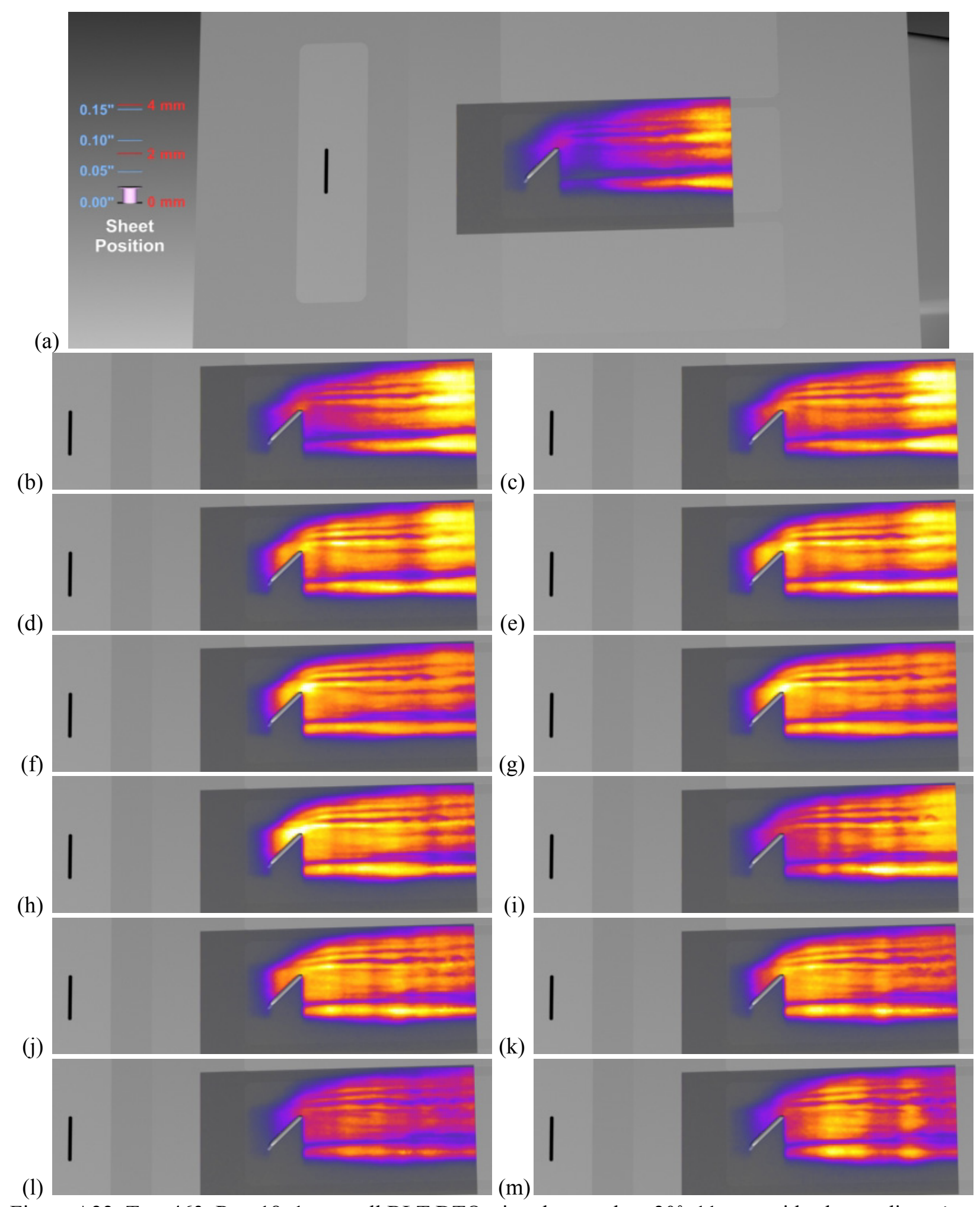

Figure A22: Test 463, Run 18, 1-mm tall BLT DTO trip, plate angle $=20^{\circ}, 11-\mathrm{mm}$ wide slot seeding, $\dot{m}=$ $300 \mathrm{sccm}, \mathrm{P}_{0}=9.31 \mathrm{MPa}$, sheet position $=0.7 \mathrm{~mm}$ above surface, framing rate $=500 \mathrm{kHz}$. 


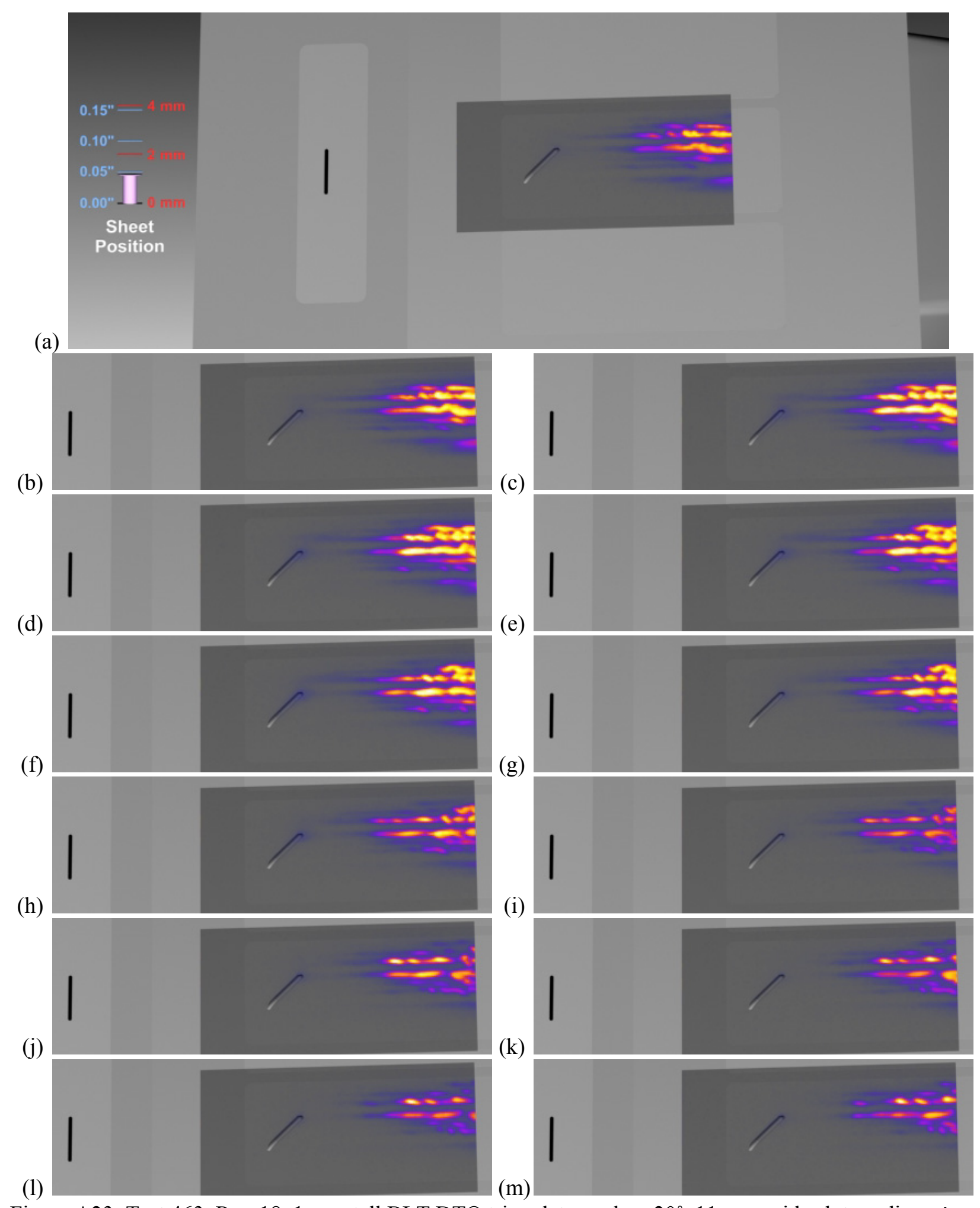

Figure A23: Test 463, Run 18, 1-mm tall BLT DTO trip, plate angle $=20^{\circ}, 11-\mathrm{mm}$ wide slot seeding, $\dot{m}=$ $300 \mathrm{sccm}, \mathrm{P}_{0}=9.31 \mathrm{MPa}$, sheet position $=1.2 \mathrm{~mm}$ above surface, framing rate $=500 \mathrm{kHz}$. 